INSTITUTO DE PESQUISAS ENERGÉTICAS E NUCLEARES

Autarquia associada à Universidade de São Paulo

\title{
DESENVOLVIMENTO DE PROCEDIMENTO UTILIZANDO PROCESSO DE SOLDAGEM PLASMA PARA CONFECÇÃO DE SEMENTES DE ${ }^{125}$ I
}

\section{ANSELMO FEHER}

\author{
Dissertação apresentada como parte dos \\ requisitos para obtenção do Grau de Mestre \\ em Ciências na Área de Tecnologia Nuclear - \\ Aplicações. \\ Orientador: \\ Dr. Paulo Roberto Rela
}

São Paulo

2006 
À minha esposa Ana Claudia $e$ às minhas filhas Giovanna $e$ Pietra. 


\section{AGRADECIMENTOS}

Ao Dr. Paulo Roberto Rela pela orientação e inestimável ajuda durante a elaboração e execução deste trabalho.

À Dra. Maria Elisa Chuery Martins Rostelato pela amizade e por acreditar na minha capacidade de desenvolver este trabalho de pesquisa.

A Vladimir Lepki, Carlos Alberto Zeituni, José Eduardo Manzoli e Ana Claudia Martinelli Feher pela amizade, sugestões e grande colaboração durante a produção do trabalho.

Ao Dr. Wilson Aparecido Parejo Calvo, coordenador do Centro de Tecnologia das Radiações do IPEN pelo apoio, incentivo e amizade.

Ao Dr. Valdir Sciani pela amizade, incentivo e valiosas contribuições no desenvolvimento deste trabalho.

À Dra. Maria Helena de Oliveira Sampa pela motivação e amizade.

Ao Dr. Eddy Segura Pino pela contribuição na elaboração do trabalho.

A Francisco Sprenger, Samir Somessari, Nelson Minoru Omi, Maria da Conceição C. Pereira, Sueli Borrely e Maria Lúcia Gili Massi pela amizade e colaboração neste trabalho.

A todos amigos do IPEN-CNEN/SP que contribuíram no desenvolvimento deste trabalho.

À Fundação de Amparo à Pesquisa do Estado de São Paulo - FAPESP pelo apoio financeiro no projeto de pesquisa. 


\title{
DESENVOLVIMENTO DE PROCEDIMENTO UTILIZANDO PROCESSO DE SOLDAGEM PLASMA PARA CONFECÇÃO DE SEMENTES DE ${ }^{125}$ I
}

\author{
Anselmo Feher
}

\section{RESUMO}

O câncer de próstata é um problema de saúde pública no Brasil, sendo a segunda causa de óbitos por câncer em homens, superado apenas pelo câncer de pulmão. Entre os possíveis tratamentos disponíveis para o câncer de próstata encontra-se a braquiterapia, onde, pequenas sementes contendo o radioisótopo ${ }^{125}$ I são implantadas na próstata. A semente consiste de uma cápsula de titânio selada de $0,8 \mathrm{~mm}$ de diâmetro externo e $4,5 \mathrm{~mm}$ de comprimento, contendo um fio de prata com ${ }^{125} \mathrm{I}$ adsorvido. A soldagem por arco plasma é uma das técnicas viáveis para selagem, o equipamento tem um custo menor que o de outros processos. Constituem os objetivos deste trabalho o desenvolvimento e a validação do procedimento de selagem utilizando processo de soldagem plasma e a elaboração de rotinas para selagem segundo as Boas Práticas de Fabricação. $O$ desenvolvimento do trabalho apresentou as seguintes fases: corte e limpeza do material, determinação dos parâmetros de soldagem, desenvolvimento de dispositivos para fixação do tubo de titânio durante o processo de soldagem, ensaios de validação de fontes seladas conforme norma ISO 2919 Sealed Radioactive Sources - General Requirements and Classification, ensaios de estanqueidade conforme norma ISO 9978 Sealed Radioactive Sources - Leakage Test Methods e ensaio metalográfico. O procedimento desenvolvido para a selagem das sementes de ${ }^{125} \mathrm{I}$ mostrou-se eficiente, atendendo a todos os requisitos estabelecidos na norma ISO 2919. Os resultados apresentados neste trabalho possibilitaram a elaboração de rotinas de fabricação segundo as orientações apresentadas na resolução RDC oㅜ 59 - Boas Práticas de Fabricação de Produtos Médicos da ANVISA - Agência Nacional de Vigilância Sanitária. 


\title{
DEVELOPMENT OF A PROCEDURE USING PLASMA WELDING PROCESS TO PRODUCE ${ }^{125}$ I SEEDS
}

\author{
Anselmo Feher
}

\begin{abstract}
The prostate cancer, which is the second cause of death by cancer in men, overcome only by lung cancer, is a problem of public health in Brazil. Brachytherapy is among the possible available treatments for prostate cancer, in which small seeds containing ${ }^{125} \mathrm{I}$ radioisotope are implanted in the prostate. The seed consists of a titanium sealed capsule with $0.8 \mathrm{~mm}$ external diameter and $4.5 \mathrm{~mm}$ length, containing a central silver wire with adsorbed ${ }^{125} \mathrm{I}$. The plasma arc welding is one of the viable techniques for the sealing process. The equipment used in this technique is less costly than in other processes. The main objective of this work was the development and the validation of the welding procedure using plasma welding process and the elaboration of a sealing routine according to Good Manufacturing Practices. The development of this work has presented the following phases: cut and cleaning of the titanium material, determination of the welding parameters, development of a device for holding the titanium tube during the welding process, validation of sealed sources according to ISO 2919 Sealed Radioactive Sources - General Requirements and Classification, leakage test according to ISO 9978 Sealed Radioactive Sources - Leakage Test Methods and metallographics assays. The developed procedure, to seal ${ }^{125}$ seeds using plasma welding process, has shown to be efficient, satisfying all the established requirements of ISO 2919. The results obtained in this work have given the possibility to establish a routine production process according to the orientations presented in resolution RDC ํo 59 - Good Manufacturing Practices to Medical Products of the ANVISA - National Agency of Sanitary Surveillance.
\end{abstract}




\section{SUMÁRIO}

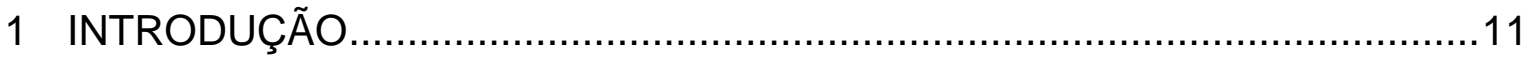

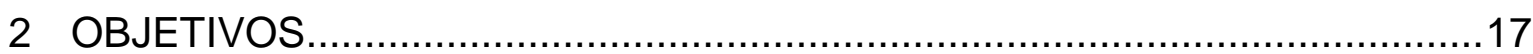

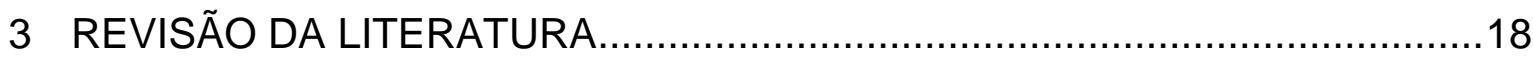

3.1 Braquiterapia............................................................................ 18

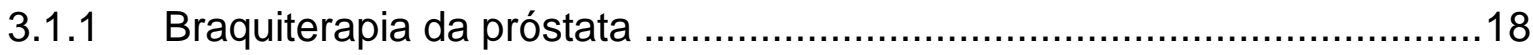

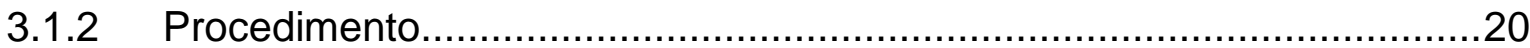

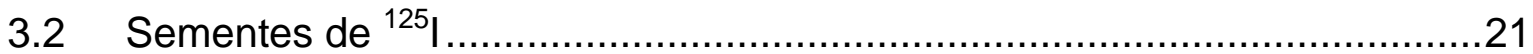

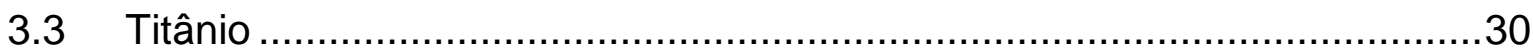

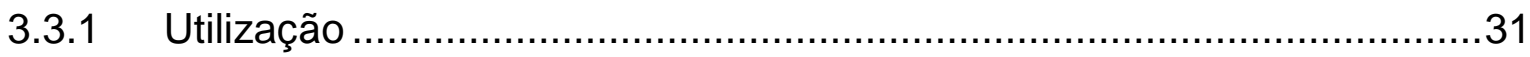

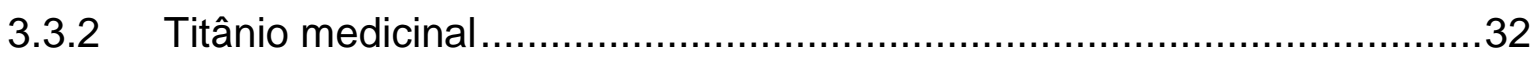

3.3.3 Normas e composição química do titânio medicinal ..............................34

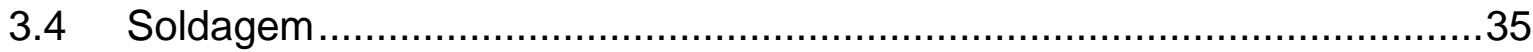

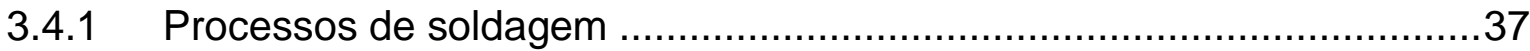

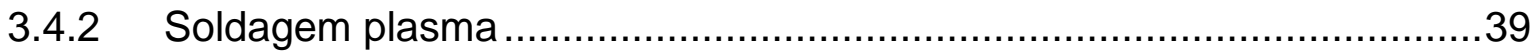

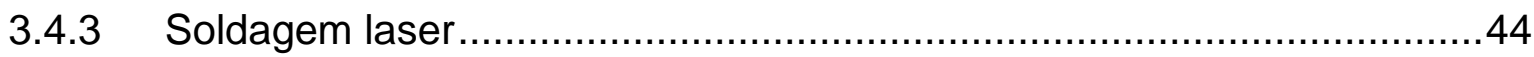

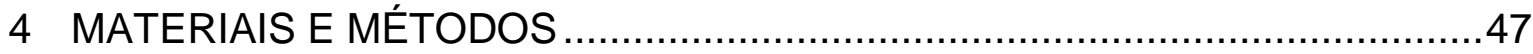

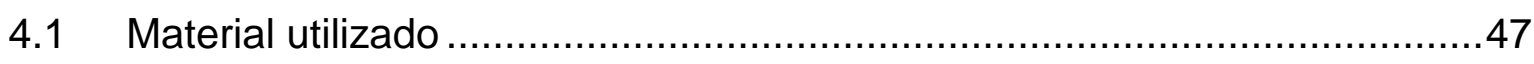

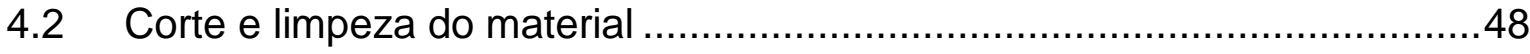

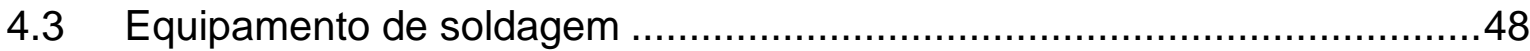

4.4 Equipamento posicionador..........................................................49

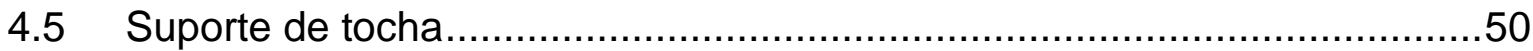

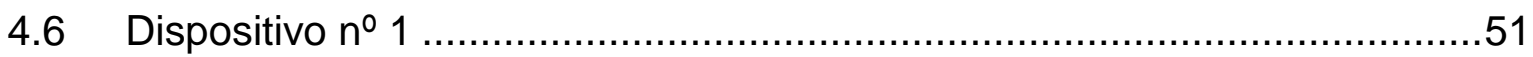

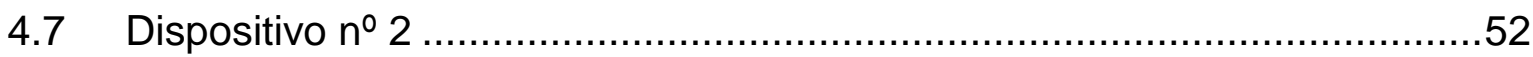

4.8 Determinação dos parâmetros de soldagem .......................................53

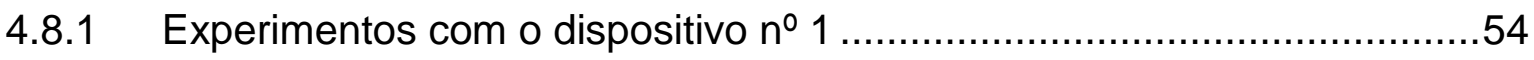

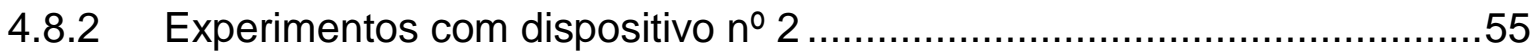

4.9 Classificação e identificação das sementes de ${ }^{125}$ l segundo a norma

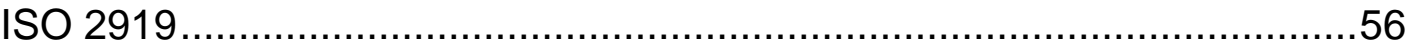

4.10 Ensaios para validação das fontes seladas .......................................60

4.10.1 Ensaios de temperatura.........................................................60

4.10.1.1 Ensaio a alta temperatura ......................................................60

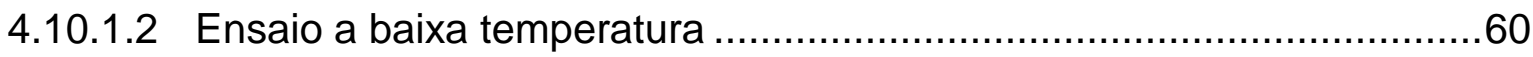

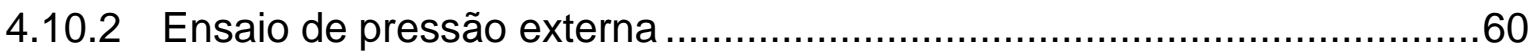




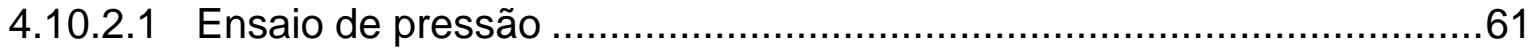

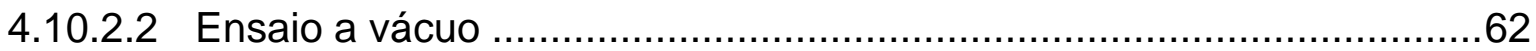

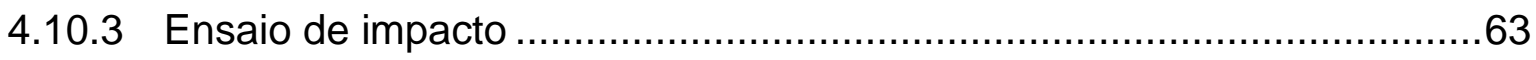

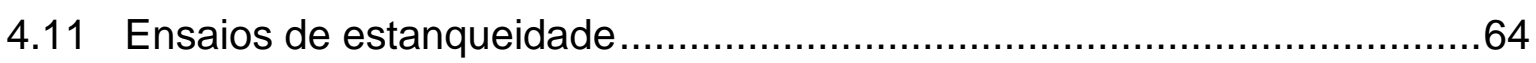

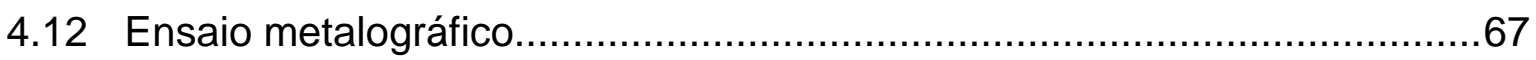

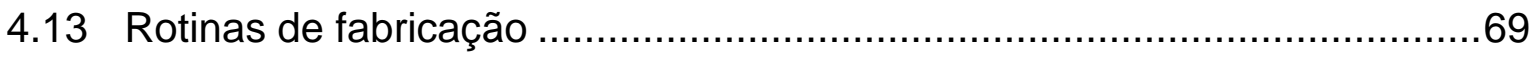

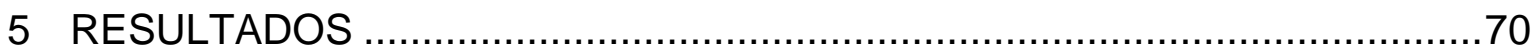

5.1 Ensaios realizados para desenvolver procedimento de soldagem .............70

5.1.1 Corte e limpeza do tubo de titânio .....................................................70

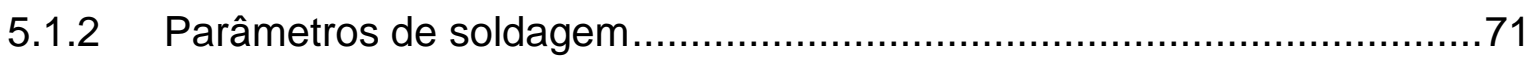

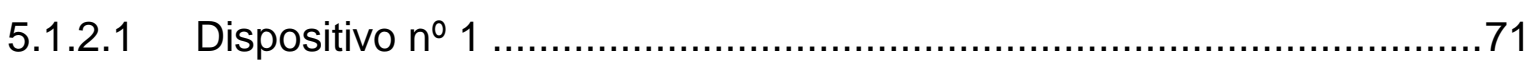

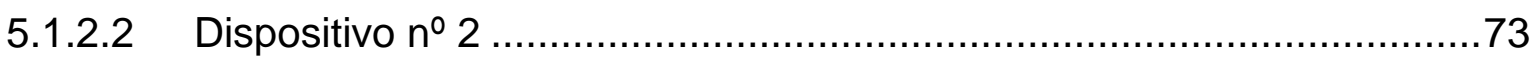

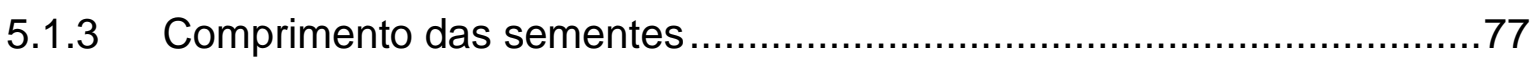

5.2 Ensaios realizados para qualificar o procedimento de selagem das sementes quanto aos requisitos estabelecidos para a utilização.................79

5.2.1 Ensaio de estanqueidade ...............................................................

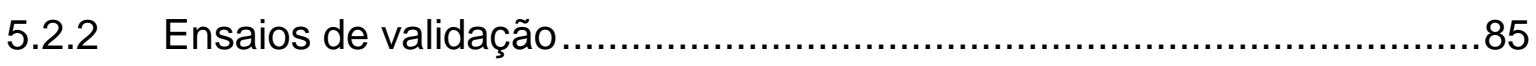

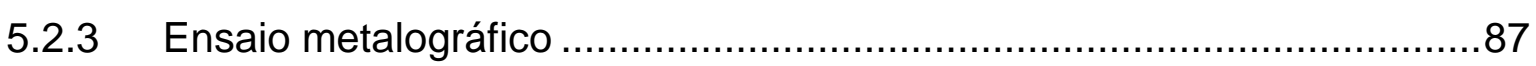

5.3 Rotinas de inspeção do corte dos tubos de titânio e de selagem de sementes de ${ }^{125}$ I segundo as Boas Práticas de Fabricação ........................88

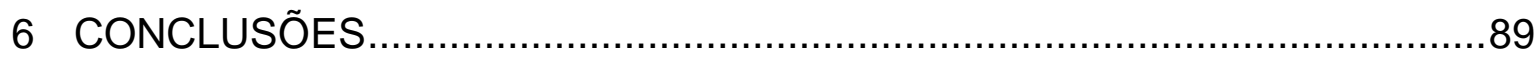

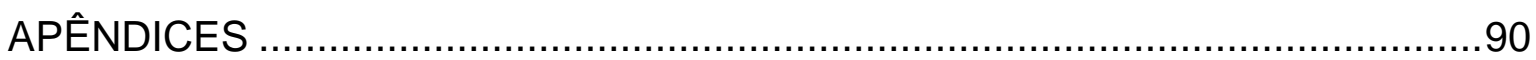

APÊNDICE A - Inspeção do corte dos tubos de titânio ......................................90

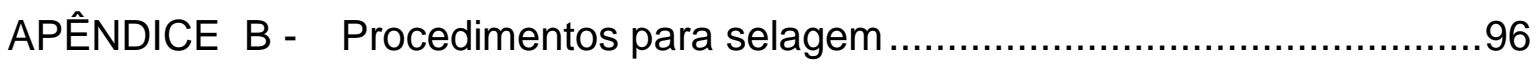

ANEXO A - Classificação do radionuclídeo de acordo com sua radiotoxicidade 100 REFERÊNCIAS BIBLIOGRÁFICAS..........................................................103 


\section{LISTA DE TABELAS}

TABELA 1 - Estimativas para o ano 2006 do número de casos novos de câncer, em homens e mulheres, segundo localização primária ${ }^{2}$...............12

TABELA 2 - Propriedades do titânio ...........................................................

TABELA 3 - Composição química do titânio medicinal ......................................35

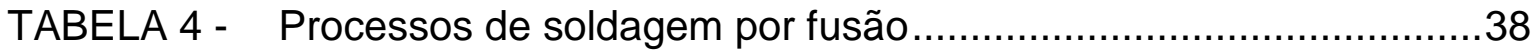

TABELA 5 - Composição química do titânio CP GR2 informada pelo fabricante

TABELA 6 - Parâmetros de soldagem utilizados no dispositivo no 1 ..................54

TABELA 7 - Parâmetros de soldagem utilizados no dispositivo ํo 2 …..............56

TABELA 8 - Classificação de fontes seladas de acordo com a performance requerida para a sua aplicação ${ }^{23}$...............................................57

TABELA 9 - Classificação de desempenho de fonte selada (5 dígitos) ${ }^{23}$.........58

TABELA 10 - Nível de atividade específica de acordo com o grupo de

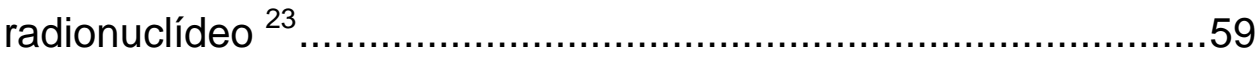

TABELA 11 - Seleção dos métodos de testes de vazamento relacionados com a

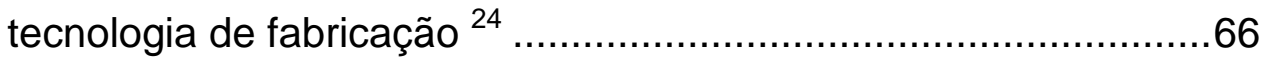

TABELA 12 - Valores dos parâmetros finais de soldagem …………………......76

TABELA 13 - Variação do comprimento das sementes após ensaio de reprodutibilidade ...............................................................

TABELA 14 - Comprimento final em um lote de 48 sementes.............................78

TABELA 15 - Medidas do padrão P3 no calibrador de dose tipo iodeto de sódio.

TABELA 16 - Medidas do padrão e dos BGs no contador de cintilação líquida em recipientes de vidro boro-silicato e polietileno (cpm) .....................80

TABELA 17 - Teste de estanqueidade das 48 sementes ( $1^{\mathrm{a}}$ limpeza) .................81

TABELA 18 - Teste de estanqueidade das 48 sementes ( $2^{\mathrm{a}}$ limpeza) .................83

TABELA 19 - Teste de estanqueidade das 5 sementes ( $3^{\mathrm{a}}$ limpeza) ..................84

TABELA 20 - Teste de estanqueidade das sementes após serem submetidas aos ensaios de validação. 


\section{LISTA DE FIGURAS}

FIGURA 1 - Taxa bruta de mortalidade por câncer de algumas localizações primárias - Brasil - Homens, 1980-1996 ${ }^{4}$.....................................11

FIGURA 2 - Esquema da Semente de ${ }^{125}$ I..................................................15

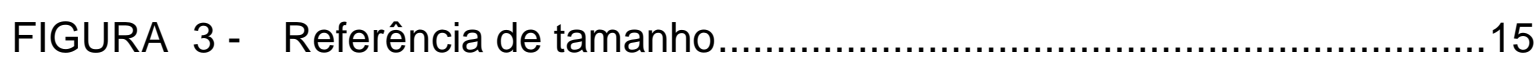

FIGURA 4 - Exemplo de um implante com sementes de ${ }^{125} \mid$..........................20

FIGURA 5 - Agulha utilizada para implante de sementes de ${ }^{125} \mid \ldots \ldots \ldots \ldots \ldots \ldots \ldots . . .21$

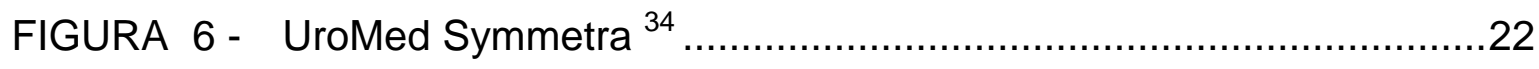

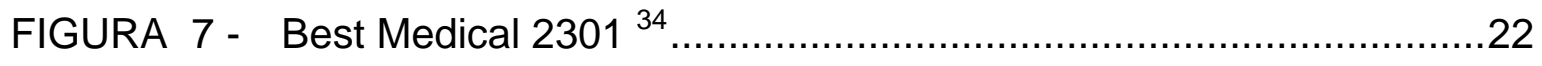

FIGURA 8 - SourceTech Medical ${ }^{125}$ Implant $^{34}$..........................................23

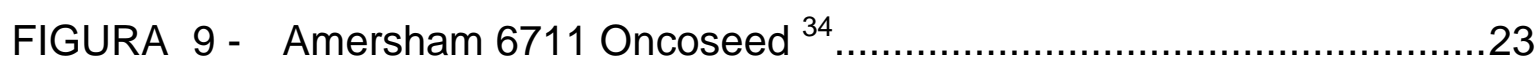

FIGURA 10 - Mentor loGold ${ }^{34}$...........................................................24

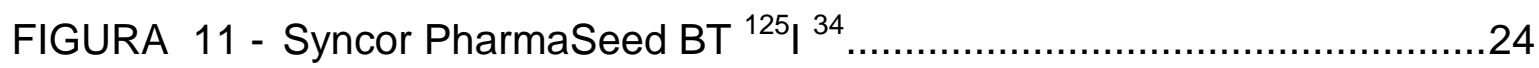

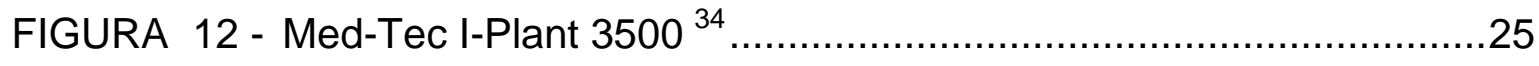

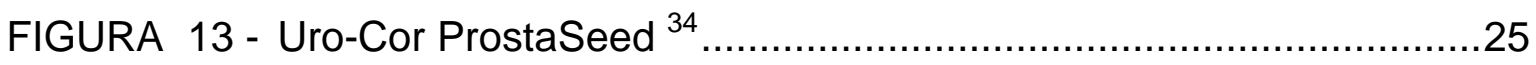

FIGURA 14 - Modelo de semente utilizando esfera de ouro como marcador .....26

FIGURA 15 - Modelo utilizando fio de prata como carregador e marcador .........26

FIGURA 16 - Selagem de semente de ${ }^{103} \mathrm{Pd}$..............................................26

FIGURA 17 - Encapsulamento da semente sem soldagem ..............................27

FIGURA 18 - Esquema de semente indicada na patente de Cutrer ....................27

FIGURA 19 - Modelo de semente de ${ }^{103} \mathrm{Pd}$ ou ${ }^{125}$ I indicada na patente de

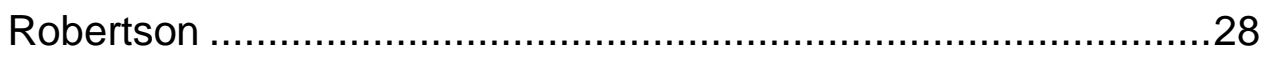

FIGURA 20 - Modelo de semente de ${ }^{125} \mathrm{I}$ ou ${ }^{103} \mathrm{Pd}$ indicado na patente de

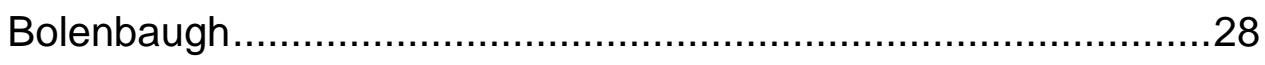

FIGURA 21 - Modelo de semente radioativa indicada na patente de Slater .......28

FIGURA 22 - Modelo de semente de ${ }^{125}$ I indicada na patente de Ziegler ...........29

FIGURA 23 - Modelo de semente de ${ }^{125}$ I indicada na patente de Cutrer .............29

FIGURA 24 - Exemplo de próteses para utilização em ortopedia ......................33

FIGURA 25 - Evolução dos processos de soldagem ao longo do tempo ${ }^{55}$.........37

FIGURA 26 - Representação esquemática de uma tocha plasma .......................40

FIGURA 27 - Tipos de arcos do processo plasma (PAW) .................................41

FIGURA 28 - Equipamento para soldagem a plasma (PAW) …........................42

FIGURA 29 - Circuito de alta freqüência do arco piloto.......................................43 
FIGURA 30 - Elementos de um sistema típico para soldagem a laser...

FIGURA 31 - Máquina de solda plasma Plasmafix 50E utilizada nos experimentos

FIGURA 32 - Sistema posicionador de tubo de titânio .49

FIGURA 33 - Sistema de controle do posicionador de tubos de titânio .49

FIGURA 34 - Desenho esquemático do suporte da tocha. .50

FIGURA 35 - Suporte da tocha. .50

FIGURA 36 - Desenho esquemático do dispositivo № 1 .51

FIGURA 37 - Dispositivo de soldagem № 1 . .51

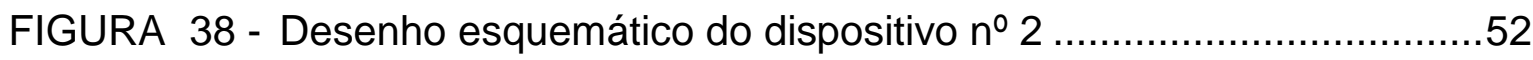

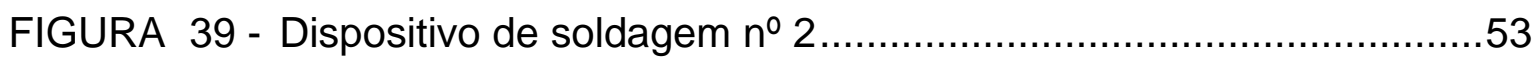

FIGURA 40 - Dispositivo utilizado para ensaio com pressão ………..................61

FIGURA 41 - Dispositivo utilizado para ensaio a vácuo ....................................63

FIGURA 42 - Dispositivo e martelo utilizado no ensaio de impacto......................64

FIGURA 43 - Corte do tubo de titânio com rebarba..........................................70

FIGURA 44 - Acabamento do tubo após lixamento .............................................70

FIGURA 45 - Falha na abertura do arco .....................................................

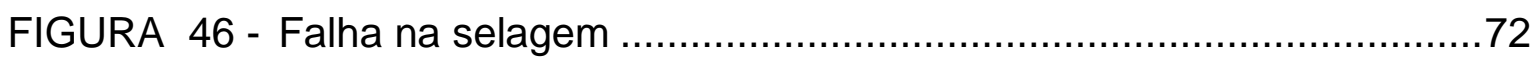

FIGURA 47 - Excesso de corrente de arco plasma.........................................72

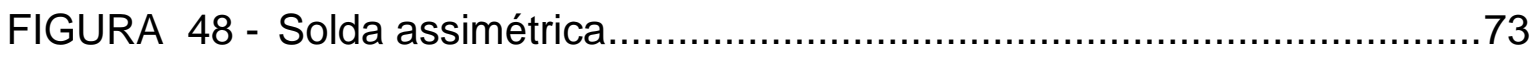

FIGURA 49 - Selagem com vazão de gás incorreta............................................74

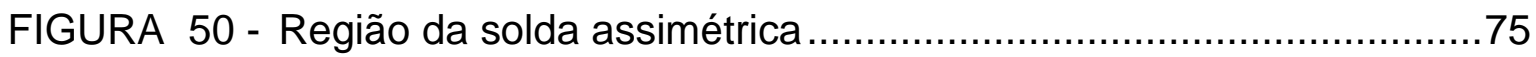

FIGURA 51 - Selagem com parâmetros ajustados...........................................75

FIGURA 52 - Selagem com parâmetros ajustados........................................76

FIGURA 53 - Variação do comprimento das sementes após ensaio de

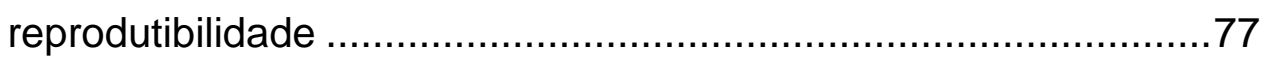

FIGURA 54 - Comprimento final no lote de 48 sementes.................................79

FIGURA 55 - Atividade na água após ensaio de estanqueidade (1 ${ }^{a}$ limpeza)......82

FIGURA 56 - Atividade na água após ensaio de estanqueidade ( $2^{\mathrm{a}}$ limpeza)......84

FIGURA 57 - Atividade na água após ensaio de estanqueidade ( $3^{\underline{a}}$ limpeza)......85

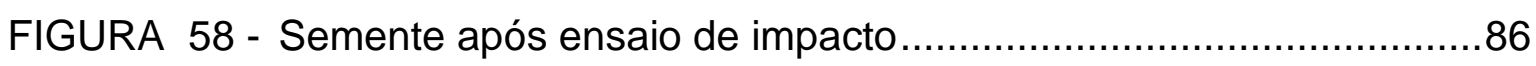

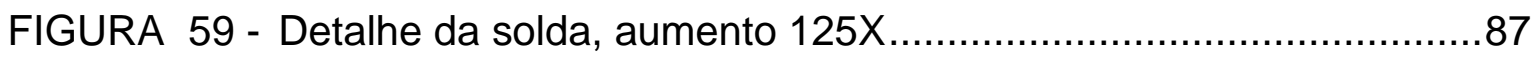

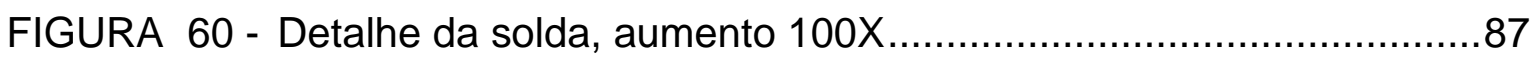




\section{INTRODUÇÃO}

Câncer é o nome dado a um conjunto de mais de 100 doenças que têm em comum o crescimento desordenado (maligno) de células que invadem os tecidos e órgãos, podendo espalhar-se (metástase) para outras regiões do corpo ${ }^{1 .}$

No mundo, o número de casos novos diagnosticados de câncer de próstata representa $15,3 \%$ de todos os casos incidentes de câncer em países desenvolvidos e 4,3\% dos casos em países em desenvolvimento. O câncer de próstata é o mais prevalecente em homens ${ }^{2}$.

O câncer de próstata representa um sério problema de saúde pública no Brasil, em função de suas altas taxas de incidência. Ele é a segunda causa de óbitos por câncer em homens, sendo superado apenas pelo câncer de pulmão ${ }^{3}$.

A cada ano, porém, os dados de mortalidade para o sexo masculino demonstram que, as taxas são crescentes para os cânceres de cólon, reto, pulmão e próstata, exceto pelo câncer de estômago, que tem tendência de queda. Essa evolução pode ser vista na FIG. 1, que mostra a taxa bruta de mortalidade por tumores, de 1980 a 1996, no Brasil, para o sexo masculino (taxa por 100.000 homens) ${ }^{4}$.

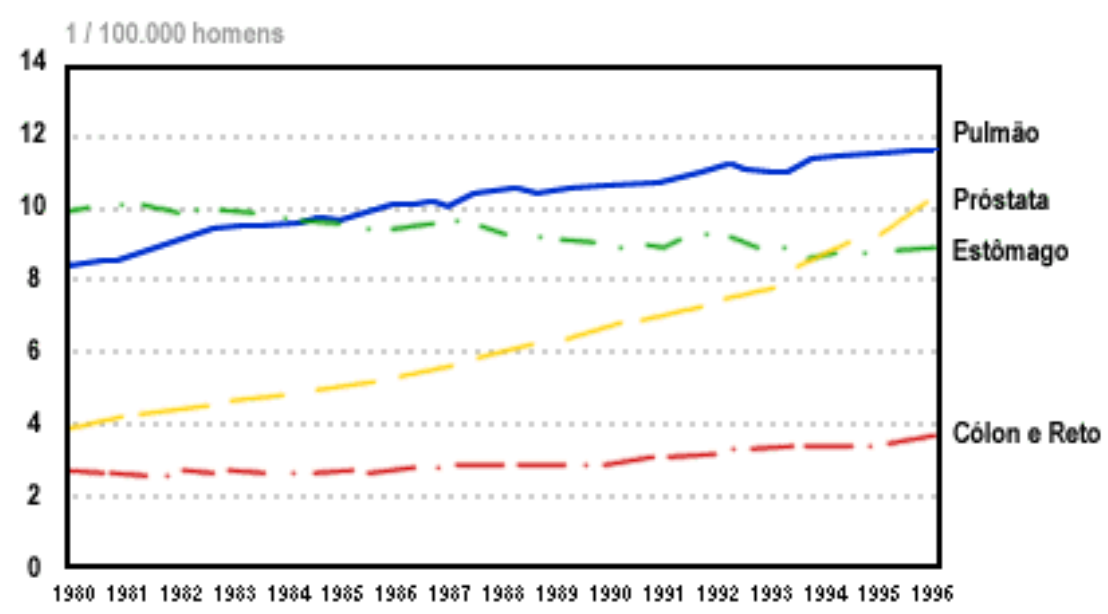

Fontes: Ministério da Saúde: DataSus, SIM, INCA; e IBGE: DEPE/DEPIS

FIGURA 1 - Taxa bruta de mortalidade por câncer de algumas localizações primárias - Brasil - Homens, 1980-1996 ${ }^{4}$. 
Entre todos os tipos de câncer, o de próstata é considerado o câncer da terceira idade, uma vez que cerca de $75 \%$ dos casos, no mundo, ocorrem a partir dos 65 anos.

Como pode ser observado na TAB 1, o número de casos novos de câncer de próstata estimados para o Brasil em 2006 é de 47.280. Estes valores correspondem a um risco estimado de 51 casos novos a cada 100 mil homens ${ }^{2}$.

TABELA 1 - Estimativas para o ano 2006 do número de casos novos de câncer, em homens e mulheres, segundo localização primária ${ }^{2}$.

\begin{tabular}{|l|r|r|r|}
\hline Localização Primária & \multicolumn{3}{|c|}{ Estimativa dos casos novos } \\
\hline Neoplasia Maligna & Masculino & \multicolumn{1}{|c|}{ Feminino } & \multicolumn{1}{c|}{ Total } \\
\hline Mama Feminina & - & 48.930 & 48.930 \\
\hline Traquéia, Brônquio e Pulmão & 17.850 & 9.320 & 27.170 \\
\hline Estômago & 14.970 & 8.230 & 23.200 \\
\hline Colo do Útero & - & 19.260 & 19.260 \\
\hline Próstata & 47.280 & - & 47.280 \\
\hline Cólon e reto & 11.390 & 13.970 & 25.360 \\
\hline Esôfago & 7.970 & 2.610 & 10.580 \\
\hline Leucemias & 5.330 & 4.220 & 9.550 \\
\hline Cavidade oral & 10.060 & 3.410 & 13.470 \\
\hline Pele Melanoma & 2.710 & 3.050 & 5.760 \\
\hline Outras localizações & 61.530 & 63.320 & 124.850 \\
\hline Subtotal & $\mathbf{1 7 9 . 0 9 0}$ & $\mathbf{1 7 6 . 3 2 0}$ & $\mathbf{3 5 5 . 4 1 0}$ \\
\hline Pele não Melanoma & 55.480 & 61.160 & 116.640 \\
\hline Todas as Neoplasias & $\mathbf{2 3 4 . 5 7 0}$ & $\mathbf{2 3 7 . 4 8 0}$ & $\mathbf{4 7 2 . 0 5 0}$ \\
\hline
\end{tabular}

Algumas das opções de tratamento para o câncer de próstata são as cirurgias e as radioterapias (teleterapia ou braquiterapia).

A primeira opção, prostatectomia radical, é um procedimento cirúrgico onde a próstata e os tecidos vizinhos são removidos enquanto o paciente está sob anestesia. Os principais efeitos colaterais são a incontinência urinária, que atinge $35 \%$, e a impotência sexual, que atinge de $65 \%$ a $90 \%$ dos pacientes ${ }^{5}$. 
A segunda opção, terapia com radiação, pode ser de dois tipos. A teleterapia, que é o tipo mais utilizado, feito com feixe de radiação externo onde a próstata e os tecidos vizinhos são tratados por um feixe de radiação proveniente de um acelerador linear. O outro tipo, chamado braquiterapia, as fontes radioativas são colocadas em contato com o tumor ${ }^{6}$.

$\mathrm{Na}$ braquiterapia, pequenas sementes, contendo o radioisótopo ${ }^{125} \mathrm{I}$ ou ${ }^{103} \mathrm{Pd}$, são implantadas na próstata ${ }^{7}$. Como a ocorrência de efeitos colaterais é menor, $85 \%$ dos pacientes de até 70 anos de idade, permanecem sexualmente ativos após implante. Também a incontinência urinária raramente os acomete ${ }^{8}$.

As vantagens dos implantes com sementes radioativas são a preservação de tecidos sadios e de órgãos próximos à próstata, a baixa taxa de impotência e a incontinência urinária comparada aos tratamentos convencionais, tais como prostatectomia radical e feixe de radiação externo ${ }^{9,10}$.

Para a maioria dos pacientes, o implante com sementes é um procedimento de baixo impacto e não uma cirurgia. O paciente pode retornar à atividade normal dentro de um a três dias, com pequena ou nenhuma dor.

As sementes são implantadas durante um procedimento não cirúrgico. Pequenas sementes são injetadas diretamente na próstata, entre o reto e o escroto, com a ajuda de uma agulha fina através da pele ${ }^{11,12}$. Uma grande dose de radiação é liberada apenas no tumor, pois $0^{125}$ I tem uma radiação com baixa energia média $(29 \mathrm{KeV})$ que é pouco penetrante, preservando assim os tecidos circunvizinhos ${ }^{13,14}$.

No Brasil, os implantes com sementes de ${ }^{125} \mid$ estão sendo realizados utilizando sementes importadas. O custo do produto para os hospitais e clínicas especializadas varia de US\$25.00 à US\$34.00 por semente. A técnica exige, em geral, a aplicação de 80 a 120 sementes por paciente ${ }^{15}$.

Os fabricantes de sementes existentes no mundo concentram-se na Inglaterra, Bélgica e Estados Unidos. Estas sementes diferem quanto ao processo utilizado na produção, sendo exclusivos e protegidos por patentes, tornando a sua 
reprodução proibida ou bastante onerosa face aos royalties da propriedade industrial, inviabilizando comercialmente a sua industrialização em outros países. Nenhuma destas patentes são de domínio público.

Uma vez que repetir as técnicas utilizadas pelos fabricantes atuais de sementes de ${ }^{125}$ I é proibido ou inviável economicamente, e que, o crescimento na demanda do País para este tipo de produto terapêutico é bastante acentuado, faz-se necessário desenvolver novos processos de fabricação de sementes com o propósito de implantar no País uma produção própria e independente de tecnologia externa.

Do ponto de vista social, o domínio tecnológico permitirá que as sementes produzidas localmente tenham menor custo, possibilitando que as camadas mais carentes da nossa população tenham acesso à terapia com o implante permanente de sementes, que apresenta sensíveis vantagens em relação aos métodos tradicionais ${ }^{16}$.

O domínio tecnológico da confecção das sementes de ${ }^{125}$ no Brasil foi obtido em duas etapas: o desenvolvimento da metodologia da adsorção do material radioativo no substrato de prata e o desenvolvimento do processo de selagem da semente utilizando a soldagem a plasma.

Durante o estudo e desenvolvimento dos métodos a serem utilizados na confecção das sementes de ${ }^{125}$, não foram encontrados artigos sobre 0 método de preparação, somente patentes que descrevem modelos de sementes, sugerindo materiais que podem ser utilizados na confecção e em alguns casos citando processos de soldagem.

Os resultados do estudo e do desenvolvimento da técnica de adsorção do ${ }^{125}$ I no substrato de prata e da selagem das sementes utilizando a soldagem a plasma constituem inovações tecnológicas, uma vez que os métodos foram desenvolvidos pelos pesquisadores do Instituto de Pesquisas Energéticas e Nucleares - IPEN. 
Levando-se em conta o preço das sementes, as dificuldades de importação e o crescimento previsto em torno de $8 \%$ ao ano neste tipo de procedimento ${ }^{17}$, o IPEN iniciou um projeto para a automação da técnica e da produção das sementes de ${ }^{125} \mathrm{I}$ com apoio da FAPESP.

Hoje, a demanda está em 3.500 sementes por mês e o laboratório a ser implantado para produção rotineira no IPEN terá a capacidade de produção de 8.000 sementes por mês.

As sementes consistem de uma cápsula de titânio (material biocompatível ao tecido humano ${ }^{18,19,20}$ ) de $0,8 \mathrm{~mm}$ de diâmetro externo, 0,05 mm de espessura de parede e $4,5 \mathrm{~mm}$ de comprimento. $O$ interior da cápsula acomoda um fio de prata, contendo o ${ }^{125}$ I adsorvido. O radioisótopo ${ }^{125}$ I possui uma meia vida de 59,6 dias e a energia de seus principais raios- $X$ e gama são: $27,2 \mathrm{KeV}(39,8 \%), 27,5 \mathrm{KeV}(74,1 \%), 31 \mathrm{KeV}(21,4 \%)$ e 35,5 (6,7\%). O fio de prata tem $0,5 \mathrm{~mm}$ de diâmetro e $3 \mathrm{~mm}$ de comprimento, conforme ilustração da FIG. 2. A atividade típica da semente é de $0,5 \mathrm{mCi}$, admitindo-se variação de no máximo $\pm 5 \%$ num mesmo lote de sementes ${ }^{21,22}$.
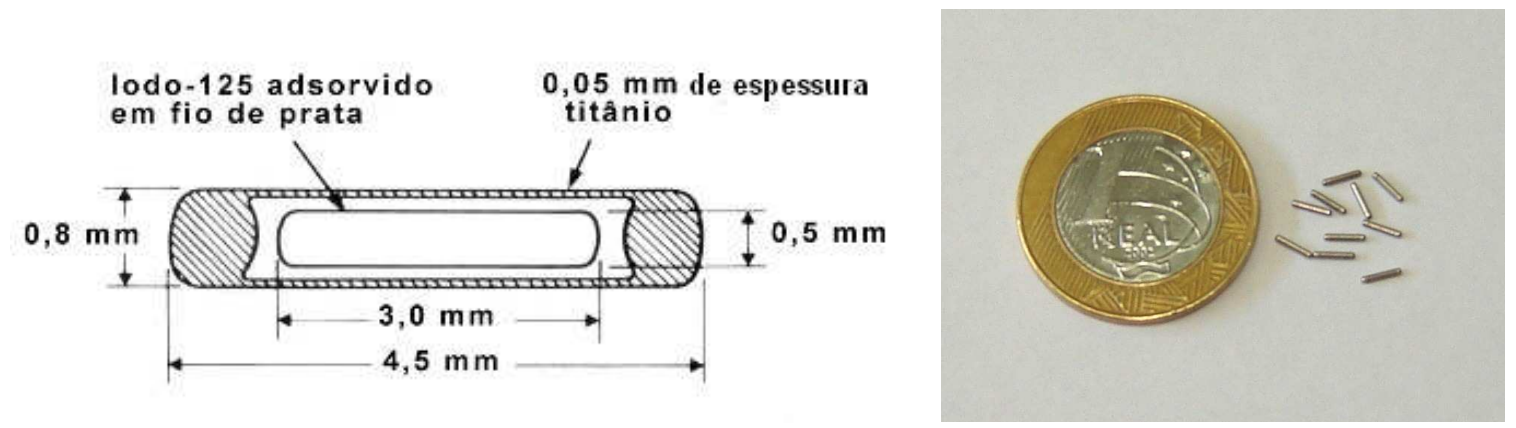

FIGURA 2 - Esquema da Semente de ${ }^{125}$

FIGURA 3 - Referência de tamanho

Uma das fases da produção das sementes de ${ }^{125}$ I é a selagem dos tubos de titânio, por meio de solda, que deverá ser realizada nas duas extremidades, de modo a permitir a classificação das sementes como fontes seladas, atendendo aos rigorosos testes estabelecidos em padronizações 
pertinentes, obedecendo-se à norma internacional ISO 2919 - Radiation protection - Sealed Radioactive Sources - General Requirements and Classification $^{23}$ e também a estanqueidade das sementes, utilizando procedimentos da norma ISO 9978 - Radiation protection - Sealed Radioactive Sources - Leakage Test Methods ${ }^{24}$.

Esta selagem deverá ser estanque, isenta de trincas, evitando-se que o ${ }^{125}$ I depositado no fio de prata escape e se espalhe pelo corpo humano.

Os aplicadores de sementes requerem que o acabamento da selagem seja o mais esférico possível, a fim de evitar travamento na hora do carregamento das sementes.

A soldagem por laser e por arco plasma são as técnicas viáveis para selagem de sementes de ${ }^{125} \mathrm{I}$, sendo que a técnica por arco plasma apresenta menor custo que o processo que utiliza a técnica laser para produção rotineira das sementes de ${ }^{125}$.

A técnica de soldagem plasma, do ponto de vista econômico, é bastante vantajosa, uma vez que o equipamento e sua infra-estrutura estão disponíveis no IPEN e também por termos o domínio tecnológico deste processo de selagem.

A expressão arco plasma é utilizada para descrever uma família de processos que utilizam um arco elétrico constrito. Processos por arco plasma são empregados para soldar, cortar e realizar revestimentos (com pó-metálico ou cerâmico) ${ }^{25}$. 


\section{OBJETIVOS}

Os objetivos deste trabalho são:

- Desenvolver procedimento de soldagem utilizando processo de soldagem plasma para selagem de sementes de ${ }^{125}$ utilizadas em braquiterapia;

- Qualificar o procedimento de selagem das sementes quanto aos requisitos estabelecidos para a utilização;

- Elaborar rotinas de fabricação, segundo as Boas Práticas de Fabricação (GMP - Good Manufacturing Practice), disponibilizando-as para implantação local de linha de produção de sementes de ${ }^{125}$. 


\section{REVISÃO DA LITERATURA}

\subsection{Braquiterapia}

A descoberta da radioatividade no final do século passado abriu espaço para o desenvolvimento da braquiterapia, um importante recurso para 0 tratamento do câncer.

A palavra braquiterapia tem origem grega (brachys = curto; terapia $=$ tratamento) e define uma forma de tratamento desenvolvida pela colocação de materiais radioativos junto ao tumor. Os materiais determinam a liberação de altas doses de radiação apenas nas proximidades da área de implantação, sem que um grande número de células normais seja atingido ${ }^{26}$.

As fontes seladas encapsuladas em metais como aço inoxidável, platina ou titânio são dispostas em moldes que podem ser colocadas interna ou externamente à lesão, em tratamentos superficiais, intracavitários ou intersticiais. Os implantes radioativos podem ser temporários ou permanentes, dependendo da localização da lesão e do radioisótopo utilizado.

Estudos de radiobiologia mostraram que a principal vantagem na braquiterapia é que se pode liberar altas doses de radiação em curto intervalo de tempo. Todo o tumor é abrangido pela radiação e os tecidos sadios, ao redor da lesão, recebem uma dose mínima, resultando numa razão terapêutica mais eficiente que aquela obtida com a teleterapia ${ }^{27}$.

\subsubsection{Braquiterapia da próstata}

As sementes de ${ }^{125}$ I surgiram em 1967, com a patente de Lawrence ${ }^{28}$, sob o título Therapeutic metal seed containing within a radioactive isotope disposed on a carrier and method of manufacture.

Os primeiros estudos utilizando as sementes de ${ }^{125}$ f foram realizados no Memorial Sloan-Kettering Cancer Center, nos Estados Unidos, em 1972, pelo grupo de Whitmore ${ }^{29}$. 
Os primeiros relatórios foram favoráveis quanto à redução da incontinência urinária e da impotência, porém, evidenciaram que o método não permitia uma distribuição uniforme da dose de radiação na próstata. Além disso, a avaliação da qualidade do implante foi seriamente questionada ${ }^{16}$.

Com a evolução na prostatectomia radical (retirada da próstata) e o refinamento da técnica de irradiação com feixe externo, diminuiu o interesse pela braquiterapia ${ }^{16}$.

A partir de 1983, avanços tecnológicos renovaram o interesse pela braquiterapia prostática. As tecnologias que surgiram, tais como o ultra-som transretal e a tomografia computadorizada, que proporcionou imagens e medidas detalhadas do tamanho e formato da próstata, facilitaram o planejamento e as colocações precisas das sementes e estimularam o uso dessa técnica. A distribuição da dose de radiação pode ser verificada após o implante por tomografia computadorizada ou raios- $\mathrm{X}^{30}$.

A técnica de implante transperineal de sementes radioativas guiadas por ultra-som é, sem dúvida, uma das técnicas mais utilizadas e alguns milhares de pacientes têm sido tratados por ela. As fontes radioativas utilizadas são $0{ }^{125} \mathrm{l} e$ o ${ }^{103} \mathrm{Pd}$ com as seguintes características:

- Ambos possuem baixa energia média: a energia do ${ }^{125} \mathrm{I}$ é de aproximadamente $29 \mathrm{KeV}$ e a do ${ }^{103} \mathrm{Pd}$ é de aproximadamente $22 \mathrm{KeV}$, o que traduz curta penetração da radiação $(<1 \mathrm{~cm}$ no tecido biológico) por eles emitida e, conseqüentemente, não há necessidade de medidas de radioproteção, como o isolamento do paciente;

- A meia-vida difere os dois radioisótopos. $\mathrm{O}^{125}$ l leva 4 meses para liberar $80 \%$ da dose, enquanto o ${ }^{103} \mathrm{Pd}$ leva um pouco mais de 1 mês. Esta diferença sugere que $0{ }^{103} \mathrm{Pd}$ seria mais adequado nos tumores com alto índice de proliferação, beneficiando-se da liberação rápida da dose e evitando a repopulação tumoral ${ }^{31}$. 


\subsubsection{Procedimento}

Após o diagnóstico da doença e da execução dos testes de estadiamento, efetua-se uma ultra-sonografia transretal para determinar o tamanho da próstata e para mapear a glândula, o que deve permitir o desenvolvimento de um plano para o posicionamento das sementes. Uma vez que o plano é concluído e as sementes estão disponíveis, o paciente é levado à sala de operações onde recebe anestesia geral ou um anestésico espinhal. A sonda do ultra-som é novamente colocada no reto para permitir ao cirurgião ver a próstata de forma contínua. Em seguida as sementes são colocadas nas posições preestabelecidas no plano mediante agulhas inseridas através da pele perineal (área entre as pernas e atrás do escroto). Essas agulhas são guiadas para a posição correta com ajuda de um gabarito com vários orifícios correspondendo às posições planejadas para as sementes (FIG. 4).

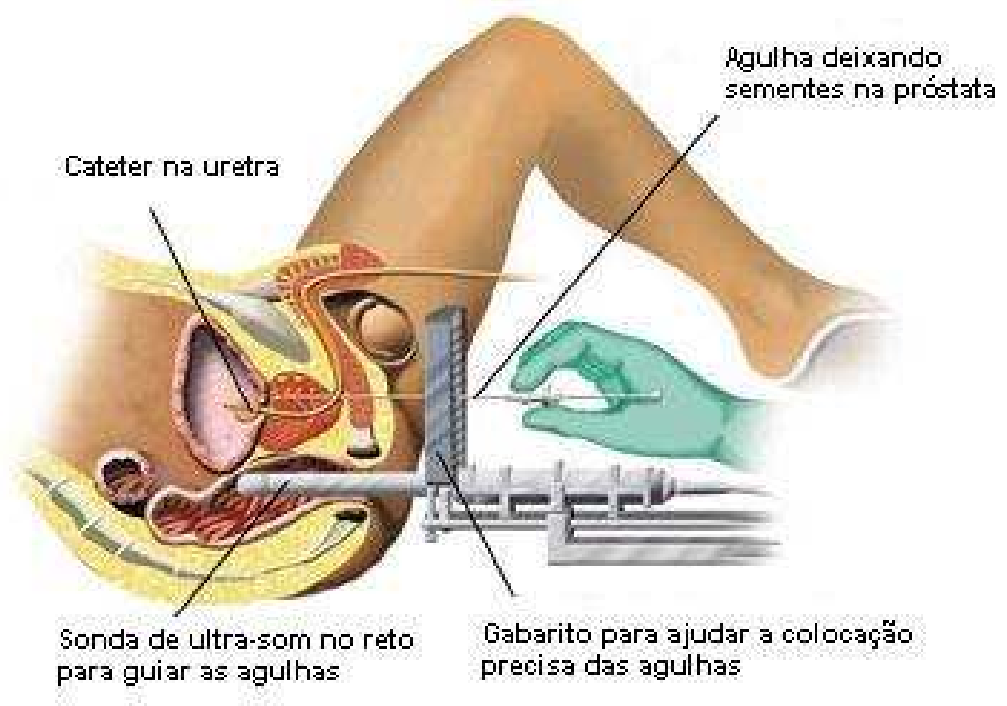

FIGURA 4 - Exemplo de um implante com sementes de $\left.{ }^{125}\right|^{32}$

O urologista e o radioterapêuta devem trabalhar em equipe para posicionar cada agulha, sempre observando a sua posição na imagem do ultrasom (um monitor de computador com imagens em tempo-real) e, então, injetar as sementes, em fileiras, por toda a próstata. Cada semente tem aproximadamente 0 tamanho de um grão de arroz e são colocadas por volta de 80 a 120 sementes através de 20 a 30 inserções de agulhas (FIG. 5). Outras técnicas de implantes de sementes baseiam-se em planejamento, por tomografia computadorizada, para 
posicionar as sementes ou combinam o planejamento e o implante num único processo. O princípio geral é planejar a intervenção com precisão e posicionar as sementes de forma que a emissão de radiação cubra toda a região doente da próstata, proporcionando suficiente radioatividade para matar as células cancerosas. Os pacientes geralmente podem voltar para casa três a doze horas após o término do implante. Embora seus corpos sejam portadores de material radioativo, o nível de radiação que atravessa a pele é extremamente baixo para colocar em risco qualquer pessoa próxima do paciente. A radiação diminui ao longo dos meses até as sementes se transformarem em metal inerte ${ }^{15}$.

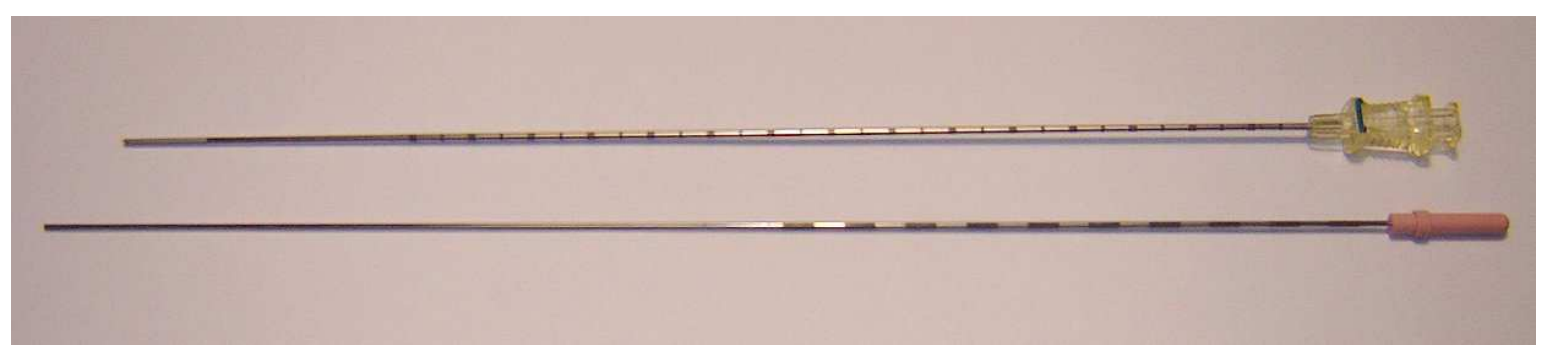

FIGURA 5 - Agulha utilizada para implante de sementes de ${ }^{125}$ I

\subsection{Sementes de ${ }^{125}$}

A literatura sobre as técnicas utilizadas na confecção das sementes é escassa e quando disponível, está na forma de patentes ou faz parte de catálogos comerciais com descrições sumárias visando à proteção do segredo industrial.

A seguir, são apresentados os principais fabricantes, algumas patentes e as respectivas técnicas de selagem utilizadas na produção das sementes radioativas:

- UroMed Corporation - Symmetra ${ }^{125}$. Consiste de uma cápsula de titânio, selada a laser, contendo no seu interior fio de ouro radio-opaco que possibilita contraste e uma camada de cerâmica com ${ }^{125}$ (FIG. 6) ${ }^{33,34}$. 


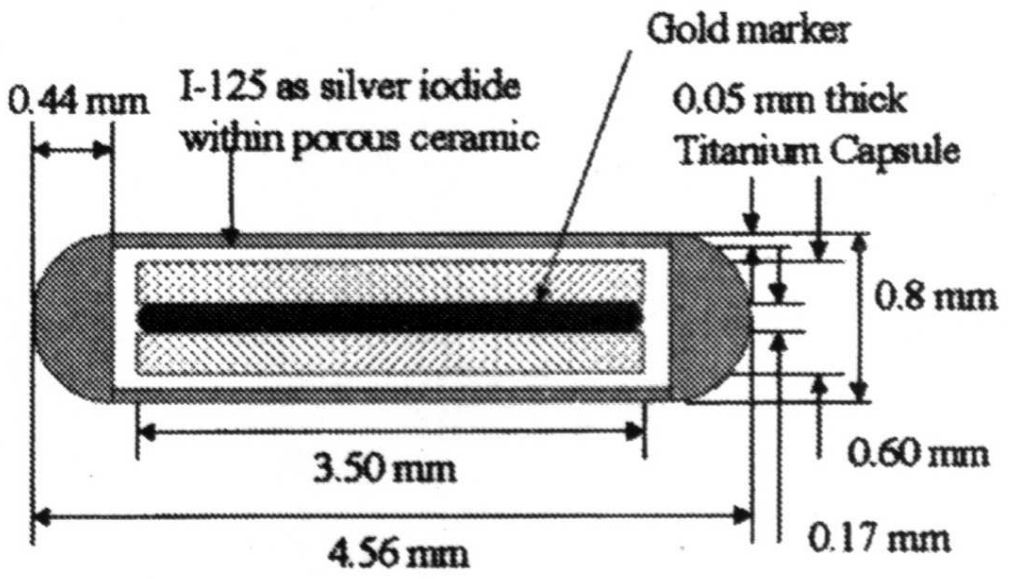

FIGURA 6 - UroMed Symmetra ${ }^{34}$

- Best Medical International - 2301. A parte externa é composta por um revestimento duplamente encapsulado de titânio, selado a laser. O interior acomoda um marcador de tungstênio e $0{ }^{125} \mathrm{I}$ adsorvido em um substrato não especificado (FIG. 7) ${ }^{34,35}$.

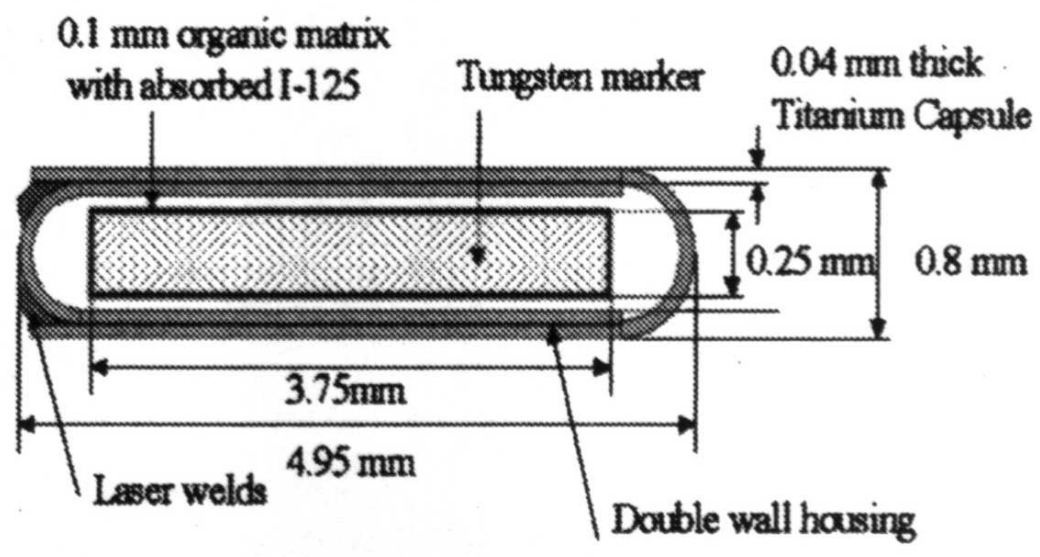

FIGURA 7 - $\quad$ Best Medical $2301^{34}$

- SourceTech Medical - ${ }^{125}$ Implant. A cápsula é de titânio selada a laser. A parte interna tem um fio de ouro como marcador, uma camada de alumínio e uma cobertura de cobre. Não especifica como está distribuído o ${ }^{125}$ (FIG. 8) ${ }^{34,36}$. 


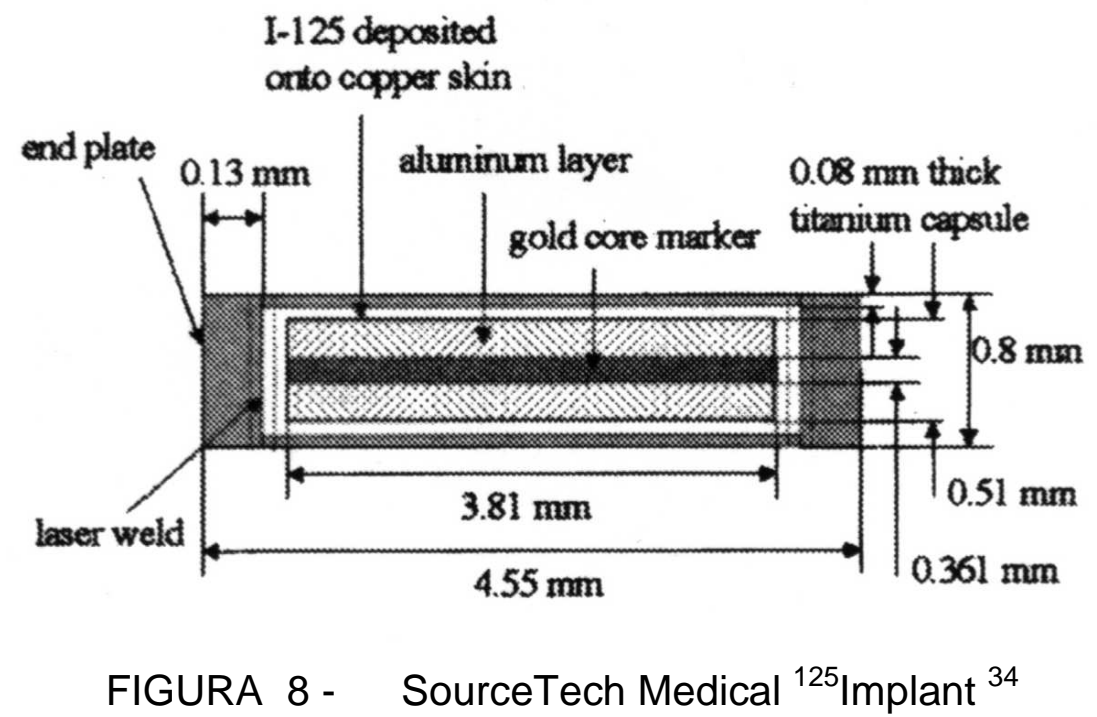

- Amersham - OncoSeed. Apresenta um núcleo de prata radio-opaco, onde o ${ }^{125}$ I está adsorvido e a cápsula externa é de titânio, com selagem a laser (FIG. 9) ${ }^{22,34}$.

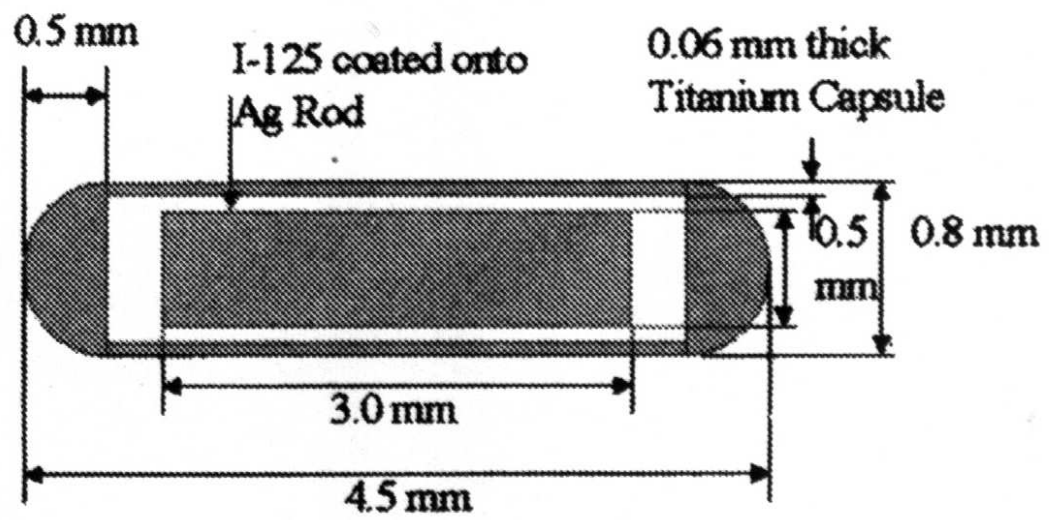

FIGURA 9 - $\quad$ Amersham 6711 Oncoseed $^{34}$

- Mentor - loGold. A fonte de braquiterapia consiste de uma cápsula de titânio selada a laser, contendo ${ }^{125}$ I adsorvido em quatro esferas de resina. O corpo da cápsula contém, também, duas esferas de ouro inativo que servem como marcadores, para identificar e localizar a fonte (FIG. 10) ${ }^{34,37}$. 


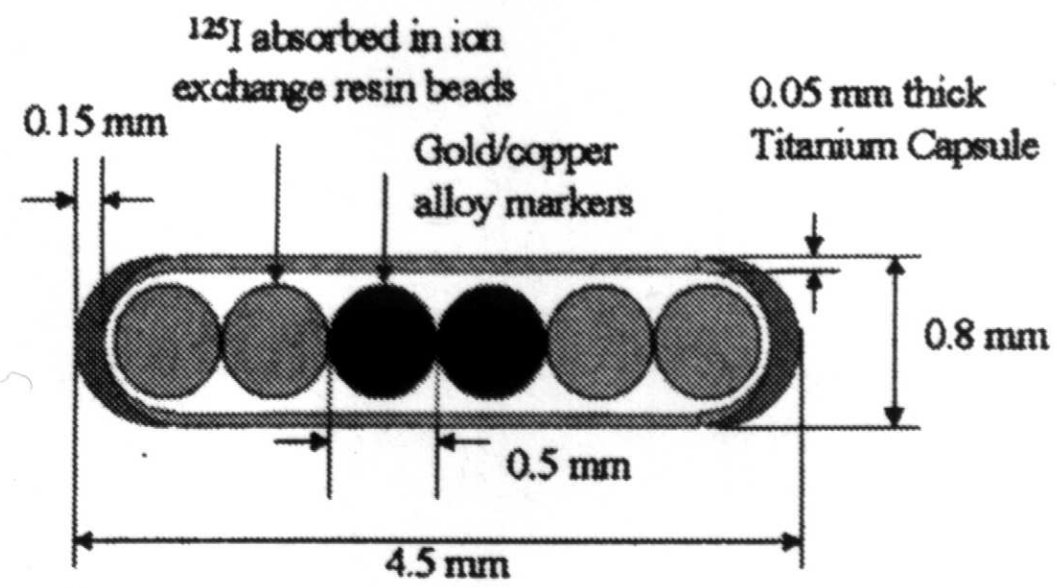

FIGURA 10 - Mentor loGold $^{34}$

- Syncor - Pharmaseed. Consiste de uma cápsula de titânio selada a laser, contendo no seu interior um fio de paládio radio-opaco coberto por uma camada de $0,5 \mu \mathrm{m}$ de ${ }^{125}$ (FIG. 11) ${ }^{34}$.

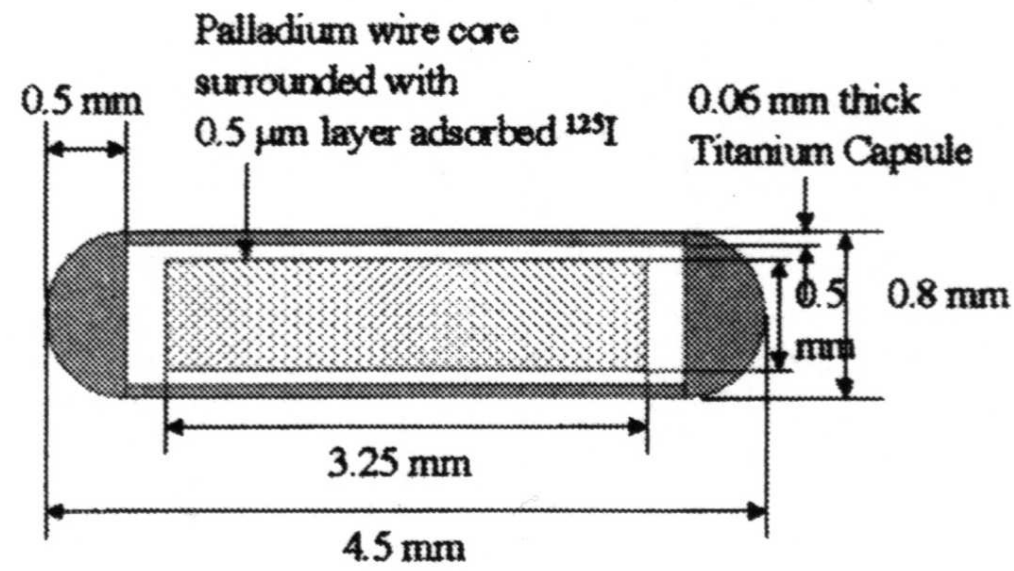

FIGURA 11 - Syncor PharmaSeed BT $\left.{ }^{125}\right|^{34}$

- Med-Tec - I-Plant 3500. A cápsula é de titânio selada a laser. ${ }^{125}$ I está adsorvido em um cilindro cerâmico e no seu interior está alojado um fio de prata que é utilizado com traçador (FIG. 12) ${ }^{34}$. 


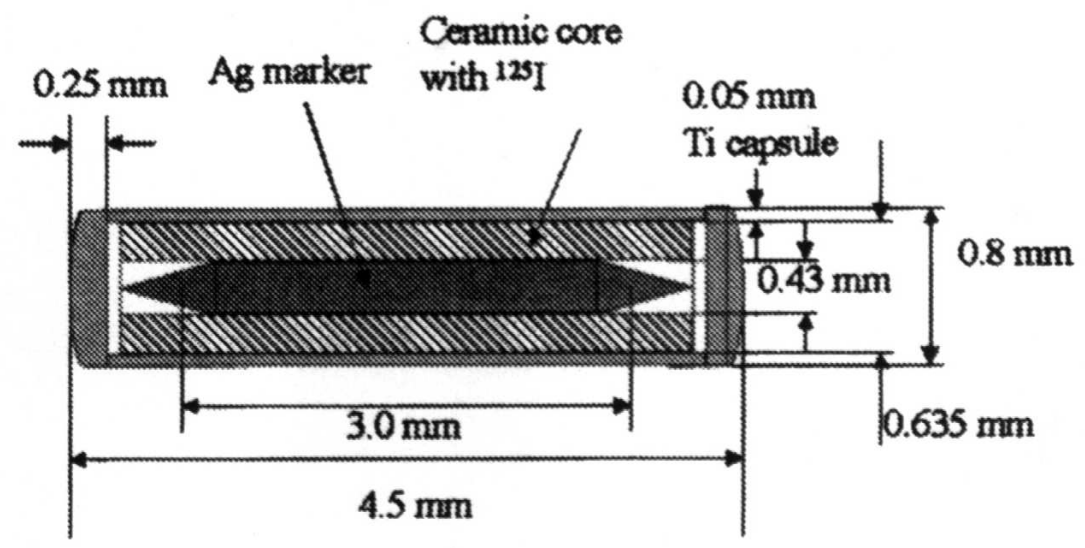

FIGURA 12 - Med-Tec I-Plant $3500^{34}$

- Uro-Cor - ProstaSeed. A fonte consiste de uma cápsula de titânio selada a laser. No seu interior estão posicionadas 5 esferas de prata radio-opaco onde o ${ }^{125}$ I está adsorvido (FIG. 13) ${ }^{34}$.

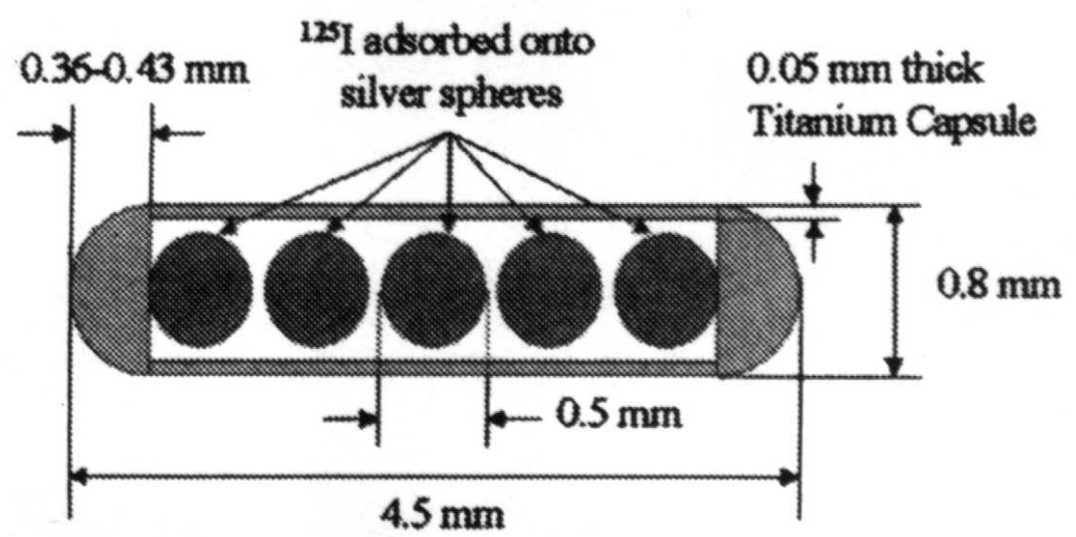

FIGURA 13 - Uro-Cor ProstaSeed ${ }^{34}$

A primeira patente para a produção de sementes de ${ }^{125}$ foi de Lawrence ${ }^{28}$ com o título Therapeutic metal seed containing within a radioactive isotope disposed on a carrier and method of manufacture registrada em 7 de novembro de 1967, onde são sugeridos diversos materiais e modelos. As sementes são descritas com as dimensões atuais, os radioisótopos sugeridos são o ${ }^{125} \mathrm{I}$, o ${ }^{103} \mathrm{Pd}$ e $\circ{ }^{131} \mathrm{Cs}$, os materiais apresentados como invólucro são o aço inoxidável e o titânio mas não apresenta detalhes da selagem. A FIG.14 ilustra um dos modelos citados por Lawrence nesta patente. 


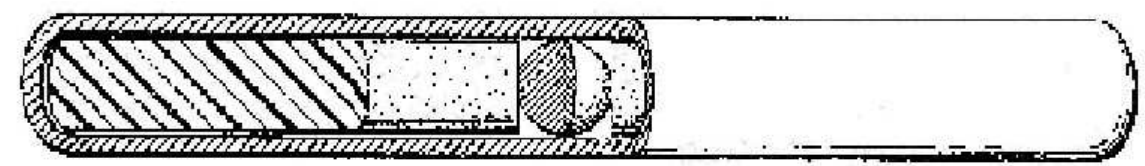

FIGURA 14 - Modelo de semente utilizando esfera de ouro como marcador

Na patente de Kubiatowicz ${ }^{38}$, Radioactive iodine seed, são descritos quatro métodos de deposição de ${ }^{125} \mathrm{I}$ em fios de prata de $3 \mathrm{~mm}$ de comprimento. O material utilizado como invólucro é o titânio. O processo de selagem utilizado para os quatro modelos é o TIG (Tungsten Inert Gas). A FIG.15 ilustra um dos modelos selado.

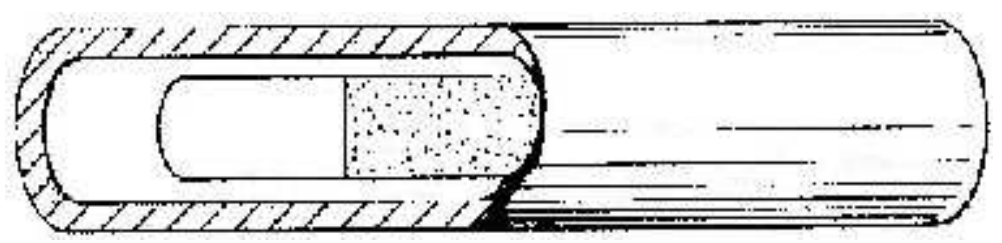

FIGURA 15 - Modelo utilizando fio de prata como carregador e marcador

Russell ${ }^{39}$ descreve, na patente $X$-ray emitting interstitial implants, a confecção de uma semente contendo ${ }^{103} \mathrm{Pd}$. São sugeridas duas formas de produção: realizar a ativação do paládio antes da montagem da semente ou realizar a ativação com a semente selada. São utilizadas duas esferas $(0,6 \mathrm{~mm}$ de diâmetro) em cada semente, separadas por um marcador de chumbo em um invólucro de titânio. O processo de selagem utilizado é o laser. Em outra patente do mesmo autor, Capsule for interstitial implants ${ }^{40}$, são apresentadas sugestões de selagem das sementes conforme a FIG.16, o invólucro externo é um tubo de titânio e em todos os casos são utilizados end caps. As técnicas de soldagem sugeridas são laser, feixe de elétrons e TIG.

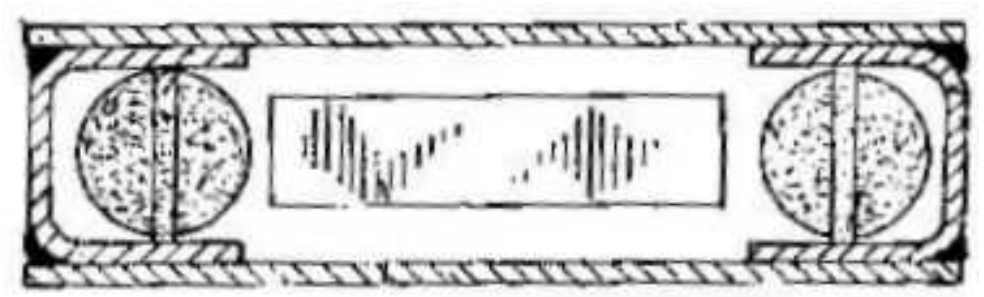

FIGURA 16 - Selagem de semente de ${ }^{103} \mathrm{Pd}$ 
Suthanthiran ${ }^{41}$ descreve na patente Device and method for encapsulanting radioactive materials uma cápsula (aço inoxidável ou titânio) para material radioativo composta de duas partes com uma extremidade fechada. Uma delas é posicionada no interior da outra sob interferência mecânica, provendo uma selagem sem necessidade de soldagem (FIG.17).

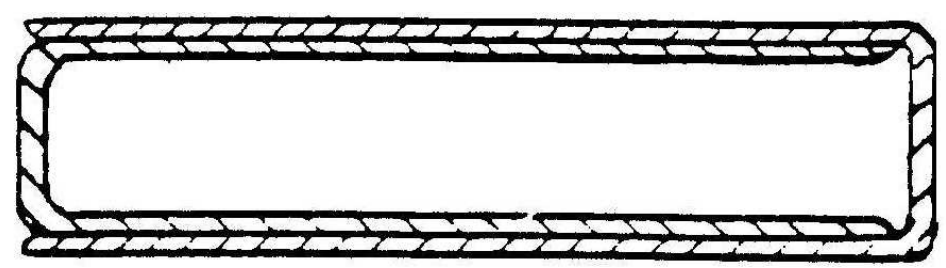

FIGURA 17 - Encapsulamento da semente sem soldagem

Cutrer $^{42}$, na patente Laser welded brachytherapy source and method of making the same, apresenta uma semente composta de 3 esferas de resina onde o material radioativo ${ }^{125} \mathrm{I}$ ou ${ }^{103} \mathrm{Pd}$ é incorporado e duas esfera de prata ou ouro que funcionam como marcador para localização da fonte. O encapsulamento é feito em titânio e a selagem é realizada com laser com o tubo em movimento de rotação. Exemplificando, o laser é acionado em uma primeira série de pulsos para iniciar o colapso no final do tubo e parcialmente fechar a extremidade. A seguir, o laser é acionado para uma segunda série de pulsos, removendo o material excedente e selando por completo este lado do tubo. O laser é acionado em uma terceira série de pulsos para iniciar o colapso e fechar parcialmente o outro extremo do tubo. Finalmente, o laser é acionado para uma quarta série de pulsos, removendo o material excedente e selando por completo a semente (FIG.18).

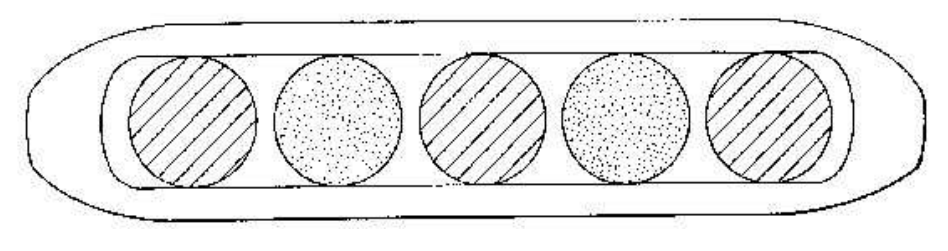

FIGURA 18 - Esquema de semente indicada na patente de Cutrer

Em outra patente, Encapsuled low-energy brachytherapy sources, Robertson ${ }^{43}$ relata uma invenção que consiste de quatro esferas contendo ${ }^{125}$, separadas, duas a duas, por um espaçador de titânio com um núcleo concêntrico de uma liga de platina e irídio (marcador). Este conjunto é envolto em dois tubos 
de titânio fechados em uma das extremidades e soldados na parte central pelo processo a laser (FIG.19).

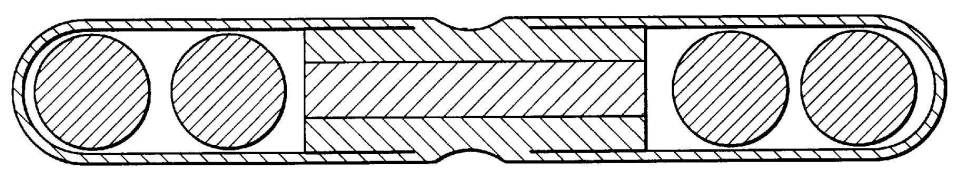

FIGURA 19 - Modelo de semente de ${ }^{103} \mathrm{Pd}$ ou ${ }^{125}$ I indicada na patente de Robertson

Bolenbaugh ${ }^{44}$ descreve, na patente Brachytherapy seeds, uma cápsula em titânio em que o diâmetro final do tubo (d2) tem uma conformação de 25 a $80 \%$ menor que o diâmetro central do tubo (d1). O material radioativo, ${ }^{125} \mathrm{I}$ ou ${ }^{103} \mathrm{Pd}$, é depositado em uma barra com seção poligonal variando de três a seis lados. A selagem da cápsula é feita por um pulso de arco plasma. A FIG.20 ilustra o modelo descrito na patente.

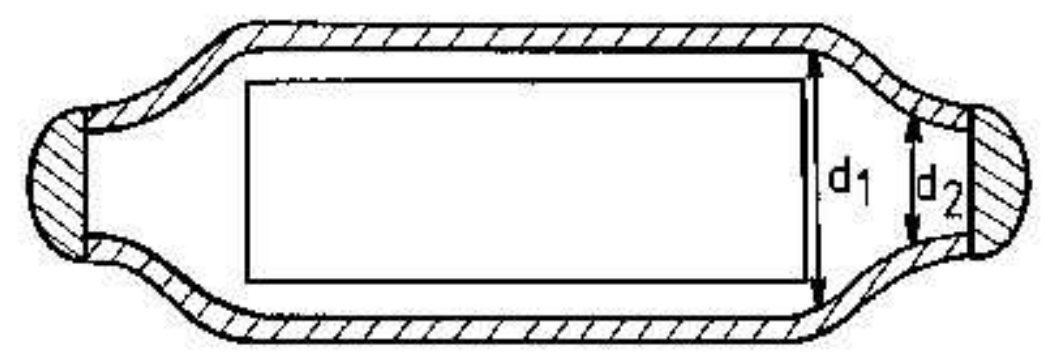

FIGURA 20 - Modelo de semente de ${ }^{125} \mathrm{I}$ ou ${ }^{103} \mathrm{Pd}$ indicado na patente de Bolenbaugh

$\mathrm{Na}$ patente Radioactive therapeutic seed having selective marker configuration, Slater ${ }^{45}$ descreve uma semente composta de uma cápsula de titânio dividida em duas metades, que acomoda em seu interior quatro esferas que podem ser de titânio, alumínio ou vidro, onde o material radioativo está depositado. Um espaçador de titânio é colocado na parte central para soldagem da semente pelo processo a laser (FIG.21).

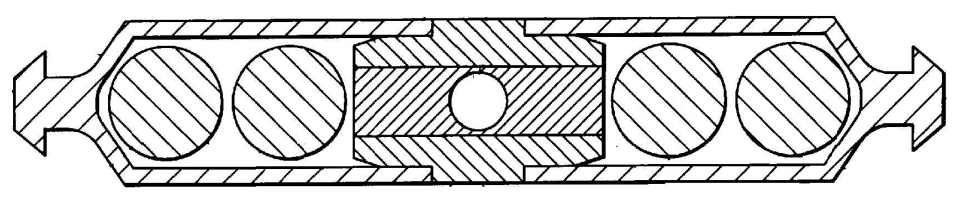

FIGURA 21 - Modelo de semente radioativa indicada na patente de Slater 
$\mathrm{Na}$ patente de Singh ${ }^{46}$, Radioactive seeds for brachytherapy and a process for making the same, é apresentada uma semente que compreende uma cápsula de material biocompatível como o titânio. No interior da cápsula são acomodados dois cilindros de resina contendo o ${ }^{125} \mathrm{I}$ ou ${ }^{103} \mathrm{Pd}$. Entre os cilindros é colocado um marcador que pode ser de prata, ouro, tungstênio ou chumbo. A cápsula é selada nas extremidades utilizando soldagem a laser ou feixe de elétrons.

$\mathrm{Na}$ patente Medical radioactive iodine-125 miniature radiation source and methods of producing the same, Ziegler ${ }^{47}$ descreve uma semente composta de uma matriz de material inorgânico poroso, tal como óxido de alumínio misturado com vidro, que contém o ${ }^{125} \mathrm{I}$ na forma de iodeto de prata. Esta matriz tem um formato cilíndrico com um núcleo concêntrico de ouro (marcador); o conjunto é encapsulado em titânio e a selagem nas extremidades do tubo é feita pelo processo de soldagem a laser (FIG.22).

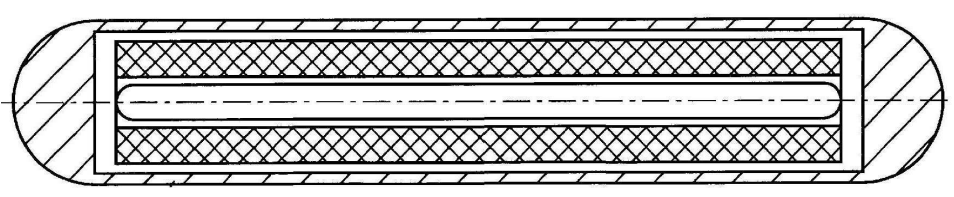

FIGURA 22 - Modelo de semente de ${ }^{125}$ I indicada na patente de Ziegler

Em outra patente de Cutrer ${ }^{48}$, Radioactive seed with multiple markers and method for using same, são descritos alguns modelos de sementes utilizando marcadores no formato de esferas que podem ser em ouro ou tungstênio. Os radioisótopos sugeridos são ${ }^{125} \mathrm{I}$ ou ${ }^{103} \mathrm{Pd}$ que podem estar adsorvidos em fios ou esferas. A soldagem a laser é a técnica recomendada nesta patente. A FIG. 23 ilustra um dos modelos citados por Cutrer.

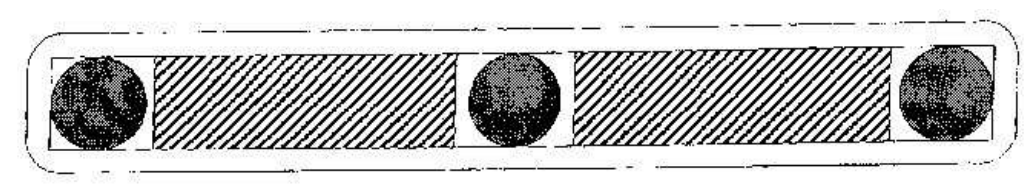

FIGURA 23 - Modelo de semente de ${ }^{125}$ I indicada na patente de Cutrer 


\subsection{Titânio}

O titânio é um metal estrutural com uma combinação inédita de propriedades. A sua cor é semelhante ao alumínio e ao aço inoxidável.

Sua superior relação resistência/peso e resistência à corrosão originaram uma variedade de aplicações, impraticáveis com outros materiais ${ }^{49}$.

O titânio foi descoberto pelo britânico Gregor Williams, em 1791. Em 1795, o químico e mineralogista alemão, Martin H. Klaproth, nomeou Titanium. Nome derivado do Titans da mitologia grega, caráter que possui um poder extremo e uma força superior ${ }^{50}$.

O titânio não foi usado intensivamente até meados do século $X X$ porque a tecnologia para separação do elemento químico não estava disponível, uma vez que o mesmo não existe em estado livre, mas, combinado a outros elementos. William Kroll, de Luxemburgo, desenvolveu um processo que permitia a produção do titânio metálico. O Departamento de Minas e Energias dos Estados Unidos usou o processo de Kroll para produzir o titânio metálico, após ter recebido incentivo financeiro do próprio governo. A produção anual aumentou rapidamente de 3 toneladas em 1948 para 20.000 toneladas nos anos $80^{50}$.

O rápido crescimento nos primeiros anos foi resultado do incentivo de programas aeronáuticos, promovidos pelos Governos dos Estados Unidos e da ex-União Soviética. Estes dois países investiram grandes somas no aperfeiçoamento do processo Kroll e no desenvolvimento de ligas de alta resistência. O Japão seguiu utilizando a tecnologia existente e contribuiu no desenvolvimento de aplicações das propriedades anticorrosivas do titânio.

O setor da indústria de titânio que mais têm crescido nos últimos anos é o dos produtos de titânio comercialmente puro, sem elementos de liga, utilizados nas indústrias de processamento químico, em virtude da grande versatilidade proporcionada por este produto ${ }^{49}$.

Algumas propriedades físicas do titânio metálico comercialmente puro (sem elementos de liga) estão relacionados na TAB. ${ }^{49}$. 
TABELA 2 - Propriedades do titânio

\begin{tabular}{|c|c|}
\hline Grandeza & Valor \\
\hline Símbolo & $\mathrm{Ti}$ \\
\hline Numero atômico & 22 \\
\hline Peso Atômico & 47,90 \\
\hline Densidade & $4,51 \mathrm{~g} / \mathrm{cm}^{3}$ \\
\hline Ponto de fusão & $1.668 \mathrm{C}$ \\
\hline Ponto de ebulição & $3.287 \mathrm{C}$ \\
\hline Dureza & $200 \mathrm{HB}$ \\
\hline Condutividade térmica & $22 \mathrm{~W} / \mathrm{m}^{\circ} \mathrm{C}$ \\
\hline Seção de choque & $5,6 \mathrm{barn}$ \\
\hline Módulo de elasticidade & $116 \mathrm{GPa}$ \\
\hline Estrutura molecular a temperatura ambiente & $\mathrm{HCP}$ \\
\hline
\end{tabular}

\subsubsection{Utilização}

O titânio tem sido aplicado nos mais diversos campos, por exemplo ${ }^{50}$ :

Aeroespacial: é usado na indústria aeroespacial por causa da sua resistência elevada. Pela necessidade de se ter aviões com alta resistência mecânica e com baixo peso, fez-se do titânio a escolha perfeita para a sua produção.

Automotivo: é usado para a fabricação de vários componentes automotivos, como por exemplo, válvulas do motor, componentes de rodas e barras de suspensão.

Acessórios Pessoais: está transformando-se em uma escolha popular para acessórios pessoais. É usado para muitos produtos incluindo óculos, colares, brincos, piercings e relógios.

Esportes e Lazer: está sendo muito utilizado para produtos de esporte e lazer, tais como, quadros de bicicleta, tacos de golfe, carros controlados por rádio, raquetes de tênis e acessórios para esportes de escalada. 
Marinho: é usado nos navios e nos submarinos por causa da sua alta resistência e baixa corrosão à água do mar. São usados para turbinas, hélices e eixos, bombas de água, válvulas submarinas e outros componentes.

Bio-Medicinal/Odontológico: é usado extensivamente para implantes médicos e odontológicos. É biocompatível ao corpo humano. É usado para implantes e sustentações para os ossos quebrados, implantes odontológicos e outras aplicações médicas.

Segurança: está sendo usado também para blindagens de carros, guaritas, caixas fortes, portas de segurança e outras aplicações que necessitam de altas proteções balísticas. A utilização do titânio começa ser bem aceita neste mercado devido ao seu baixo peso e alta resistência, comparado ao do aço que normalmente é utilizado.

Outros exemplos não detalhados podem ser citados: indústria farmacêutica, alimentícia, galvanoplastia, química e derivados, papel e celulose, indústrias de álcalis, siderúrgicas, mineração, petróleo e petroquímicas ${ }^{49}$.

\subsubsection{Titânio medicinal}

Uma das propriedades do titânio é sua biocompatibilidade. Hoje, implantes dentários (substituindo a raiz do dente) são possíveis graças ao titânio. Também são fabricados verdadeiros ossos ortopédicos ${ }^{51}$.

Nestas aplicações, os tipos de titânio utilizados são o ASTM-F-67 e o ASTM-F-136. Estes tipos, para medicina, são fabricados com rigoroso controle de qualidade, já que se tratam de componentes temporários ou permanentes a serem incorporados ao corpo humano ${ }^{51}$.

A eficácia e a confiabilidade dos implantes, instrumentos, dispositivos médicos e cirúrgicos são fatores essenciais nesta área. O implante representa uma grande mudança na estrutura química, fisiológica e mecânica do corpo humano. Não há nada comparável a um implante metálico em tecido vivo, pois a corrosão do metal implantado por líquidos do corpo resulta na liberação de íons 
metálicos não desejados, com interferência provável nos processos da vida. A resistência à corrosão não é suficiente para suprimir a reação do corpo aos metais tóxicos ou aos elementos alérgicos, podendo iniciar reações de rejeição. $O$ titânio é completamente inerte e imune à corrosão por todos os líquidos e tecidos do corpo, e é assim considerado biocompatível. A seleção natural do titânio para implantes é determinada por uma combinação da maioria das características favoráveis incluindo a imunidade à corrosão, a biocompatibilidade, a resistência mecânica e a capacidade para integrar com ossos ou outros tecidos Osseointegração ${ }^{52}$. A FIG.24 ilustra algumas próteses para implantes ósseos.

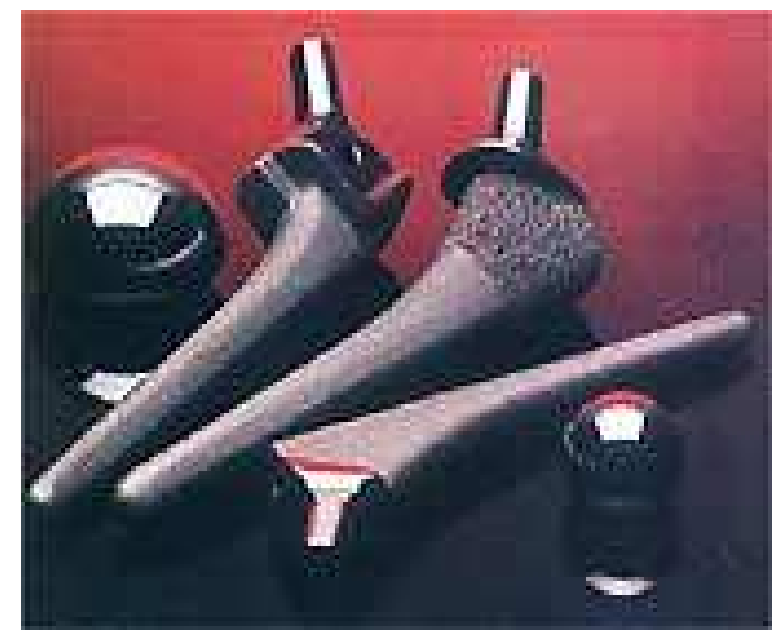

FIGURA 24 - Exemplo de próteses para utilização em ortopedia ${ }^{53}$

Algumas aplicações do titânio no campo da medicina são citadas abaixo ${ }^{52}$ :

Ortopédico: aproximadamente um milhão de pacientes no mundo são tratados anualmente com a implantação de elementos ortopédicos. Estas próteses podem ser para joelho, quadril, coluna, maxila, trauma e endoprótese.

Implantes Dentários: uma mudança significativa na prática dental restaurativa foi possível com o uso dos implantes de titânio. Uma raiz de titânio é introduzida no osso da maxila para que ocorra a osseointegração. A superestrutura do dente é fixada ao implante para uma recolocação eficaz.

Tratamentos de Maxilofacial e de Craniofacial: as cirurgias para reparar danos faciais são realizadas com implantes artificiais para restaurar a habilidade de falar 
ou comer. Os implantes de titânio, permitindo osseointegração e atendendo todas as exigências da biocompatibilidade, fizeram avanços antes não possíveis na cirurgia.

Dispositivos Cardiovasculares: o titânio é usado regularmente para caixas e desfibriladores de marca-passos, como estrutura de válvulas do coração e para stents intravenosos.

Próteses Externas: o titânio é apropriado para fixação de dispositivos externos provisórios e membros artificiais. Ambos utilizam extensivamente o titânio devido ao seu leve peso, resistência mecânica e resistência à corrosão.

Instrumentos Cirúrgicos: uma grande quantidade de instrumentos cirúrgicos é fabricada em titânio. A leveza do metal é fator positivo para minimizar a fadiga do cirurgião. O titânio não é magnético e não há, conseqüentemente, nenhuma ameaça de danos aos pequenos dispositivos eletrônicos implantados ${ }^{52}$.

\subsubsection{Normas e composição química do titânio medicinal}

Nenhum material para implante cirúrgico demonstra ser completamente livre de reações adversas no corpo humano. Entretanto, experiências clínicas prolongadas do emprego do material titânio medicinal mostram que um nível aceitável de resposta biológica pode ser esperado quando o material é usado em aplicações apropriadas ${ }^{20}$. Desta maneira, as normas ASTM F67-77 ${ }^{18}$, NBR ISO $5832-2^{20}$ e o ASM Metals Handbook ${ }^{19}$ foram utilizados na especificação do titânio medicinal utilizado para confecção das sementes de ${ }^{125}$.

A patente Capsule for interstitial implants de Russell ${ }^{40}$, recomenda a utilização do titânio comercialmente puro grau 2.

Pode-se observar na TAB. 3 a composição química do titânio medicinal conforme as normas ASTM F67-77 ${ }^{18}$ e NBR ISO 5832-2 ${ }^{20}$ 
TABELA 3 - Composição química do titânio medicinal

\begin{tabular}{|c|c|c|c|c|c|}
\hline \multirow{2}{*}{ Elemento - Limites máximos de composição - \% - fração de massa } \\
\cline { 2 - 6 } & Grau 1 ELI & Grau 1 & Grau 2 & Grau 3 & $\begin{array}{c}\text { Graus 4Ae } \\
\text { 4B }\end{array}$ \\
\hline Nitrogênio & 0,012 & 0,03 & 0,03 & 0,05 & 0,05 \\
\hline Carbono & 0,03 & 0,10 & 0,10 & 0,10 & 0,10 \\
\hline Hidrogênio & $0,0125^{1}$ & $0,0125^{1}$ & $0,0125^{1}$ & $0,0125^{1}$ & $0,0125^{1}$ \\
\hline Ferro & 0,10 & 0,20 & 0,30 & 0,30 & 0,50 \\
\hline Oxigênio & 0,10 & 0,18 & 0,25 & 0,35 & 0,40 \\
\hline Titânio & Balanço & Balanço & Balanço & Balanço & Balanço \\
\hline $\begin{array}{l}\text { 1 Exceto para tarugos, para os quais o teor máximo de hidrogênio deve ser } 0,010 \% \text { (fração de } \\
\text { massa), e para produtos planos, para os quais o teor máximo de hidrogênio deve ser 0,015\% } \\
\text { (fração de massa). }\end{array}$ \\
\hline
\end{tabular}

\subsection{Soldagem}

A história da soldagem mostra que, desde as mais remotas épocas, muitos artefatos já eram confeccionados utilizando recursos de brasagem. As mais antigas notícias que se tem sobre a soldagem estão em uma peça do Museu do Louvre em Paris: um pingente de ouro com indícios de solda, feito na Pérsia ( $\approx 4.000$ a.C.). A soldagem por forjamento também tem sido utilizada há mais de 3000 anos: um exemplo é a Espada de Damasco (1.300 a.C.) e a utilização de uma espécie de maçarico soprado pela boca, usado para fundir e soldar bronze ${ }^{54,55}$.

O ferro, cuja fabricação se iniciou em torno de 1500 a.C., substituiu o cobre e o bronze na confecção de diversos artefatos. O ferro era conformado por martelamento na forma de blocos, com um peso de poucos quilogramas. Quando peças maiores eram necessárias, os blocos eram soldados por forjamento, isto é, o material era aquecido ao rubro, colocava-se areia entre as peças para escorificar impurezas e martelava-se até a soldagem. Como exemplo de utilização deste processo, cita-se um pilar de cerca de sete metros de altura e mais de cinco toneladas existente ainda hoje na cidade de Delhi (Índia) ${ }^{56}$.

A técnica da moderna soldagem começou a ser moldada a partir do século XIX, com a descoberta do arco elétrico por Sir Humphrey Davy, bem como 
com a descoberta do acetileno por Edmund Davy e do desenvolvimento de fontes produtoras de energia elétrica, permitindo que se iniciassem alguns processos de fabricação de peças utilizando estes novos recursos ${ }^{54}$.

Segue abaixo um resumo cronológico da história da soldagem ${ }^{54}$ :

1801 - Sir Humphrey Davy descobre o fenômeno do arco elétrico;

1836 - Edmund Davy descobre o Acetileno;

1835 - N. Bernardos e S. Olsewski depositam patente do processo de soldagem por arco elétrico;

1889 - N. G. Slavianoff e C. Coffin substituem o eletrodo de grafite por arame metálico;

1901 - Fouché e Picard desenvolvem o primeiro maçarico industrial para soldagem oxiacetilênica;

1903 - Goldschmidt descobre a solda aluminotérmica;

1907 - O. Kjellberg deposita a patente do primeiro eletrodo revestido;

1919 - C. J. Halsag introduz a corrente alternada nos processos de soldagem;

1926 - H.M. Hobart e P.K. Denver utilizam gás inerte como proteção do arco elétrico;

1930 - Primeiras normas para eletrodo revestido nos EUA;

1935 - Desenvolvimento dos processos de soldagem TIG e Arco Submerso;

1948 - H.F. Kennedy desenvolve o processo de soldagem MIG;

1950 - França e Alemanha desenvolvem o processo de soldagem por feixe de elétrons;

1953 - Surgimento do processo MAG;

1957 - Desenvolvimento do processo de soldagem com arame tubular e proteção gasosa;

1958 - Desenvolvimento do processo de soldagem por eletro-escória, na Rússia;

1960 - Desenvolvimento de processo de soldagem a laser, nos EUA;

1970 - Aplicados os primeiros robôs nos processos de soldagem.

Com o advento da Primeira Guerra Mundial, a técnica da soldagem começou a ser mais utilizada nos processos de fabricação; a Segunda Guerra Mundial imprimiu grande impulso na tecnologia de soldagem, desenvolvendo novos processos e aperfeiçoando os já existentes ${ }^{54}$. 
A FIG. 25 ilustra a evolução dos processos de soldagem ao longo do tempo ${ }^{55}$.

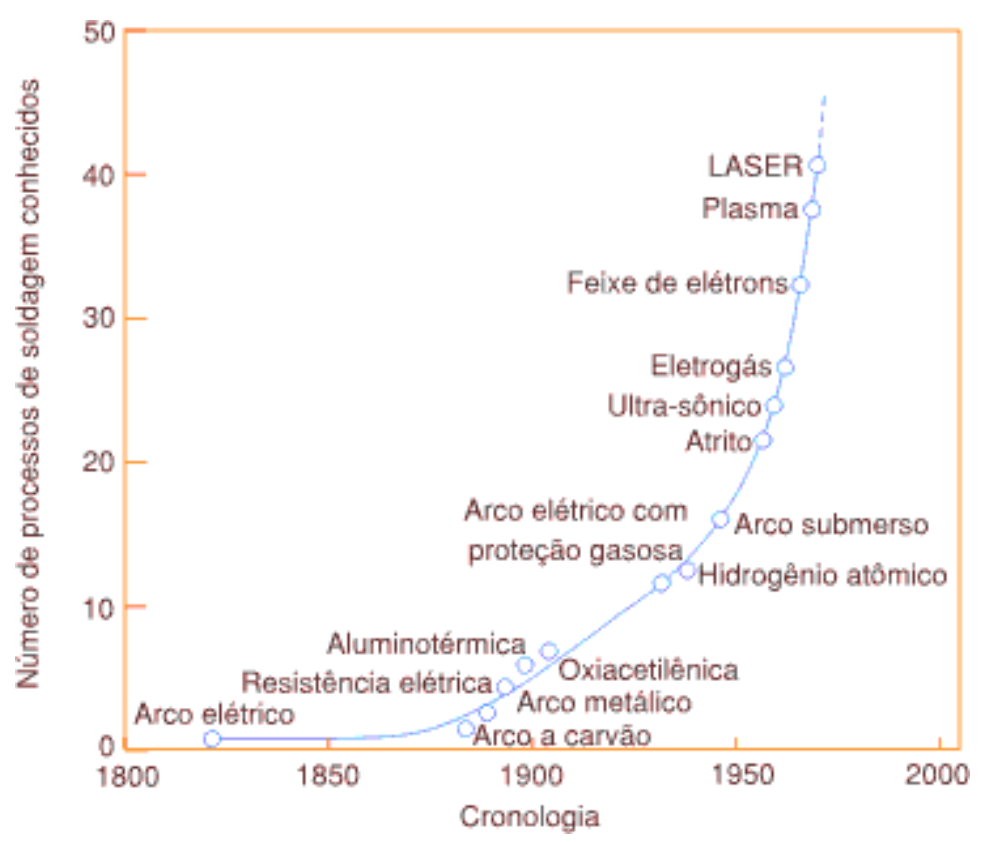

FIGURA 25 - Evolução dos processos de soldagem ao longo do tempo ${ }^{55}$

\subsubsection{Processos de soldagem}

Soldagem por fusão é um processo no qual as partes são fundidas por meio de energia elétrica ou processo químico, sem aplicação de pressão ${ }^{57}$.

Soldagem por pressão baseia-se na deformação localizada das partes a serem unidas, que pode ser auxiliada pelo aquecimento dessas até uma temperatura inferior à temperatura de fusão, conhecido como processos de soldagem por pressão ou processos de soldagem no estado sólido ${ }^{58}$.

Uma operação parecida com soldagem, que também tem por objetivo a união permanente de peças, é a brasagem. Ela se diferencia da soldagem pelo fato de que na soldagem por fusão as peças a serem unidas sempre se fundem e na brasagem elas nunca se fundem. A união é obtida pelo uso de um material suplementar, chamado de material de adição, e somente esse é fundido durante a operação. Outra diferença é que na brasagem o mecanismo responsável pelo preenchimento do espaço entre as peças pelo material de adição é a capilaridade ${ }^{58}$. 
Existe um grande número de processos por fusão que podem ser separados em sub-grupos, por exemplo, de acordo com o tipo de fonte de energia usada para fundir as peças. Dentre estes, os processos de soldagem a arco (fonte de energia: arco elétrico) são os de maior importância industrial na atualidade. Devido à tendência de reação do material fundido com os gases da atmosfera, a maioria dos processos de soldagem por fusão utiliza algum meio de proteção para minimizar estas reações. A TAB. 4 ilustra os principais processos de soldagem por fusão e suas características ${ }^{56}$.

TABELA 4 - Processos de soldagem por fusão

\begin{tabular}{|c|c|c|c|}
\hline Processo & Fontes de calor & $\begin{array}{c}\text { Tipo de } \\
\text { corrente e } \\
\text { polaridade }\end{array}$ & $\begin{array}{l}\text { Agente protetor ou de } \\
\text { corte }\end{array}$ \\
\hline $\begin{array}{l}\text { Soldagem por } \\
\text { eletro-escória }\end{array}$ & $\begin{array}{l}\text { Aquecimento por } \\
\text { resistência da } \\
\text { escória líquida }\end{array}$ & $\begin{array}{l}\text { Contínua ou } \\
\text { alternada }\end{array}$ & Escória \\
\hline $\begin{array}{l}\text { Soldagem ao } \\
\text { Arco-Submerso }\end{array}$ & Arco elétrico & $\begin{array}{l}\text { Contínua ou } \\
\text { alternada } \\
\text { Eletrodo + }\end{array}$ & Escória e gases gerados \\
\hline $\begin{array}{l}\text { Soldagem com } \\
\text { Eletrodo } \\
\text { Revestido }\end{array}$ & Arco elétrico & $\begin{array}{l}\text { Contínua ou } \\
\text { alternada } \\
\text { Eletrodo + }\end{array}$ & Escória e gases gerados \\
\hline $\begin{array}{l}\text { Soldagem com } \\
\text { Arame Tubular }\end{array}$ & Arco elétrico & $\begin{array}{l}\text { Contínua } \\
\text { Eletrodo + }\end{array}$ & $\begin{array}{l}\text { Escória e gases gerados } \\
\text { ou fornecidos por fonte } \\
\text { externa. Em geral } \mathrm{CO}_{2}\end{array}$ \\
\hline $\begin{array}{l}\text { Soldagem } \\
\text { MIG/MAG }\end{array}$ & Arco elétrico & $\begin{array}{l}\text { Contínua } \\
\text { Eletrodo + }\end{array}$ & $\begin{array}{c}\text { Argônio ou Hélio, Argônio } \\
+\mathrm{O}_{2} \text {, Argônio }+\mathrm{CO}_{2}, \\
\mathrm{CO}_{2}\end{array}$ \\
\hline $\begin{array}{c}\text { Soldagem a } \\
\text { Plasma }\end{array}$ & Arco elétrico & $\begin{array}{l}\text { Contínua ou } \\
\text { Eletrodo - }\end{array}$ & $\begin{array}{c}\text { Argônio, Hélio ou Argônio } \\
+ \text { Hidrogênio }\end{array}$ \\
\hline Soldagem TIG & Arco elétrico & $\begin{array}{l}\text { Contínua ou } \\
\text { alternada } \\
\text { Eletrodo - }\end{array}$ & $\begin{array}{c}\text { Argônio, Hélio ou mistura } \\
\text { de destes }\end{array}$ \\
\hline $\begin{array}{l}\text { Soldagem por } \\
\text { Feixe Eletrônico }\end{array}$ & Feixe Eletrônico & $\begin{array}{l}\text { Contínua. Alta } \\
\text { Tensão. } \\
\text { Peça }+\end{array}$ & Vácuo (>> $\left.10^{-4} \mathrm{mmHg}\right)$ \\
\hline $\begin{array}{c}\text { Soldagem a } \\
\text { Laser }\end{array}$ & Feixe de Luz & & Argônio ou Hélio \\
\hline Soldagem a Gás & $\begin{array}{l}\text { Chama oxi- } \\
\text { acetilênica }\end{array}$ & & Gás $\left(\mathrm{CO}, \mathrm{H}_{2}, \mathrm{CO}_{2}, \mathrm{H}_{2} \mathrm{O}\right)$ \\
\hline
\end{tabular}




\subsubsection{Soldagem plasma}

A soldagem a arco plasma (PAW - Plasma Arc Welding) é um processo de soldagem que produz coalescência dos metais, pelo aquecimento com um arco constrito entre o eletrodo e a peça de trabalho (arco transferido) ou entre o eletrodo e o bocal constrito da tocha (arco não transferido). A proteção é obtida do gás quente e ionizado, proveniente da tocha. Este gás é usualmente fornecido por uma fonte auxiliar de gás de proteção, que deve ser um gás inerte ou uma mistura de gases inertes. O metal de adição pode ou não ser utilizado ${ }^{59}$.

O processo consiste inicialmente em provocar em uma coluna de gás, com o auxílio de um arco elétrico, o aumento de sua temperatura, o suficiente para que os impactos entre as moléculas de gás provoquem entre si certo grau de dissociação e ionização. O gás ionizado é forçado a passar através de um orifício de parede fina e esta repentina mudança provoca um grande gradiente térmico entre o centro da coluna de gás com a periferia, que está em contato com a parede de cobre, fazendo com que a densidade no centro da coluna diminua, favorecendo aos elétrons adquirirem energia suficiente para provocar a ionização de outros átomos. Este efeito eleva, de maneira sensível, o grau de ionização da coluna do arco e sua temperatura, possibilitando o aumento da taxa de energia transferida para a peça a ser soldada, sendo o aumento da velocidade do plasma conseqüência direta da constrição.

A proteção da peça de fusão é obtida parcialmente com o gás ionizado em alta temperatura, que escoa através do bocal de constrição. Uma proteção auxiliar de gás pode ser necessária para proteger completamente a poça de fusão da oxidação do ar. O gás auxiliar de proteção pode ser um gás inerte ou uma mistura de gases ${ }^{60}$.

$O$ processo de soldagem a arco plasma (PAW), assim como o processo TIG (GTAW), usa eletrodo não consumível. A tocha tem um bocal que cria uma câmara de gás ao redor do eletrodo. $O$ arco aquece o gás na câmara até uma temperatura em que se torna ionizado e conduz eletricidade. Este gás ionizado é definido como plasma, que sai do orifício do bocal a uma temperatura 
próxima de $16.700^{\circ} \mathrm{C}$. A FIG. 26 ilustra, em corte, os componentes do bocal de uma tocha plasma ${ }^{59}$.

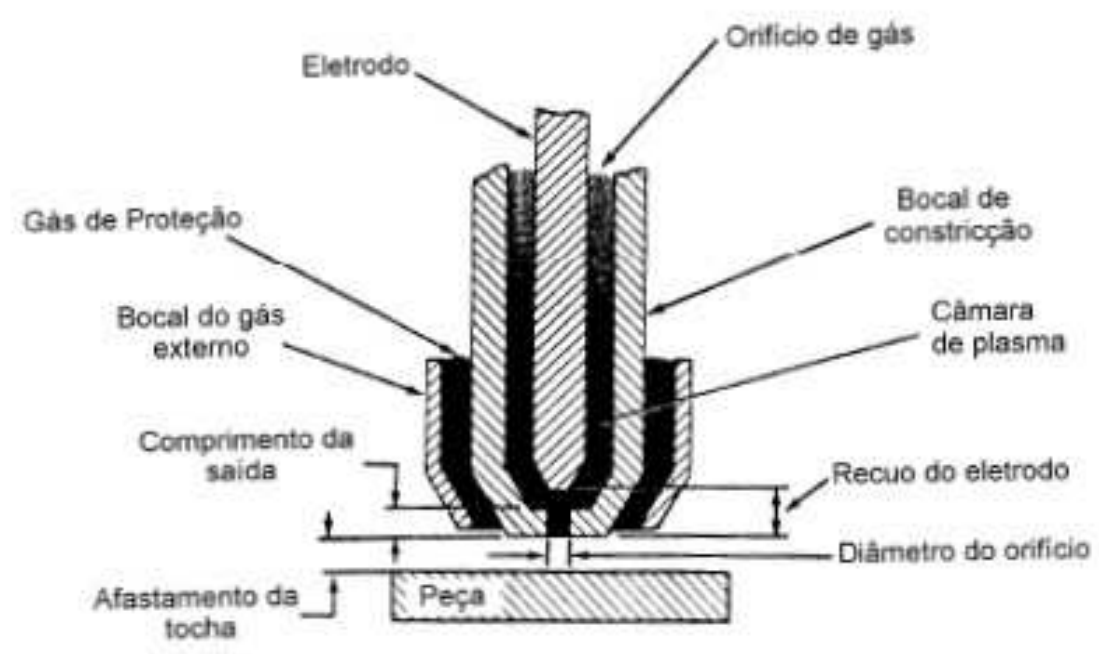

FIGURA 26 - Representação esquemática de uma tocha plasma

Uma série de melhorias no desempenho do processo pode ser obtida fazendo o arco por plasma passar através de um pequeno orifício refrigerado. A mais notável melhoria é a estabilidade do arco. No processo TIG, o arco é atraído para a região mais próxima da peça a ser soldada e pode ser defletido por campos magnéticos fracos. No processo de soldagem com plasma, o jato por plasma pode ser considerado como sendo rijo, ou seja, seu percurso tem a direção para o qual ele é apontado, sendo menos afetado por campos magnéticos.

A constrição possibilita grandes densidades de corrente $e$, conseqüentemente, grande concentração de energia: as altas densidades de corrente resultam em altas temperaturas na coluna do arco.

A constrição do arco oferece melhor controle sobre a energia do arco. O grau de colimação, a força do arco, a densidade de energia sobre a peça a ser soldada e outras características são funções das seguintes variáveis: intensidade de corrente do plasma, forma e diâmetro do orifício de constrição, tipo de gás do arco plasma e vazão do gás. As diferenças fundamentais entre muitos processos 
que utilizam o plasma no trabalho com metais são decorrentes de variações dos quatro fatores mencionados ${ }^{60}$.

Dois tipos de arcos são utilizados no processo de soldagem com plasma: arco transferido e arco não transferido. No arco transferido, o arco principal é estabelecido entre o eletrodo e a peça a ser soldada. A peça a ser soldada é parte integrante do circuito elétrico. $O$ arco transferido produz um aquecimento entre o ânodo e o fluxo de plasma. Este modo é geralmente utilizado para soldagem devido a maior energia transferida para a peça.

No arco não transferido o arco é estabelecido entre o eletrodo e o orifício de constrição. $O$ arco plasma é forçado através do orifício pelo gás de plasma, neste caso a peça soldada não faz parte do circuito elétrico do arco. $\mathrm{O}$ calor gerado sobre a peça a ser soldada é obtido somente pelo jato de plasma que atravessa o orifício do bocal de constrição. Este tipo de arco é utilizado para corte e junção de peças não condutoras e em aplicações que exigem baixa concentração de energia ${ }^{60,61}$. A FIG. 27 ilustra os dois tipos de arcos: transferido e não transferido.

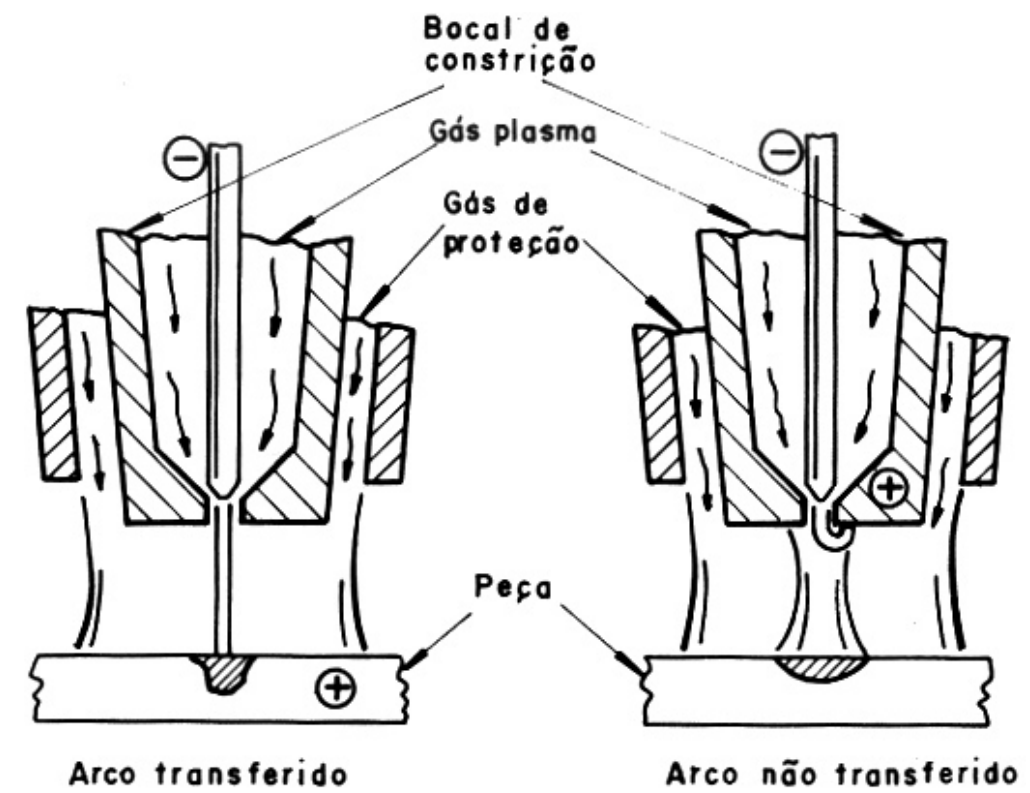

FIGURA 27 - Tipos de arcos do processo plasma (PAW) 
A soldagem por arco plasma pode ser feita manualmente ou por meio de máquinas, com algumas adaptações. Os dois processos são amplamente utilizados e podem ser empregados em qualquer posição ${ }^{62}$.

O equipamento básico para soldagem com plasma consiste de uma tocha, fonte de energia, painel de controle, cilindros de gases de plasma e proteção, circuito de água de refrigeração e controle remoto de corrente de soldagem ${ }^{60}$ (FIG. 28).

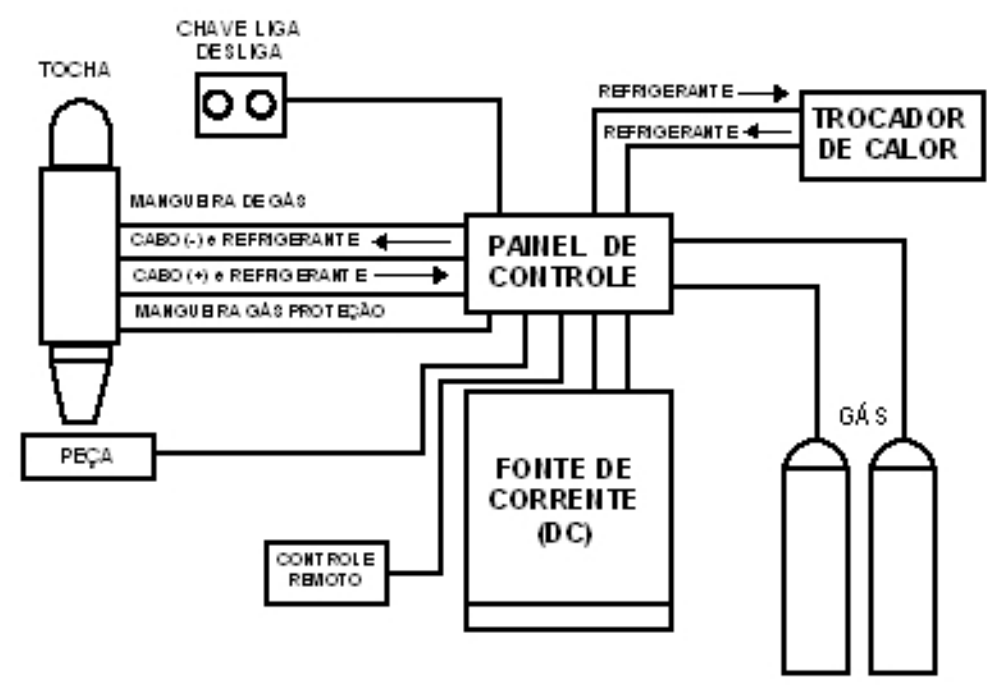

FIGURA 28 - Equipamento para soldagem a plasma (PAW)

O arco plasma não pode ser iniciado com as técnicas normais utilizadas no processo TIG, pois estando o eletrodo confinado no interior do bocal de constrição, ele não pode tocar a peça a ser soldada para a abertura do arco. Para o arco ter início, é estabelecido entre os eletrodos e a peça a ser soldada um arco piloto, obtido por um circuito de alta freqüência, interligado com o circuito de potência, conforme ilustra a FIG. 29. O circuito elétrico é completado através de uma resistência. $\mathrm{O}$ arco formado entre o eletrodo e o bocal tem corrente elétrica baixa e forma um caminho de baixa resistência entre o eletrodo e a peça a ser soldada, permitindo o fácil estabelecimento do arco plasma quando a fonte de potência é energizada. Quando o arco plasma é formado, o arco piloto é eliminado e somente volta a ser restabelecido quando o arco plasma é extinto ${ }^{60}$. 


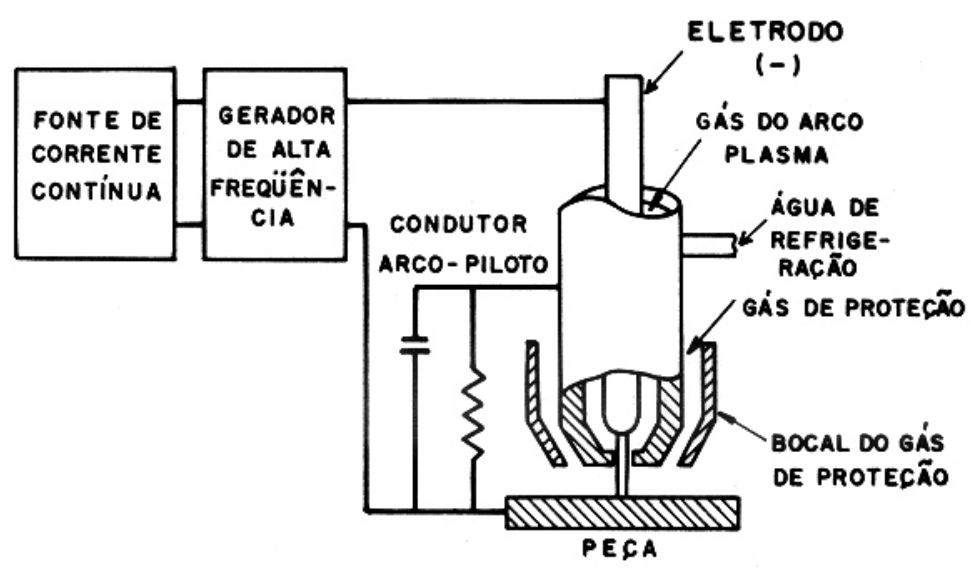

FIGURA 29 - Circuito de alta freqüência do arco piloto

As vantagens do processo de soldagem por arco plasma, em relação ao processo TIG ou a outro processo de soldagem convencional são ${ }^{60,61,62 .:}$

a) Maior concentração de energia e densidade de corrente, conseqüentemente, menores distorções, maior velocidade de soldagem e maior penetração;

b) Maior estabilidade direcional e focal do arco em baixos níveis de corrente, permitindo a soldagem de finas espessuras, a partir de $0,05 \mathrm{~mm}$;

c) Arco mais homogêneo e de maior extensão, permitindo melhor visibilidade operacional, maior constância da poça de fusão e menor sensibilidade a variações no comprimento do arco;

d) Menor probabilidade de contaminação do cordão por inclusões de tungstênio e de contaminação do eletrodo pelo material de adição;

e) Menor zona termicamente afetada.

Em relação às limitações, pode-se dizer:

a) A soldagem com arco plasma requer do operador maior conhecimento do processo;

b) A tocha é mais complexa, o eletrodo requer configuração e posicionamento preciso; 
c) Devido ao arco estreito, o processo tem pequena tolerância para desalinhamento da junta de solda;

d) Para uma qualidade consistente da solda, o bocal de constrição deve ser manuseado com cuidado e inspecionado regularmente para detectar sinais de deterioração.

\subsubsection{Soldagem laser}

O nome laser é a abreviatura da descrição do processo em inglês Light Amplification by Stimulated Emission of Radiation. Em uma tradução livre para o português pode-se dizer Amplificação da luz através da emissão estimulada da radiação ${ }^{63}$.

A soldagem com laser (LBW - Laser Beam Welding) é um processo de união baseado na fusão localizada da junta através de seu bombardeamento por um feixe de luz concentrada, coerente e monocromática de alta intensidade. Este feixe de alta intensidade é suficiente para fundir e vaporizar parte do material da junta no ponto de entrada do feixe no material, causando um furo com formato de buraco de fechadura (Key hole) que penetra profundamente no metal de base ${ }^{56}$.

Para produção do laser podem ser usadas cavidades laser com dióxido de carbono, capazes de produzir laser de infravermelho e densidades de energia em torno de $1 \times 10^{10} \mathrm{~W} / \mathrm{m}^{2}$, ou fontes pulsadas de YAG (Ytrium aluminum garnet) no estado sólido. As primeiras são usadas para a soldagem laser de elevada penetração, enquanto que os lasers de estado sólido são mais usados para a soldagem de ponto e de costura em juntas de pequena espessura, soldagem em microeletrônica e em outras aplicações que exijam um controle preciso da quantidade de energia fornecida à peça ${ }^{56}$.

A soldagem com laser é um processo de alta velocidade, ideal para aplicações automatizadas, exigindo um perfeito ajuste das peças. $O$ valor do equipamento de soldagem é elevado, fazendo com que o processo seja tipicamente usado em aplicações com um grande volume de soldas, em aplicações críticas que necessitem de características especiais do cordão ou uma 
grande reprodutibilidade. A eficiência do equipamento LBW é baixa, de 8 a 15\%, necessitando de grandes unidades de refrigeração para aplicações de alta potência ${ }^{56}$.

Embora o equipamento seja muito sofisticado, ele é projetado para ser operado sem a necessidade de soldadores altamente treinados ${ }^{56}$.

A FIG. 30 ilustra de forma esquemática um sistema de soldagem LBW.

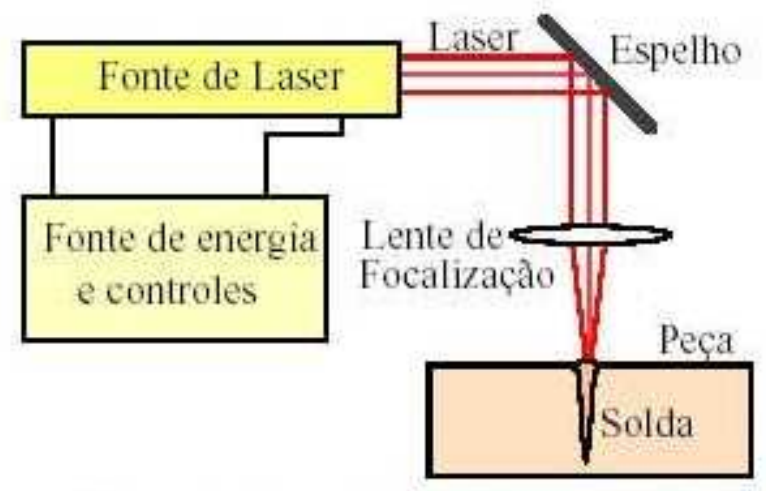

FIGURA 30 - Elementos de um sistema típico para soldagem a laser

Os processos de soldagem a laser e soldagem a plasma, apresentam as seguintes características:

- LASER

- O feixe de laser pode ser facilmente direcionado, o que facilita a automação do processo;

- Permite a soldagem em lugares de difícil acesso;

- Permite a transmissão do feixe a longas distâncias;

- Apresenta problemas de soldagem com metais que refletem o feixe;

- Baixa eficiência, de 8 a 15\%, necessitando de grandes unidades de refrigeração para aplicação de alta potência ${ }^{56,60}$. 
- PLASMA

- Estabilidade direcional e focal do arco, que não sofre mudanças de suas características quando ocorrem variações da distância da tocha à peça a ser soldada;

- O custo do equipamento para soldagem a plasma é muito menor que o de soldagem a laser;

- Aceita a técnica de soldagem do tipo buraco de fechadura, que permite a soldagem da maioria dos metais em certas faixas de espessura com juntas de topo, sem a necessidade de chanfrar as peças a serem soldadas;

- O processo de soldagem com plasma é limitado para espessuras acima de $25 \mathrm{~mm}$, sendo necessário novos desenvolvimentos para utilização com chapas de seções mais espessas;

- Requer do operador maior conhecimento do processo ${ }^{56,60}$. 


\section{MATERIAIS E MÉTODOS}

No desenvolvimento do trabalho objeto da dissertação, as atividades foram focalizadas para a viabilização técnica de um produto com emissão de radiação ionizante para utilização na área da saúde, requerendo desempenho compatível com o rigor da sua aplicação, estabelecidos pelas normas internacionais ISO 2919 - Radiation protection - Sealed Radioactive Sources General Requirements and Classification e ISO 9978 - Radiation protection Sealed Radioactive Sources - Leakage Test Methods. Além dos estudos, testes e ensaios requeridos para a utilização da técnica de soldagem plasma em uma das etapas de fabricação da fonte selada para aplicação em braquiterapia, buscou-se a otimização do processo com o propósito de elaborar procedimentos de fabricação para implantação de produção rotineira dentro das Boas Práticas de Fabricação (do inglês GMP - Good Manufacturing Practices).

\subsection{Material utilizado}

O material utilizado nos experimentos de soldagem das fontes seladas foi o titânio, comercialmente puro, grau 2 (titânio CP GR2), fabricado pela empresa Accellent Endoscopy; apresentava-se na forma de tubo com diâmetro externo variando de 0,790 a $0,808 \mathrm{~mm}$ e a espessura de parede variando de 0,043 a $0,058 \mathrm{~mm}$ em 1 metro de comprimento. $O$ material encontrava-se normalizado e pertencia ao lote de fabricação número $3861 \mathrm{M}$.

A composição química nominal fornecida pelo fabricante no certificado de análise e teste número 18828 é transcrito na TAB. 5

TABELA 5 - Composição química do titânio CP GR2 informada pelo fabricante

\begin{tabular}{|c|c|}
\hline Elemento químico & Composição (\% em peso) \\
\hline $\mathrm{Ti}$ & Balanço \\
\hline $\mathrm{C}$ & 0,0070 \\
\hline $\mathrm{Fe}$ & 0,0240 \\
\hline $\mathrm{H}$ & 0,0040 \\
\hline $\mathrm{N}$ & 0,0090 \\
\hline $\mathrm{O}$ & 0,1320 \\
\hline
\end{tabular}




\subsection{Corte e limpeza do material}

Os tubos de titânio foram cortados com o auxílio de uma máquina de corte marca Buehler LTD, modelo Isomet 11-1180 Low Speed Saw, utilizando-se um disco de óxido de alumínio, marca Struers, código 357CA. Após o corte os tubos foram lixados nas faces com lixa d'água grana 400 e desengraxados, por um período de 1 hora, com uma mistura de $8 \mathrm{ml}$ de água destilada e $2 \mathrm{ml}$ de detergente Extran MA 02 Neutro, da marca Merck, em um equipamento de limpeza por ultra-som, modelo USC1450 da marca UNIQUE. Após este procedimento, os tubos foram lavados em $10 \mathrm{ml}$ de água destilada e colocados para secagem.

\subsection{Equipamento de soldagem}

Foi utilizada nos experimentos de selagem dos tubos de titânio uma máquina de solda plasma marca Secheron Soudure S.A., modelo Plasmafix 50E, corrente máxima 50A, corrente de arco piloto máxima 5A (FIG. 31). As soldas foram realizadas em corrente contínua, com um ângulo de $90^{\circ}$ do arco plasma em relação à face do tubo.

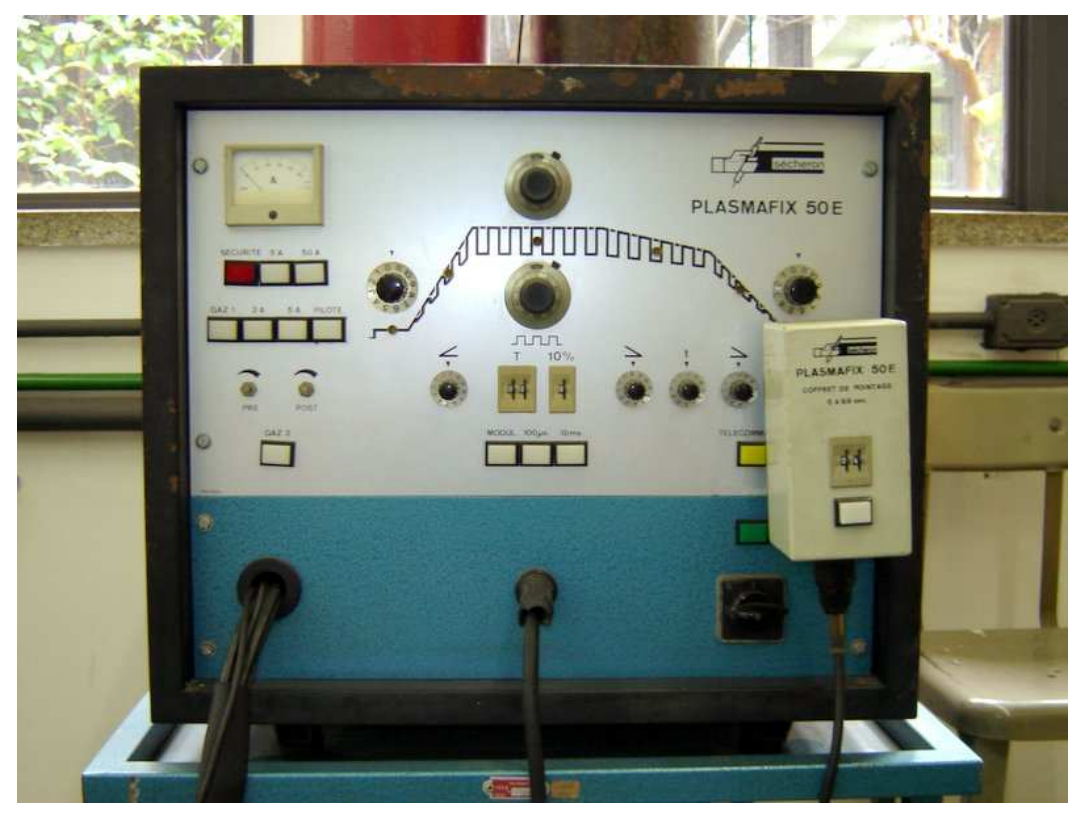

FIGURA 31 - Máquina de solda plasma Plasmafix 50E utilizada nos experimentos 


\subsection{Equipamento posicionador}

Foi utilizado para posicionar os tubos de titânio nos experimentos de selagem um acionador com sistema de movimentação $X Y$ da marca Syncro, composto de um quadro eixo de $16 \mathrm{~mm}$ com curso de $500 \mathrm{~mm} \times 500 \mathrm{~mm}$, 2 motores de passo de 2 fases e 1,8 grau com precisão de posicionamento de $25 \mu \mathrm{m}$ por passo, 2 controladores para motores de passo (FIG. 32) e 1 software de controle de posicionamento (FIG. 33).

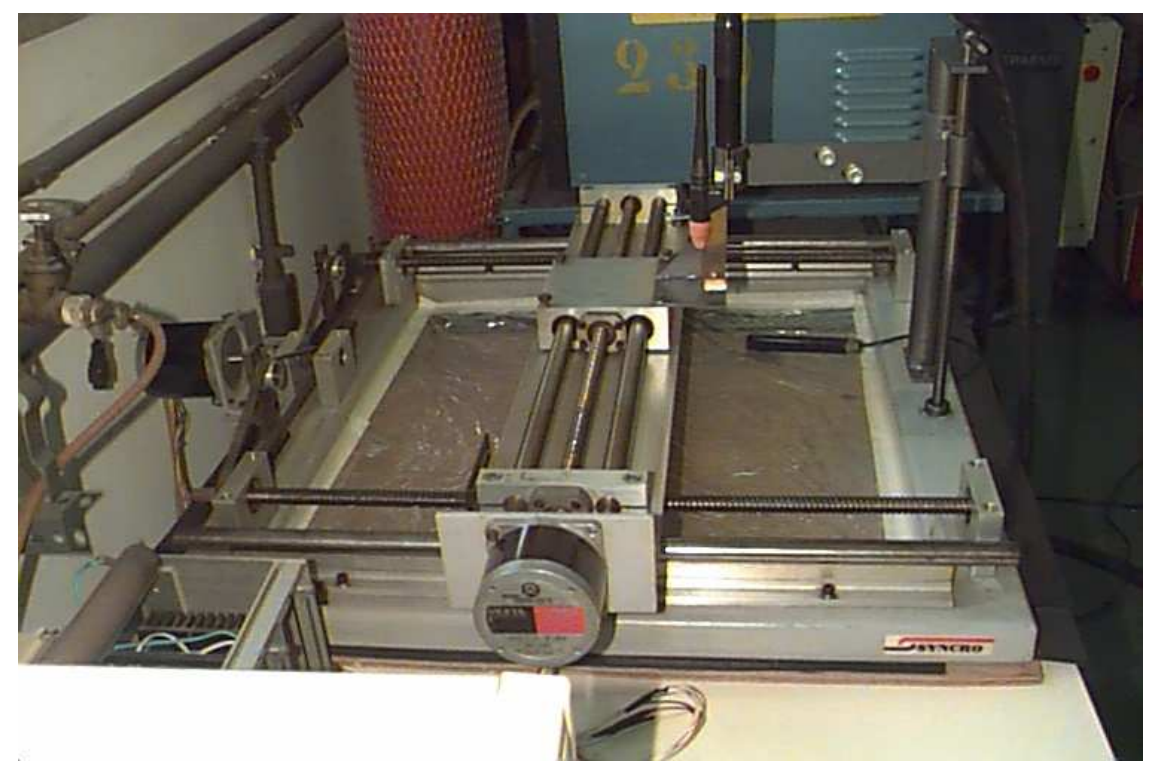

FIGURA 32 - Sistema posicionador de tubo de titânio

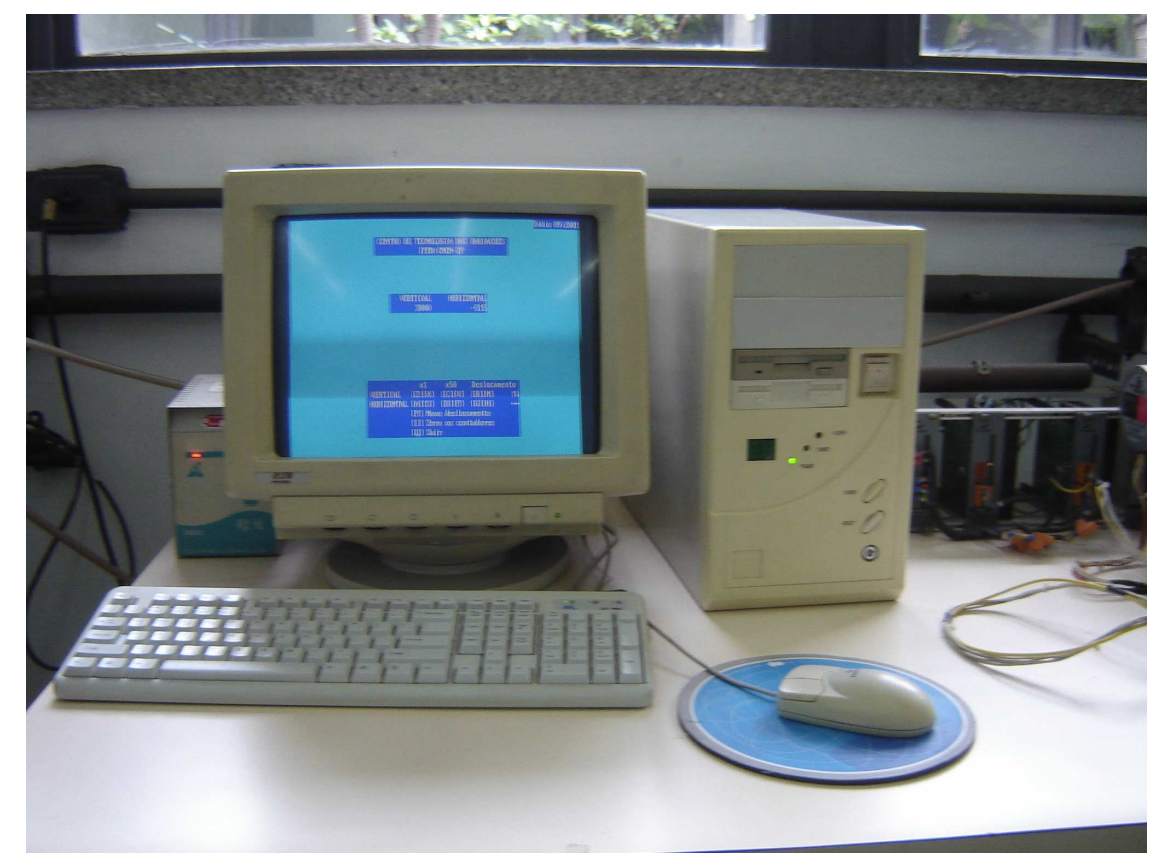

FIGURA 33 - Sistema de controle do posicionador de tubos de titânio 


\subsection{Suporte de tocha}

Foi desenvolvido um suporte de tocha plasma, com regulagem de altura, para ser fixado no acionador de movimentação XY (FIG. 34 e 35).

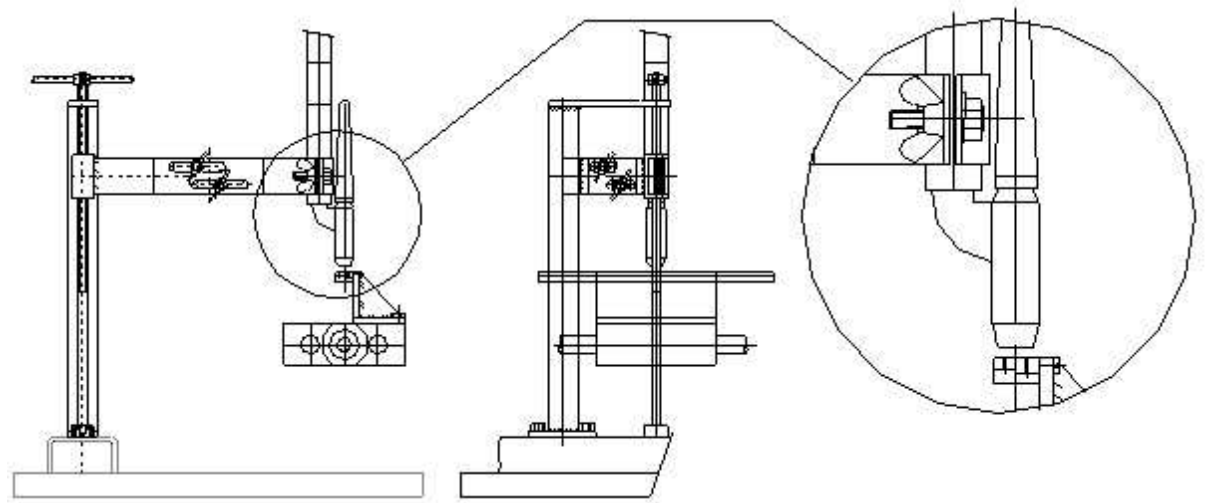

FIGURA 34 - Desenho esquemático do suporte da tocha

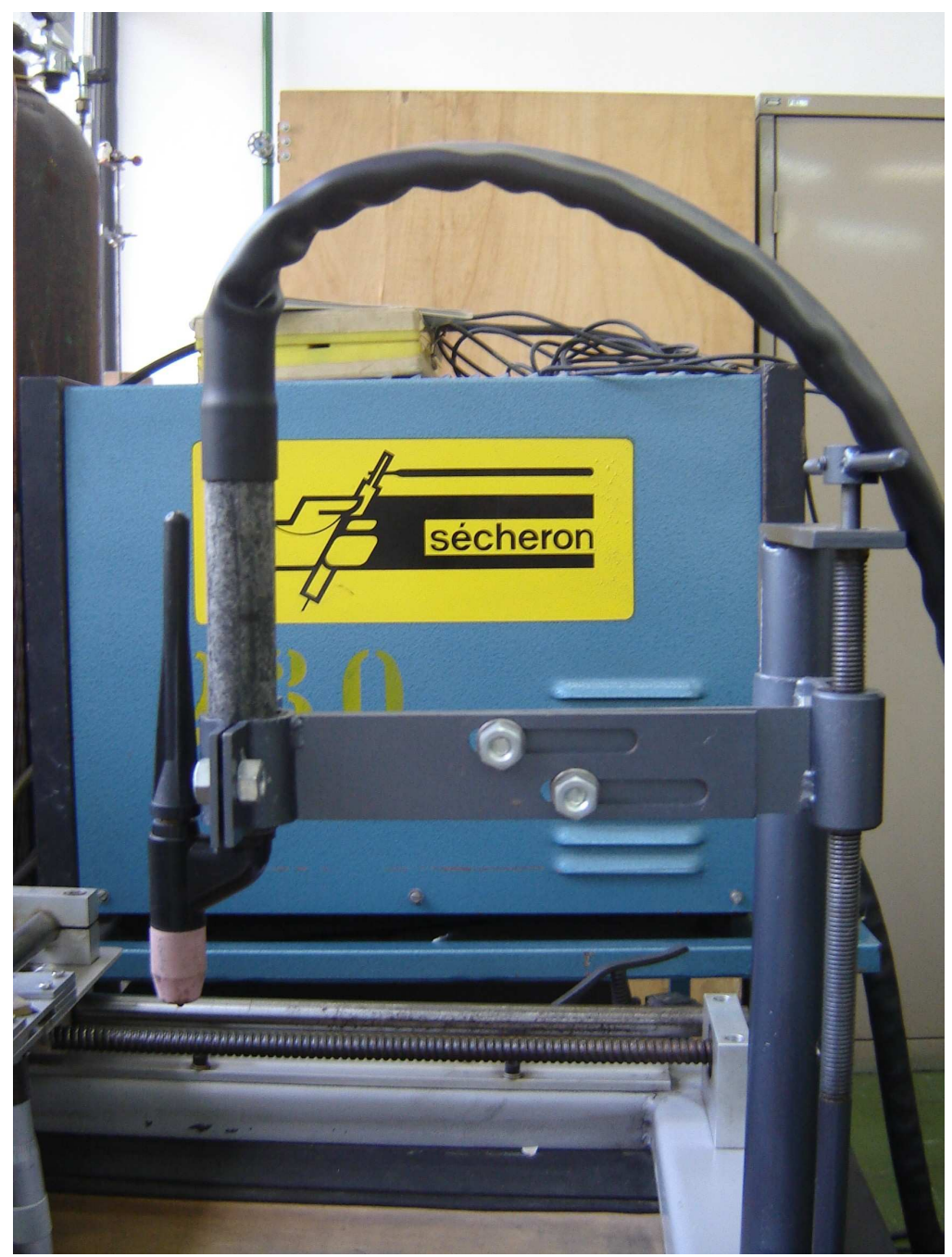

FIGURA 35 - Suporte da tocha 


\subsection{Dispositivo no 1}

Foi desenvolvido um dispositivo para fixação do tubo de titânio durante a selagem e montado ao sistema de movimentação $X Y$.

O dispositivo consistiu de uma barra de cobre medindo $250 \mathrm{~mm} \mathrm{x}$ $19 \mathrm{~mm} \times 5,5 \mathrm{~mm}$. Este dispositivo possui 42 furos com 0,9 mm de diâmetro e eqüidistantes a $10 \mathrm{~mm}$, sendo 21 furos com profundidade de $5,5 \mathrm{~mm}$ para selagem do primeiro lado do tubo e 21 furos com 4,5 $\mathrm{mm}$ de profundidade para a segunda selagem. A base do dispositivo para os tubos foi confeccionada em alumínio estrutural medindo $250 \mathrm{~mm} \times 19 \mathrm{~mm} \times 5,5 \mathrm{~mm}$. As FIG. 36 e 37 ilustram o dispositivo $n^{\circ}-1$.
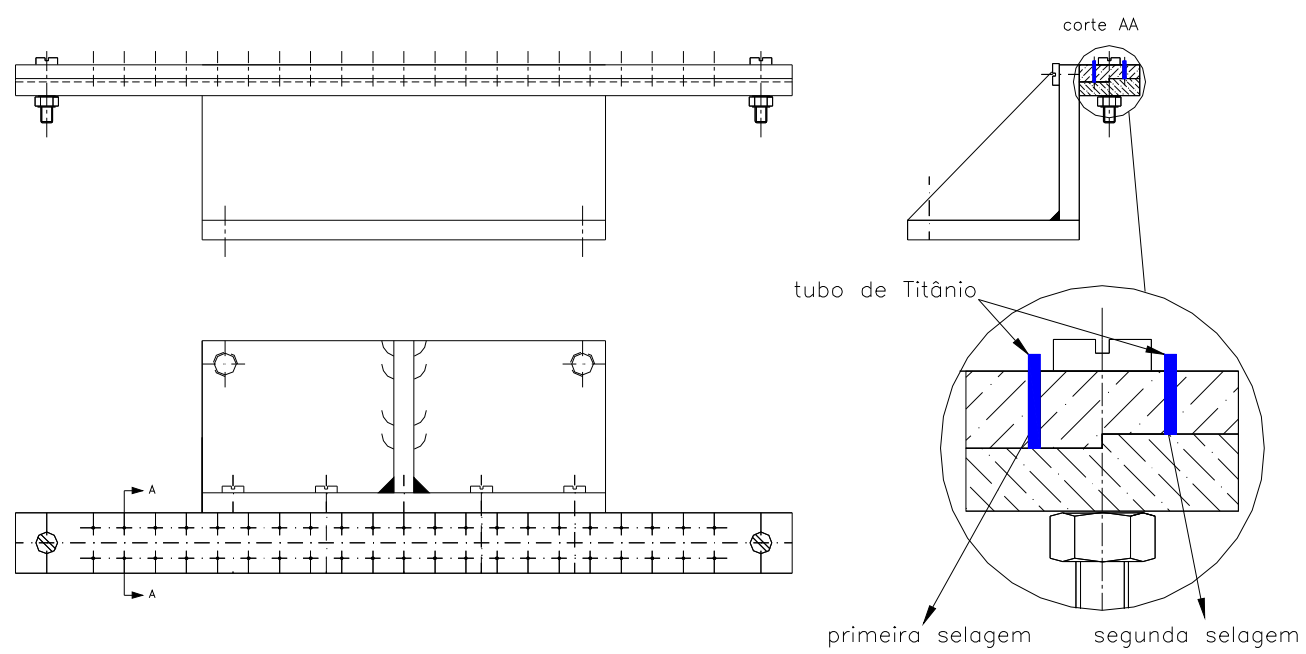

FIGURA 36 - Desenho esquemático do dispositivo nํำ

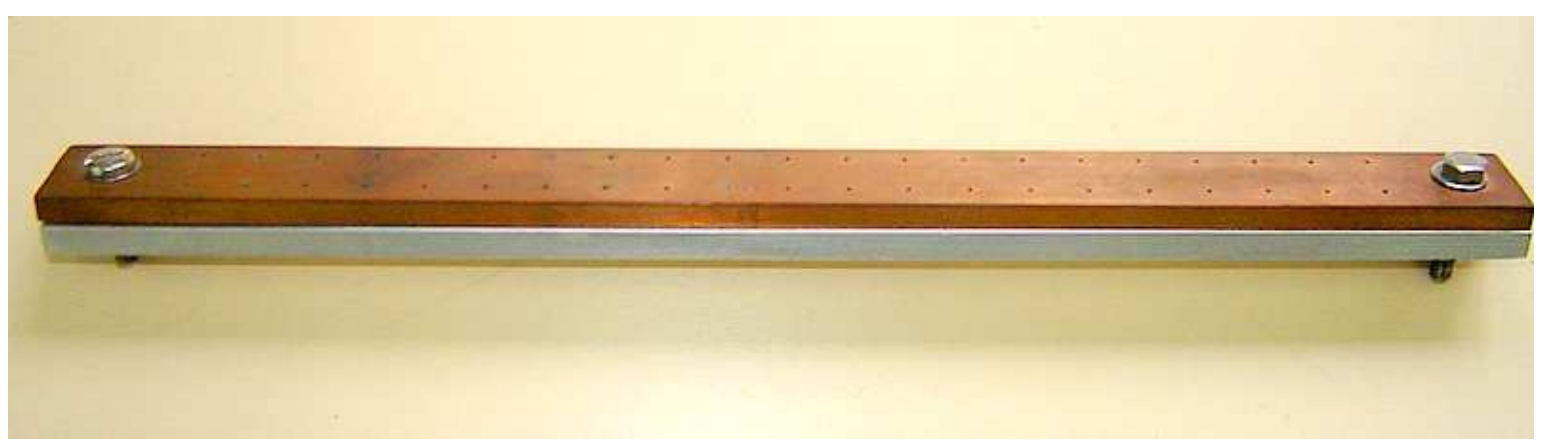

FIGURA 37 - Dispositivo de soldagem no 1 


\subsection{Dispositivo no 2}

Foi desenvolvido um segundo dispositivo para selagem do tubo de titânio e montado na posição do dispositivo nำ1.

O dispositivo consiste de uma placa de latão bipartida formando duas castanhas, medindo $18 \mathrm{~mm} \times 18 \mathrm{~mm} \times$ 9,5 mm e um micrômetro com precisão de $0,01 \mathrm{~mm}$.

Neste dispositivo o tubo de titânio é posicionado entre as duas placas de latão. O micrômetro é utilizado para ajustar o comprimento de sobrematerial necessário para a selagem. Foi utilizado o próprio tubo de titânio como sobrematerial para eliminar a necessidade de utilizar metal de adição (cap) na selagem da semente. As placas de latão são fixadas pelo regulador e pelo parafuso fixador.

As FIG. 38 e 39 ilustram o dispositivo $\mathrm{n}^{\circ} 2$.

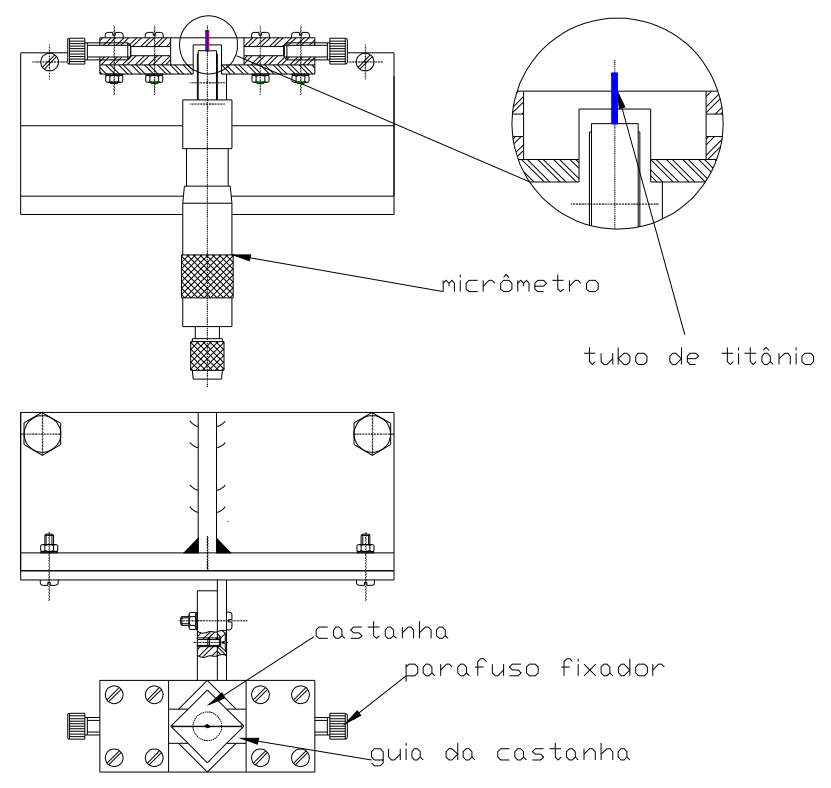

FIGURA 38 - Desenho esquemático do dispositivo nํㅡ 2 


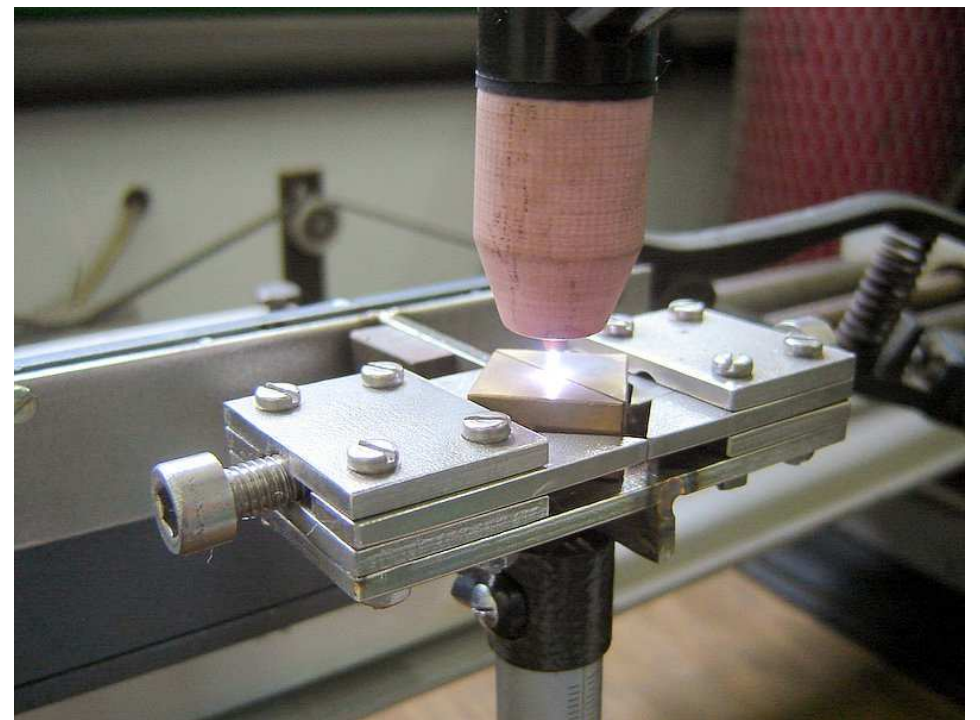

FIGURA 39 - Dispositivo de soldagem nำ 2

\subsection{Determinação dos parâmetros de soldagem}

Foram realizados experimentos de selagem nos tubos de titânio com os dois dispositivos descritos nos itens 4.6 e 4.7 deste capítulo para determinar os parâmetros de soldagem para a confecção das sementes de ${ }^{125}$ I.

Os parâmetros avaliados nestes experimentos foram os seguintes:

- Corrente de arco plasma;

- Corrente de arco piloto;

- Tempo de abertura de arco;

- Diâmetro do bocal de constrição;

- Standoff - Distância da face externa do bocal de constrição e a peça de trabalho ${ }^{59}$;

- Vazão do gás do arco plasma;

- Vazão do gás de proteção;

- Sobrematerial para selagem. 


\subsubsection{Experimentos com o dispositivo no 1}

Colocou-se um tubo de titânio em um dos furos do dispositivo $\mathrm{n}^{\circ} 1 \mathrm{e}$ com o sistema de movimentação $X Y$, posicionou-se o tubo sob o bocal de constrição da tocha plasma com o arco piloto desligado.

Ajustou-se o Standoff, a corrente de arco plasma, o tempo de abertura de arco, a vazão do gás de proteção e a vazão do gás do arco piloto.

Com o arco piloto ligado, acionou-se o dispositivo de soldagem automática da máquina de solda.

Com um lado selado, inverteu-se o tubo no dispositivo ํㅜ 1 , de modo que a outra face do tubo ficasse posicionada como no início do experimento.

Colocou-se uma semente de prata no interior do tubo e acionou-se novamente o dispositivo de soldagem automática.

Os parâmetros utilizados nos experimentos com o dispositivo nํㅜ 1 são mostrados na TAB. 6.

TABELA 6 - Parâmetros de soldagem utilizados no dispositivo no 1

\begin{tabular}{|l|c|}
\hline \multicolumn{1}{|c|}{ Parâmetros } & Variações \\
\hline Corrente de arco plasma & 1 a $4,5 \mathrm{~A}$ \\
\hline Corrente de arco piloto (constante) & $2 \mathrm{~A}$ \\
\hline Tempo de abertura de arco & 0,5 a $0,7 \mathrm{~s}$ \\
\hline Diâmetro do bocal de constrição & 0,8 a $1,2 \mathrm{~mm}$ \\
\hline Standoff & $5,1 \mathrm{~mm}$ \\
\hline Vazão do gás do arco plasma & 0,1 a $0,3 \mathrm{l} / \mathrm{min}$ \\
\hline Vazão do gás de proteção & 8 a $10 \mathrm{l} / \mathrm{min}$ \\
\hline Sobrematerial & 2,2 a $2,7 \mathrm{~mm}$ \\
\hline
\end{tabular}




\subsubsection{Experimentos com dispositivo nㅇ 2}

Colocou-se um tubo de titânio no centro da placa de latão bipartida. Com auxílio do micrômetro ajustou-se a altura de sobrematerial. O tubo foi fixado pelas placas através dos parafusos de fixação.

Com o arco piloto desligado, utilizando-se do sistema de movimentação $X Y$, centralizou-se o tubo com o eixo do bocal de constrição da tocha plasma.

Ajustou-se o Standoff, a corrente de arco plasma, o tempo de abertura de arco, a vazão do gás de proteção e a vazão do gás do arco piloto.

Com o arco piloto ligado, acionou-se o dispositivo de soldagem automática da máquina de solda.

Com um lado selado, inverteu-se o tubo no dispositivo $\mathrm{n}^{\circ} 2$ de modo que a outra face do tubo ficasse posicionada como no início do experimento.

Com auxílio do micrômetro ajustaram-se as diferentes alturas de sobrematerial.

Colocou-se uma semente de prata no interior do tubo e acionou-se novamente o dispositivo de soldagem automática.

Os parâmetros utilizados nos experimentos com o dispositivo nำ 2 são apresentados na TAB.7. 
TABELA 7 - Parâmetros de soldagem utilizados no dispositivo nํ 2

\begin{tabular}{|l|c|}
\hline \multicolumn{1}{|c|}{ Parâmetros } & Variações \\
\hline Corrente de arco plasma & 0,5 a $2 \mathrm{~A}$ \\
\hline Corrente de arco piloto (constante) & $2 \mathrm{~A}$ \\
\hline Tempo de abertura de arco & 0,2 a $0,6 \mathrm{~s}$ \\
\hline Diâmetro do bocal de constrição & 1 a $1,2 \mathrm{~mm}$ \\
\hline Standoff & $4,6 \mathrm{~mm}$ \\
\hline Vazão do gás do arco plasma & 0,1 a $0,3 \mathrm{l} / \mathrm{min}$ \\
\hline Vazão do gás de proteção & 8 a $10 \mathrm{l} / \mathrm{min}$ \\
\hline Sobrematerial da $1^{\mathrm{a}}$ solda & 1 a $2 \mathrm{~mm}$ \\
\hline Sobrematerial da $2^{\mathrm{a}}$ solda & 1 a $2 \mathrm{~mm}$ \\
\hline
\end{tabular}

\subsection{Classificação e identificação das sementes de ${ }^{125}$ I segundo a norma ISO 2919}

A classificação das fontes seladas de acordo com a norma ISO 2919 Radiation protection - Sealed Radioactive Sources - General Requirements and Classification é orientada para a aplicação final do produto, requerendo desempenho ou características que impeçam a liberação/vazamento de material radioativo. As fontes seladas devem ser submetidas a grupos de ensaios térmicos e mecânicos com diferentes níveis de severidade, dependendo da performance requerida para sua aplicação.

A TAB. 8, transcrita da norma ISO 2919, apresenta uma lista de aplicações das fontes seladas bem como a performance mínima requerida nos ensaios necessários para cada uma das aplicações. 
TABELA 8 - Classificação de fontes seladas de acordo com a performance requerida para a sua aplicação ${ }^{23}$

\begin{tabular}{|c|c|c|c|c|c|c|}
\hline \multirow{2}{*}{\multicolumn{2}{|c|}{ Aplicação das fontes seladas }} & \multicolumn{5}{|c|}{ Ensaios requeridos } \\
\hline & & \multirow{2}{*}{$\begin{array}{c}\begin{array}{c}\text { Tempera- } \\
\text { tura }\end{array} \\
4 \\
\end{array}$} & \multirow{2}{*}{$\begin{array}{c}\text { Pressão } \\
3 \\
\end{array}$} & \multirow{2}{*}{$\begin{array}{c}\text { Impacto } \\
5 \\
\end{array}$} & \multirow{2}{*}{$\begin{array}{c}\text { Vibração } \\
1 \\
\end{array}$} & \multirow{2}{*}{$\begin{array}{c}\text { Punção } \\
5\end{array}$} \\
\hline & Fonte selada & & & & & \\
\hline $\begin{array}{l}\text { Radiografia } \\
\text { industrial }\end{array}$ & $\begin{array}{l}\text { Fonte para ser } \\
\text { usada em } \\
\text { equipamento }\end{array}$ & 4 & 3 & 3 & 1 & 3 \\
\hline \multirow{4}{*}{ Médico } & Radiografia & 3 & 2 & 3 & 1 & 2 \\
\hline & Teleterapia Gama & 5 & 3 & 5 & 2 & 4 \\
\hline & Braquiterapia $^{1)}$ & 5 & 3 & 2 & 1 & 1 \\
\hline & $\begin{array}{l}\text { Aplicadores em } \\
\text { superfície }^{2)}\end{array}$ & 4 & 3 & 3 & 1 & 2 \\
\hline \multirow{2}{*}{$\begin{array}{l}\text { Medidores } \\
\text { Gama }\end{array}$} & Fonte desprotegida & 4 & 3 & 3 & 3 & 3 \\
\hline & $\begin{array}{l}\text { Fonte em } \\
\text { equipamento }\end{array}$ & 4 & 3 & 2 & 3 & 2 \\
\hline \multicolumn{2}{|c|}{$\begin{array}{c}\text { Medidor Beta e fontes para } \\
\text { medidores de baixa energia gama } \\
\text { ou análise por fluorescência de } \\
\text { Raio- } X^{2)}\end{array}$} & 3 & 3 & 2 & 2 & 2 \\
\hline \multicolumn{2}{|c|}{ Medidor de poço de petróleo } & 5 & 6 & 5 & 2 & 2 \\
\hline \multicolumn{2}{|c|}{$\begin{array}{l}\text { Medidor de densidade e umidade } \\
\text { portátil }\end{array}$} & 4 & 3 & 3 & 3 & 3 \\
\hline \multicolumn{2}{|c|}{$\begin{array}{c}\text { Aplicações gerais de fontes de } \\
\text { nêutron (excluindo inicializador de } \\
\text { reator }\end{array}$} & 4 & 3 & 3 & 2 & 3 \\
\hline \multicolumn{2}{|c|}{$\begin{array}{l}\text { Fontes de calibração atividade }>1 \\
\text { MBq }\end{array}$} & 2 & 2 & 2 & 1 & 2 \\
\hline \multirow{2}{*}{$\begin{array}{l}\text { Fontes de } \\
\text { Irradiação } \\
\text { gama }\end{array}$} & Categoria I $^{2)}$ & 4 & 3 & 3 & 2 & 3 \\
\hline & 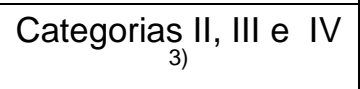 & 5 & 3 & 4 & 2 & 4 \\
\hline \multirow{3}{*}{$\begin{array}{l}\text { Geradores } \\
\text { de Íons }\end{array}$} & Cromatografia & 3 & 2 & 2 & 1 & 1 \\
\hline & Eliminadores estáticos & 2 & 2 & 2 & 2 & 2 \\
\hline & Detectores de fumaça $_{2)}$ & 3 & 2 & 2 & 2 & 2 \\
\hline \multicolumn{7}{|c|}{$\begin{array}{l}\text { 1) Fontes desta natureza podem estar sujeitas a severas deformações em uso. Fabricantes e usuários } \\
\text { podem formular ensaios adicionais. } \\
\text { 2) Excluindo fontes gasosas. } \\
\text { 3) Fontes em equipamentos ou um grupo de fontes podem ser testadas. }\end{array}$} \\
\hline
\end{tabular}

Obs: Os números grifados em amarelo correspondem ao grau de severidade dos ensaios para semente utilizada em braquiterapia.

O grau de severidade dos ensaios requeridos para cada aplicação de fonte selada são apresentados com detalhe na TAB. $9 .{ }^{23}$ 
TABELA 9 - Classificação de desempenho de fonte selada (5 dígitos) ${ }^{23}$

\begin{tabular}{|c|c|c|c|c|c|c|c|}
\hline \multirow{2}{*}{ Ensaio } & \multicolumn{7}{|c|}{ Classe } \\
\hline & 1 & 2 & 3 & 4 & 5 & 6 & $X$ \\
\hline $\begin{array}{l}\text { Tempe- } \\
\text { ratura }\end{array}$ & $\begin{array}{l}\text { Sem } \\
\text { Ensaio }\end{array}$ & $\begin{array}{l}-40^{\circ} \mathrm{C} \\
(20 \mathrm{~min})+ \\
80^{\circ} \mathrm{C}(1 \mathrm{~h})\end{array}$ & $\begin{array}{l}-40^{\circ} \mathrm{C} \\
(20 \mathrm{~min})+ \\
180^{\circ} \mathrm{C}(1 \mathrm{~h})\end{array}$ & $\begin{array}{l}-40^{\circ} \mathrm{C} \\
\left(20^{\circ} \mathrm{min}\right)+ \\
400^{\circ} \mathrm{C}(1 \mathrm{~h}) \\
\text { e choque } \\
\text { térmico a } \\
2^{\circ} \mathrm{C}\end{array}$ & \begin{tabular}{|l|}
$-40^{\circ} \mathrm{C}$ \\
$(20 \mathrm{~min})+$ \\
$60^{\circ} \mathrm{C}(1 \mathrm{~h})$ \\
e choque \\
térmico a \\
$2^{\circ} \mathrm{C}$
\end{tabular} & $\begin{array}{l}-40^{\circ} \mathrm{C} \\
\left(20^{\circ} \mathrm{min}\right)+ \\
800^{\circ} \mathrm{C}(1 \mathrm{~h}) \\
\text { e choque } \\
\text { térmico a } \\
2^{\circ} \mathrm{C}\end{array}$ & \begin{tabular}{|l|} 
Ensaio \\
Especial
\end{tabular} \\
\hline $\begin{array}{l}\text { Pressão } \\
\text { Externa }\end{array}$ & $\begin{array}{l}\text { Sem } \\
\text { Ensaio }\end{array}$ & $\begin{array}{l}25 \mathrm{kPa} \\
\text { absoluto } \\
\text { até atmos- } \\
\text { férico }\end{array}$ & $\begin{array}{l}25 \mathrm{kPa} \\
\text { absoluto } \\
\text { até } 2 \mathrm{MPa} \\
\text { absoluto }\end{array}$ & $\begin{array}{l}25 \mathrm{kPa} \\
\text { absoluto } \\
\text { até } 7 \mathrm{MPa} \\
\text { absoluto }\end{array}$ & $\begin{array}{l}25 \mathrm{kPa} \\
\text { absoluto } \\
\text { até } \\
70 \mathrm{MPa} \\
\text { absoluto }\end{array}$ & $\begin{array}{l}25 \mathrm{kPa} \\
\text { absoluto } \\
\text { até } \\
170 \mathrm{MPa} \\
\text { absoluto }\end{array}$ & \begin{tabular}{|l|} 
Ensaio \\
Especial
\end{tabular} \\
\hline Impacto & $\begin{array}{l}\text { Sem } \\
\text { Ensaio }\end{array}$ & $\begin{array}{l}50 \mathrm{~g} \text { de } \\
1 \mathrm{~m} \text { ou } \\
\text { energia } \\
\text { equivalen } \\
\text {-te }\end{array}$ & $\begin{array}{l}200 \mathrm{~g} \text { de } \\
1 \mathrm{~m} \text { ou } \\
\text { energia } \\
\text { equivalen- } \\
\text { te }\end{array}$ & $\begin{array}{l}2 \mathrm{Kg} \text { de } \\
1 \mathrm{~m} \text { ou } \\
\text { energia } \\
\text { equivalen- } \\
\text { te }\end{array}$ & \begin{tabular}{|l}
$5 \mathrm{Kg}$ de \\
$1 \mathrm{~m}$ ou \\
energia \\
equivalen- \\
te
\end{tabular} & $\begin{array}{l}20 \mathrm{Kg} \text { de } \\
1 \mathrm{~m} \text { ou } \\
\text { energia } \\
\text { equivalen- } \\
\text { te }\end{array}$ & \begin{tabular}{|l|} 
Ensaio \\
Especial
\end{tabular} \\
\hline Vibração & $\begin{array}{l}\text { Sem } \\
\text { Ensaio }\end{array}$ & $\begin{array}{l}3 \text { vezes de } \\
10 \text { min. } \\
25 \text { a } 500 \\
\mathrm{~Hz} \mathrm{a} \\
49 \mathrm{~m} / \mathrm{s}^{2} \\
\left(5 \mathrm{~g}_{\mathrm{n}}\right)^{*}\end{array}$ & $\begin{array}{l}3 \text { vezes de } \\
10 \mathrm{~min} \text {. } \\
25 \text { a } 50 \mathrm{~Hz} \\
\text { a } 49 \mathrm{~m} / \mathrm{s}^{2} \\
\left(5 \mathrm{~g}_{\mathrm{n}}\right)^{\star} \text { e } 50 \\
\text { a } 90 \mathrm{~Hz} \text { a } \\
0,635 \mathrm{~mm} \\
\text { de } \\
\text { amplitude } \\
\text { de pico a } \\
\text { pico e } 90 \\
\text { a } 500 \mathrm{~Hz} \text { a } \\
98 \mathrm{~m} / \mathrm{s}^{2} \\
\left(10 \mathrm{~g}_{\mathrm{n}}\right)^{*}\end{array}$ & $\begin{array}{l}3 \text { vezes de } \\
30 \mathrm{~min} . \\
25 \mathrm{a} 80 \mathrm{~Hz} \\
1,5 \mathrm{~mm} \text { de } \\
\text { amplitude } \\
\text { de pico a } \\
\text { pico e } 80 \\
\text { a } 2000 \mathrm{~Hz} \\
\text { a } 196 \mathrm{~m} / \mathrm{s}^{2} \\
\left(20 \mathrm{~g}_{\mathrm{n}}\right)^{*}\end{array}$ & $\begin{array}{l}\text { Não } \\
\text { Utilizado }\end{array}$ & $\begin{array}{l}\text { Não } \\
\text { Utilizado }\end{array}$ & \begin{tabular}{|l|} 
Ensaio \\
Especial
\end{tabular} \\
\hline Punção & $\begin{array}{l}\text { Sem } \\
\text { Ensaio }\end{array}$ & $\begin{array}{l}1 \mathrm{~g} \text { de } 1 \mathrm{~m} \\
\text { ou energia } \\
\text { equivalen- } \\
\text { te }\end{array}$ & $\begin{array}{l}10 \mathrm{~g} \text { de } \\
1 \mathrm{~m} \mathrm{ou} \\
\text { energia } \\
\text { equivalen- } \\
\text { te }\end{array}$ & $\begin{array}{l}50 \mathrm{~g} \mathrm{de} \\
1 \mathrm{~m} \text { ou } \\
\text { energia } \\
\text { equivalen- } \\
\text { te }\end{array}$ & $\begin{array}{l}300 \mathrm{~g} \mathrm{de} \\
1 \mathrm{~m} \mathrm{ou} \\
\text { energia } \\
\text { equivalen- } \\
\text { te }\end{array}$ & $\begin{array}{l}1 \mathrm{Kg} \text { de } \\
1 \mathrm{~m} \text { ou } \\
\text { energia } \\
\text { equivalen- } \\
\text { te }\end{array}$ & \begin{tabular}{|l|} 
Ensaio \\
Especial
\end{tabular} \\
\hline
\end{tabular}

Obs: Os itens grifados em amarelo correspondem aos critérios de classificação para semente utilizada em braquiterapia.

Uma vez estabelecida a classificação, as fontes seladas devem ter no seu projeto a identificação seguindo o critério de codificação estabelecido na ISO 2919. Para aplicação em braquiterapia a identificação é ISO/99/C53211, onde os dois números após o código ISO/ indicam o ano da aprovação da norma utilizada, seguindo de uma barra sólida (/), seguido de uma letra $C$ ou $E$ que 
indica se a atividade da fonte selada excede os limites especificados na TAB. 10. 23

TABELA 10 - Nível de atividade específica de acordo com o grupo de radionuclídeo ${ }^{23}$

\begin{tabular}{|c|c|c|}
\hline \multirow{2}{*}{$\begin{array}{l}\text { Grupo de } \\
\text { Radionuclídeo } \\
\text { (anexo A) }\end{array}$} & \multicolumn{2}{|c|}{ Atividade Específica TBq (Ci) } \\
\hline & Lixiviável ${ }^{1)}$ & Não Lixiviável ${ }^{2)}$ \\
\hline$A$ & 0,01 (aproximadamente 0,3 ) & 0,1 (aproximadamente 3) \\
\hline B1 & 1 (aproximadamente 30 ) & 10 (aproximadamente 300) \\
\hline $\mathrm{B} 2$ & 10 (aproximadamente 300) & 100 (aproximadamente 3000) \\
\hline C & 20 (aproximadamente 500) & 200 (aproximadamente 5000) \\
\hline \multicolumn{3}{|c|}{$\begin{array}{l}\text { Lixiviável: Maior que } 0,01 \% \text { da atividade total em } 100 \mathrm{ml} \text { de } \mathrm{H}_{2} \mathrm{O} \text { a } 50^{\circ} \mathrm{C} \text { por } 4 \mathrm{~h} \text { conforme } \\
\text { o item } 5.1 .1 \text { da ISO } 9978: 1982 \text {. } \\
\text { Não Lixiviável: Menor que } 0,01 \% \text { da atividade total em } 100 \mathrm{ml} \text { de } \mathrm{H} 2 \mathrm{O} \text { a } 50{ }^{\circ} \mathrm{C} \text { por } 4 \mathrm{~h} \\
\text { conforme o item } 5.1 .1 \text { da ISO } 9978: 1982\end{array}$} \\
\hline
\end{tabular}

Obs: No Anexo A são apresentados grupos de radionuclídeos de acordo com as suas radiotoxicidades.

Os cinco dígitos a seguir estabelecem em ordem crescente o grau de severidade (TAB. 9) que as fontes devem suportar para os ensaios de temperatura, pressão externa, impacto, vibração e punção conforme indicação feita de acordo com a aplicação mostrada na TAB. 9.

De acordo com a identificação acima, as fontes de braquiterapia deverão ser aprovadas nos testes:

- Temperatura - Grau de severidade 5;

- Pressão externa - Grau de severidade 3;

- Impacto - Grau de severidade 2;

- Vibração - Não é necessário realização do teste;

- Puncionamento - Não é necessário realização do teste.

A aprovação dos ensaios está condicionada a capacidade da fonte selada manter a sua estanqueidade após a sua realização. 


\subsection{Ensaios para validação das fontes seladas}

Para validação das sementes de braquiterapia ou fontes seladas seguindo a classificação estabelecida na norma ISO 2919 - Radiation protection Sealed Radioactive Sources - General Requirements and Classification foram realizados os ensaios apresentados a seguir e após a realização dos mesmos as fontes seladas foram examinadas visualmente quanto à manutenção da sua integridade e à sua capacidade de manter a estanqueidade sem a perda do material radioativo, de acordo com teste apropriado estabelecido na norma ISO 9978 - Radiation protection - Sealed Radioactive Sources - Leakage Test Methods, também descrito na seqüência com detalhes do procedimento adotado.

\subsubsection{Ensaios de temperatura}

\subsubsection{Ensaio a alta temperatura}

Foram colocadas duas sementes contendo material radioativo em um vasilhame refratário cerâmico e posto em uma mufla a $600{ }^{\circ} \mathrm{C}$ por uma hora na pressão atmosférica.

Após serem retiradas da mufla, as sementes foram colocadas em um recipiente com água a $20^{\circ} \mathrm{C}$ para um choque térmico.

\subsubsection{Ensaio a baixa temperatura}

Duas sementes contendo material radioativo foram colocadas em um vasilhame cerâmico com dióxido de carbono em cubos (gelo seco) a -79 $\mathrm{C}$ por vinte minutos na pressão atmosférica.

Após serem retiradas do dióxido de carbono, as sementes foram colocadas em um recipiente com água a $20{ }^{\complement} \mathrm{C}$ para um choque térmico.

\subsubsection{Ensaio de pressão externa}

Seguindo recomendação da norma ISO 2919, diferentes câmaras de testes foram utilizadas para o ensaio de pressão e de vácuo. 


\subsubsection{Ensaio de pressão}

Para a realização do ensaio de pressão, foi montado um dispositivo conforme orientação da norma ISO 2919, que consiste de uma câmara (vaso) de pressão em aço inoxidável com diâmetro de $60 \mathrm{~mm}$ x $240 \mathrm{~mm}$ de comprimento; uma válvula para alívio de pressão tipo gaveta, marca Deca, modelo 1S02B; um manômetro; um tubo flexível para alimentação de gás; um regulador de pressão de 2 estágios, marca Record e um cilindro de gás argônio industrial.

No dispositivo de pressão foi utilizado um manômetro classe $B$ da marca Pressotemp-Socios, com escala de 0 a $3,93 \mathrm{Mpa} \quad\left(\approx 0\right.$ a $\left.40 \mathrm{Kgf} / \mathrm{cm}^{2}\right)$. $\mathrm{O}$ manômetro foi calibrado no Laboratório de Calibração - LAC do Centro de Engenharia Nuclear - CEN do Instituto de Pesquisas Energéticas e Nucleares. A calibração do manômetro recebeu certificado de calibração no $183 / 05$ com validade até $21 / 10 / 06$, cujos padrões apresentam rastreabilidade junto a Rede Brasileira de Calibração - RBC.

A primeira semente foi posicionada no alojamento para fonte no interior da câmara de ensaio e submetida a uma pressão de $2 \mathrm{MPa}\left(\approx 21 \mathrm{Kgf} / \mathrm{cm}^{2}\right)$ em dois ciclos de 5 minutos. No final de cada ciclo a pressão retornou para o valor da pressão atmosférica. Repetiu-se o mesmo procedimento para a segunda semente. A FIG. 40 ilustra o dispositivo utilizado neste ensaio.

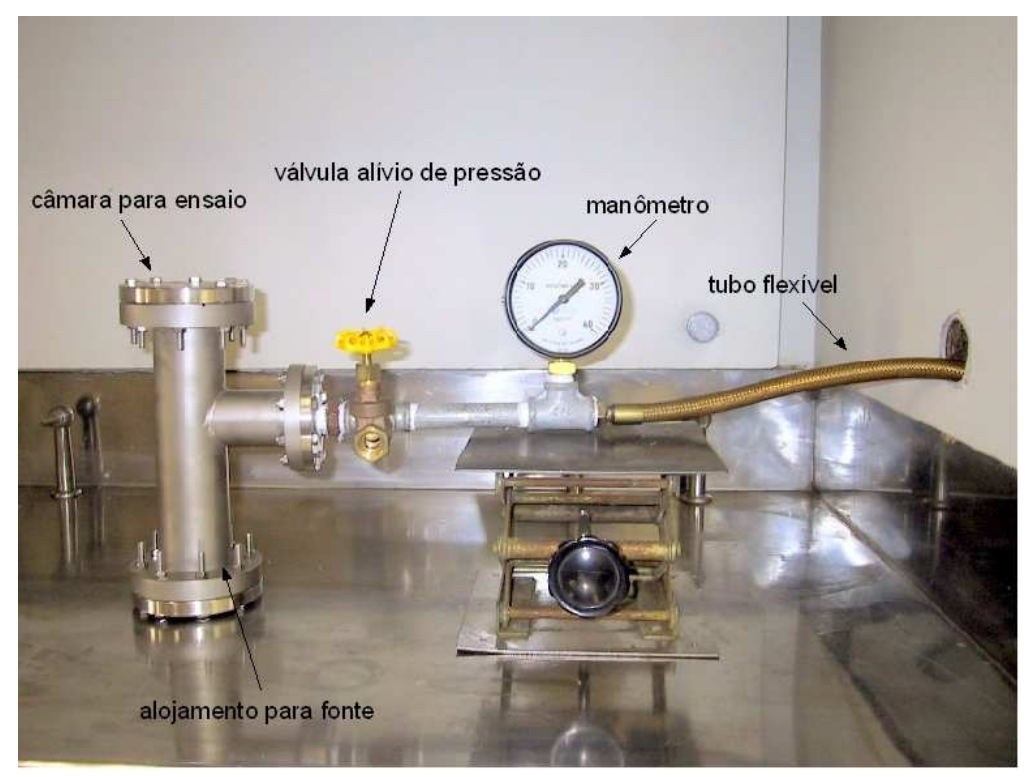

FIGURA 40 - Dispositivo utilizado para ensaio com pressão 


\subsubsection{Ensaio a vácuo}

Para a realização do ensaio a vácuo, foi montado um dispositivo conforme orientação da norma ISO 2919, que consiste em uma câmara de pressão; uma válvula para admissão de gás, tipo agulha, marca Edwards; uma válvula de bloqueio, tipo membrana, modelo Speedvalve, marca Edwards; um manovacuômetro; um tubo flexível metálico e uma bomba de vácuo, modelo E2M2, marca Edwards.

A câmara de pressão foi montada utilizando conexões apropriadas para vácuo em alumínio e aço inoxidável.

No dispositivo para ensaio a vácuo, foi utilizado um manovacuômetro classe $\mathrm{C}$ da marca Pressotemp-Socios, com escala manométrica de 0 a $207 \mathrm{KPa}$ $\left(\approx 30 \mathrm{lbf} / \mathrm{pol}^{2}\right)$ e com escala em vácuo de 0 a $102 \mathrm{KPa}(\approx 30 \mathrm{pol} \mathrm{Hg})$. O manovacuômetro foi calibrado no Laboratório de Calibração - LAC do Centro de Engenharia Nuclear - CEN do Instituto de Pesquisas Energéticas e Nucleares. A calibração do manovacuômetro recebeu certificado de calibração nำ182/05 com validade até $21 / 10 / 06$, cujos padrões apresentam rastreabilidade junto a Rede Brasileira de Calibração - RBC.

A primeira semente foi posicionada no alojamento para fonte no interior da câmara de ensaio e submetida a uma pressão negativa de $25 \mathrm{kPa}$ $(\approx 7,4 \mathrm{pol} \mathrm{Hg})$ em dois ciclos de 5 minutos. No final de cada ciclo a pressão negativa retornou para o valor da pressão atmosférica.

Repetiu-se o mesmo procedimento para a segunda semente.

A FIG. 41 ilustra a câmara de vácuo utilizada neste ensaio. 


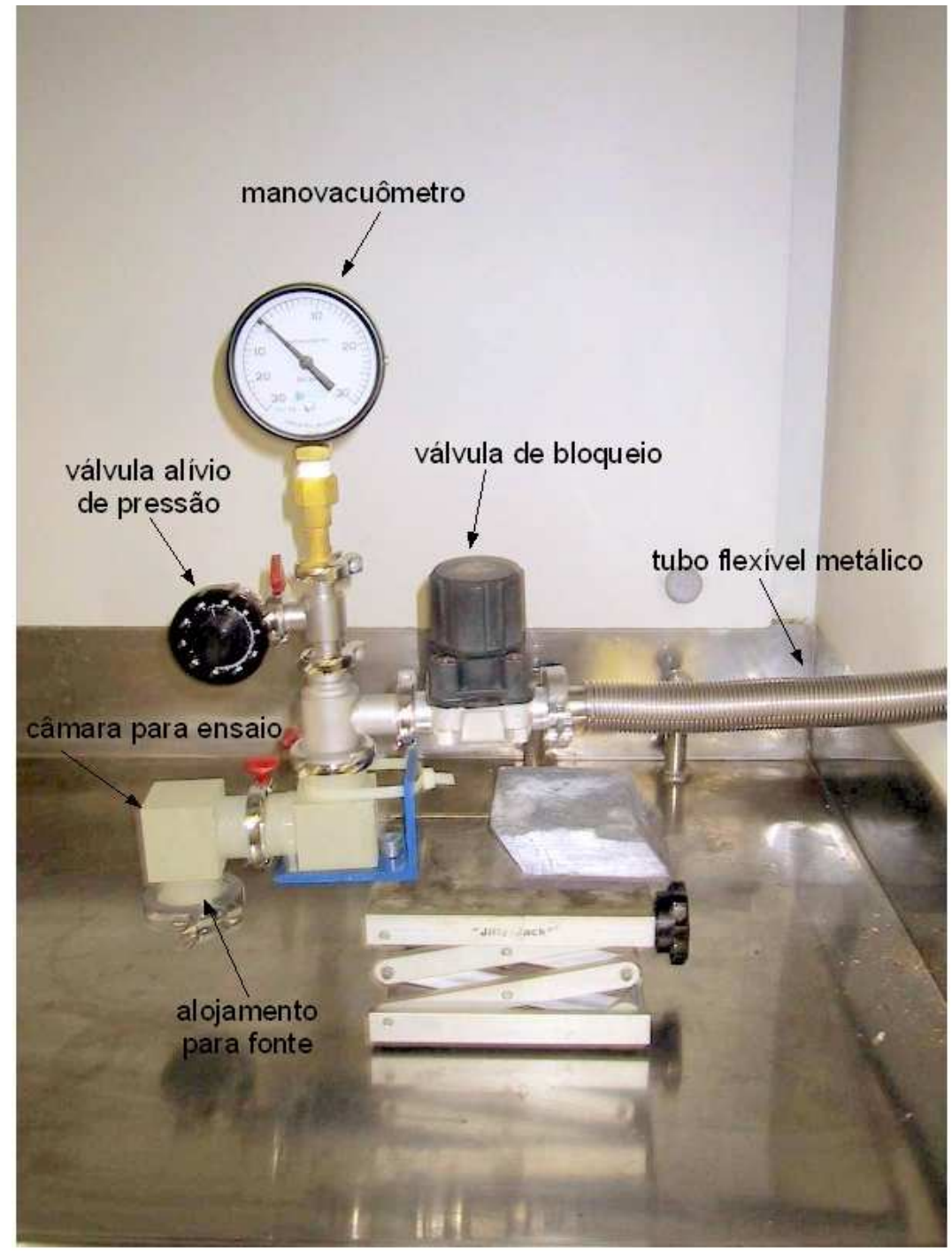

FIGURA 41 - Dispositivo utilizado para ensaio a vácuo

\subsubsection{Ensaio de impacto}

Para este ensaio, foi montado um dispositivo conforme a orientação da norma ISO 2919, que consiste de um cilindro de aço carbono com diâmetro de $25 \mathrm{~mm}$ e uma massa calibrada denominada martelo, um tubo direcionador e uma base de aço carbono medindo 280 × 220 × 90 mm denominada bigorna.

A massa do martelo, de $50,445 \mathrm{~g}$, foi medida em uma balança calibrada da marca Mettler Toledo, modelo AB304S.

O dispositivo é dotado de uma trava que permite o posicionamento do martelo na altura desejada para o ensaio e a liberação para queda livre até a bigorna. 
O martelo foi posicionado a uma altura de 1 metro, medido entre a superfície superior da semente sobre a bigorna e a face inferior de impacto do martelo.

As sementes, uma de cada vez, foram posicionadas sobre a bigorna na posição horizontal, de modo que sua área ficasse mais vulnerável ao impacto do martelo.

A FIG. 42 ilustra o dispositivo de impacto e o martelo utilizado neste ensaio.
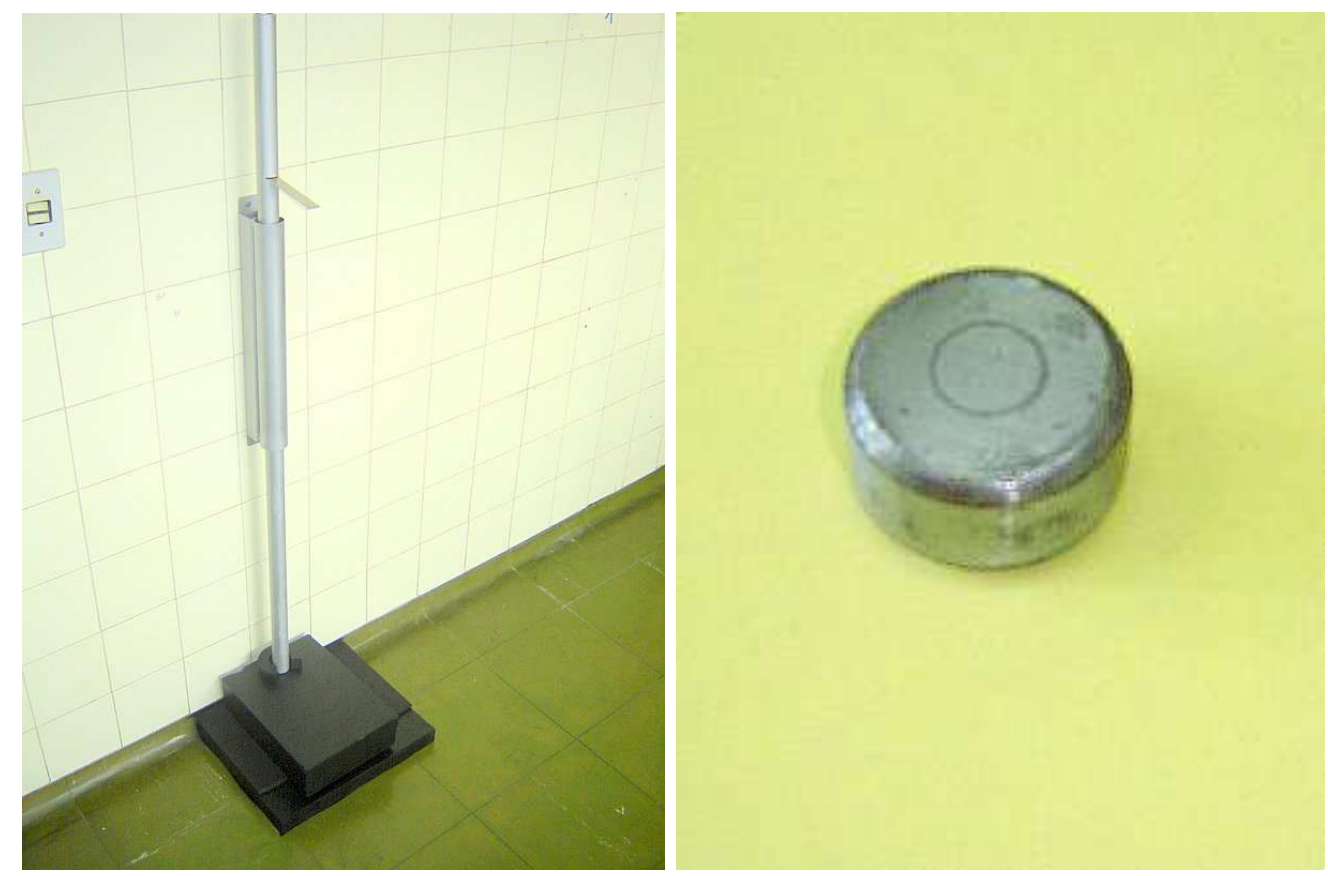

FIGURA 42 - Dispositivo e martelo utilizado no ensaio de impacto

\subsection{Ensaios de estanqueidade}

Para a realização dos ensaios de estanqueidade das sementes conforme a norma ISO 9978 - Radiation protection - Sealed Radioactive Sources - Leakage Test Methods ${ }^{24}$, foram seladas 48 sementes de prata com ${ }^{131} \mathrm{I}$. Foi utilizado o ${ }^{131} \mathrm{I}$, por ser produzido no IPEN e ter o mesmo comportamento químico do ${ }^{125}$ I. O radioisótopo ${ }^{131} \mathrm{I}$ possui uma meia vida de 8 dias e a energia de seus principais raios gama são: $80,2 \mathrm{KeV}(2,62 \%), 284,3 \mathrm{KeV}(6,06 \%), 364,5 \mathrm{KeV}$ $(81,2 \%)$ e $636,4 \mathrm{KeV}(7,27 \%)^{16}$. 
Foi utilizado um contador de cintilação líquida, marca Packard/Camberra, modelo Tri-Carb 1600 TR para determinar o padrão de ${ }^{131} \mathrm{I}$ e para os ensaios de estanqueidade das sementes.

O padrão tem a finalidade de determinar a região do espectro onde se situa o pico do ${ }^{131}$ I e quantificar, em contagem por minuto (cpm), a atividade máxima permitida contida no líquido onde foi lavada a semente após a selagem. Conforme a norma ISO $9978{ }^{24}$ o valor máximo de atividade permitida na amostra líquida após a lavagem é de $185 \mathrm{~Bq}(\approx 5 \mathrm{nCi})$.

Foi disponibilizada uma amostra de ${ }^{131} \mathrm{I}$, produzido no Reator IEA-R1, na forma química de iodeto de sódio, com atividade de 10,36 $\mathrm{MBq} \quad(0,28 \mathrm{mCi})$ em um volume de $1 \mathrm{ml}$.

Esta amostra foi diluída em $200 \mathrm{ml}$ de água purificada por um sistema de troca iônica da marca Milli-Q, modelo Academic, resultando no padrão P1 com uma atividade específica de $51,8 \mathrm{KBq} / \mathrm{ml} \quad(1,4 \mu \mathrm{Ci} / \mathrm{ml})$.

Foi retirada uma amostra de $1 \mathrm{ml}$ do padrão P1 e adicionado $99 \mathrm{ml}$ de água do Milli-Q, obtendo-se o padrão P2 com uma atividade específica de $518 \mathrm{~Bq} / \mathrm{ml}(14 \mathrm{nCi} / \mathrm{ml})$.

Foi retirada do padrão P2 uma amostra de $350 \mu$ l e obteve-se o padrão P3 com um valor médio de $(181,8 \pm 4,8) \mathrm{Bq}$ ou $(4,91 \pm 0,13 \mathrm{nCi})$, medido em um calibrador de dose tipo iodeto de sódio da marca Capintec, modelo CRC 15W.

Este padrão P3 foi utilizado para a determinação do valor de referência em contagens por minuto (cpm) no equipamento de cintilação líquida.

Como o valor da atividade a ser medida é de pequeno valor (menor que $185 \mathrm{~Bq}(\approx 5 \mathrm{nCi})$ ), foram experimentados dois tipos de recipientes, um em vidro de boro-silicato (Pyrex) e outro de polietileno, para contagem das amostras do padrão P3, BG (Back Ground) da água do Milli-Q e do titânio.

Como o valor obtido em cpm é relativo ao padrão P3 $(181,8 \pm 4,8) \mathrm{Bq}$, foi calculado proporcionalmente o valor em cpm para $185 \mathrm{~Bq}(\approx 5 \mathrm{nCi})$. 
O ensaio estanqueidade foi escolhido conforme a orientação disponibilizada no Guia da norma ISO 9978 e que permitia escolha dos testes a serem realizados de acordo com controle e tipo de fonte selada.

Conforme a TAB. 11, as fontes para braquiterapia são classificadas como sendo do tipo A3 e os ensaios preferenciais são os de imersão (5.1) e hélio (6.1) ${ }^{24}$. Optou-se pelo ensaio de imersão em temperatura ambiente (5.1) com auxílio de um ultra-som, para verificação da estanqueidade das sementes.

TABELA 11 - Seleção dos métodos de testes de vazamento relacionados com a tecnologia de fabricação ${ }^{24}$

\begin{tabular}{|c|c|c|c|c|c|}
\hline \multirow{2}{*}{\multicolumn{2}{|c|}{ Tipo de fonte }} & \multicolumn{2}{|c|}{$\begin{array}{c}\text { Testes para produção } \\
\text { de fontes }\end{array}$} & \multicolumn{2}{|c|}{$\begin{array}{c}\text { Testes para } \\
\text { classificação de fontes }\end{array}$} \\
\hline & & 1’a opção & $2^{\text {a }}$ opção & $1^{a}$ opção & $2^{a}$ opção \\
\hline$A$ & $\begin{array}{c}\text { Fontes seladas contendo } \\
\text { material radioativo }\end{array}$ & \multirow{3}{*}{$\begin{array}{l}\text { Imersão } \\
\quad(5.1)\end{array}$} & \multirow{3}{*}{$\begin{array}{c}\text { Vazamento } \\
(5.3)\end{array}$} & \multirow{3}{*}{$\begin{array}{c}\text { Imersão } \\
(5.1)\end{array}$} & \multirow{3}{*}{$\begin{array}{c}\text { Vazamento } \\
(5.3)\end{array}$} \\
\hline A1 & $\begin{array}{l}\text { Janela única e fina, por } \\
\text { exemplo, detectores de } \\
\text { fumaça }\end{array}$ & & & & \\
\hline A2 & $\begin{array}{c}\text { Fontes de referência de baixa } \\
\text { atividade, por exemplo, } \\
\text { encapsuladas em plástico }\end{array}$ & & & & \\
\hline A3 & $\begin{array}{c}\text { Fontes encapsuladas uma ou } \\
\text { duas vezes (excluindo Trítio } \\
\text { e Radio) para medição, } \\
\text { radiografia e braquiterapia }\end{array}$ & $\begin{array}{l}\text { Imersão } \\
\quad(5.1) \\
\text { Hélio (6.1) }\end{array}$ & Bolhas (6.2) & $\begin{array}{l}\text { Imersão } \\
\qquad(5.1) \\
\text { Hélio (6.1) } \\
\end{array}$ & Bolhas (6.2) \\
\hline A4 & $\begin{array}{c}\text { Fontes encapsuladas uma ou } \\
\text { duas vezes de Rádio e outras } \\
\text { fontes gasosas }\end{array}$ & $\begin{array}{c}\text { Emanação } \\
\text { gasosa (5.2) }\end{array}$ & $\begin{array}{l}\text { Imersão } \\
\quad(5.1)\end{array}$ & $\begin{array}{l}\text { Emanação } \\
\text { gasosa (5.2) }\end{array}$ & Imersão (5.1) \\
\hline A5 & $\begin{array}{c}\text { Fontes encapsuladas duas } \\
\text { vezes para teleterapia e } \\
\text { fontes de alta atividade de } \\
\text { irradiação }\end{array}$ & Hélio (6.1) & $\begin{array}{c}\text { Vazamento } \\
(5.3 .2)\end{array}$ & $\begin{array}{l}\text { Imersão } \\
\quad(5.1) \\
\text { Hélio (6.1) }\end{array}$ & Bolhas (6.2) \\
\hline \multirow[t]{2}{*}{$B$} & Fontes simuladas seladas & & & \multirow{2}{*}{\begin{tabular}{|c|} 
Imersão \\
(5.1) \\
Hélio (6.1)
\end{tabular}} & \multirow{2}{*}{ Bolhas (6.2) } \\
\hline & Dos tipos A3, A4 e A5 & & & & \\
\hline C & $\begin{array}{l}\text { Fontes seladas do tipo } \\
\text { Dummy }\end{array}$ & & & Hélio (6.1) & Bolhas (6.2) \\
\hline
\end{tabular}

Obs.: os números entre parênteses referenciam os respectivos ensaios da norma ISO 9978.

Quarenta e oito sementes soldadas foram utilizadas nos ensaios de estanqueidade de imersão seguindo procedimento da norma ISO 9978. Cada uma das sementes, separadamente, foram imersas em um frasco contendo uma 
mistura de $8 \mathrm{ml}$ de água destilada e $2 \mathrm{ml}$ de detergente Extran. Os frascos foram colocados em um equipamento de limpeza por ultra-som por um período de 1 hora e deixadas por mais 24 horas à temperatura ambiente. Após este tempo as sementes foram removidas e ao líquido remanescente acrescentou-se $10 \mathrm{ml}$ de solução cintiladora (nome comercial Insta-Gel) e mediu-se a atividade radioativa da solução em um contador de cintilação líquida.

Repetiu-se o procedimento acima, com exceção da mistura de água destilada e detergente, que foi substituída por $10 \mathrm{ml}$ de água destilada.

\subsection{Ensaio metalográfico}

O ensaio metalográfico, embora não solicitado na norma ISO 2919, foi realizado com o propósito de verificar o metal da soldagem sob ponto de vista de sua estrutura, procurando relacioná-lo ao processo de fabricação, de modo a poder esclarecer ou prever seu comportamento para aplicação final. O ensaio foi realizado com auxílio de um microscópio (ensaio micrográfico ou micrografia). Esses ensaios foram feitos em seções do material, polidas e atacadas com reativos adequados.

Foram analisados o aspecto de conjunto da homogeneidade do material da peça, a distribuição, a natureza, a quantidade de certas impurezas e o processo de fabricação, com a finalidade de se garantir que após a selagem não tenham ocorrido trincas ou porosidades na região da solda. Os ensaios foram realizados em sementes com fio de prata sem a deposição do material radioativo (dummy).

Na preparação das amostras foi utilizado um kit de embutimento a frio com resina acrílica da marca Metalotest. Este kit de embutimento possibilita a montagem de amostras para ensaios metalográficos, pois, além de facilitar o manuseio de pequenas peças, evita que as amostras com arestas rasguem a lixa ou o pano de polimento, o qual influencia no acabamento superficial da amostra. 
Foi posicionada a semente a ser embutida no centro de um molde, deixando um espaço, de pelo menos $5 \mathrm{~mm}$ entre a semente e a parede do molde, para que se pudesse encher este espaço com a resina.

Em um becker foram colocadas 2 medidas de resina acrílica em pó e misturada com uma medida de catalisador.

Cuidadosamente foi derramada a resina acrílica no molde de embutimento até enchê-lo.

Aguardou-se um tempo superior a 25 minutos em temperatura ambiente para que ocorresse a polimerização da resina. Após este tempo a peça embutida na resina acrílica foi extraída do molde.

Foram utilizadas lixas grana 320, 600 e 800 até chegar aproximadamente no meio das amostras em uma lixadeira e politriz modelo PLF, marca Fortel, 250 rpm.

O polimento mecânico foi realizado utilizando-se feltro impregnado com pasta de diamante granulação de $6 \mu \mathrm{m}$. O lubrificante utilizado foi uma mistura de glicerina com álcool na proporção de $10 \%$ de glicerina e $90 \%$ de álcool. 0 polimento mecânico foi realizado durante aproximadamente 15 minutos em uma politriz modelo DP-10, marca Panambra, 300 rpm.

$O$ ataque foi realizado agitando-se a superfície polida mergulhada no reativo posto numa pequena cuba. O tempo de duração do ataque foi de aproximadamente 10 segundos. Após o ataque lavou-se imediatamente a superfície atacada com água e sabão e em seguida efetuou-se a secagem, passando-se primeiramente um pequeno chumaço de algodão umedecido com álcool e depois um jato de ar quente à superfície.

A solução de ataque utilizada era composta por:

- Ácido Fluorídrico 40\% em $10 \mathrm{ml}$;

- Ácido Nítrico 65\% em $10 \mathrm{ml}$;

- Ácido Lático 90\% em 30 ml. 


\subsection{Rotinas de fabricação}

As rotinas resultantes dos ensaios produzidos neste trabalho foram elaboradas segundo as orientações disponibilizadas pela ANVISA - Agência Nacional de Vigilância Sanitária no anexo I da resolução RDC № 59 - Boas Práticas de Fabricação de produtos médicos ${ }^{64}$.

Para a redação das rotinas de inspeção do corte dos tubos de titânio e de selagem de sementes de ${ }^{125}$, foi utilizada, especificamente, a Parte G Controles de Processo e Produção do referido anexo, que propõe que o fabricante deverá estabelecer e manter procedimentos de controle de processo que descrevam todo controle necessário para assegurar conformidade às especificações. Os controles de processo deverão incluir:

1) Instruções documentadas, procedimentos padrões de operação e métodos que definem e controlem a forma de produção, instalação e assistência técnica;

2) Monitoração e controle dos parâmetros de processo e características de componentes e características dos produtos durante a produção, instalação e assistência técnica;

3) Conformidade com normas, padrões ou códigos de referência aplicados e procedimentos de controle de processo;

4) Aprovação dos processos e equipamentos dos processos e

5) Critérios de trabalho que deverão ser expressos em normas ou padrões documentados e através de amostras representativas. 


\section{RESULTADOS}

\subsection{Ensaios realizados para desenvolver procedimento de soldagem}

\subsubsection{Corte e limpeza do tubo de titânio}

Após operação de corte notou-se excesso de rebarbas causadas pelo disco de corte, ilustrado na FIG. 43.

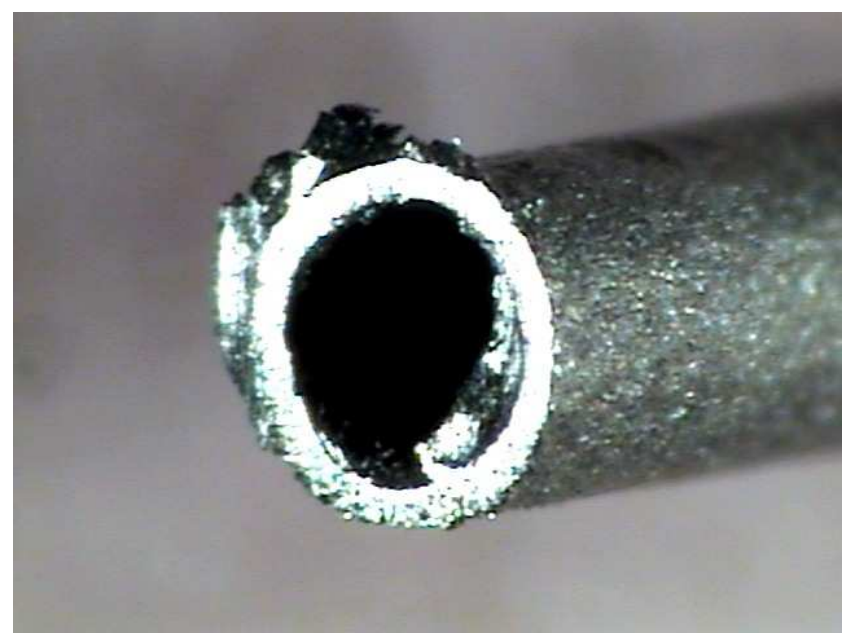

FIGURA 43 - Corte do tubo de titânio com rebarba

Foi necessário um acabamento com lixa grana 400 para se eliminar as rebarbas produzidas no momento do corte.

Na FIG. 44 observa-se a inexistência de rebarbas e o acabamento desejável nos tubos de titânio para a confecção das sementes de ${ }^{125}$.

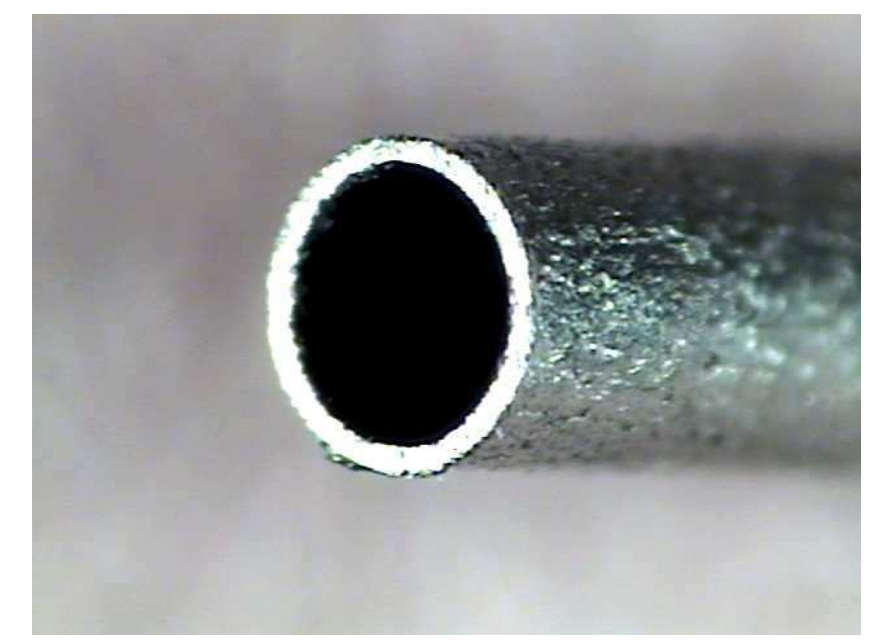

FIGURA 44 - Acabamento do tubo após lixamento 


\subsubsection{Parâmetros de soldagem}

As sementes apresentam dimensões milimétricas, dificultando sensivelmente o manuseio e os ajustes das amostras durante os ensaios, com isso, foram necessários aproximadamente 900 ensaios de selagem para se otimizar os parâmetros de soldagem e determinar o modelo de dispositivo de fixação de tubo para confecção de sementes.

\subsubsection{Dispositivo $\mathrm{n} \times 1$}

O dispositivo no 1 foi desenvolvido com o propósito de soldar 21 sementes por ciclo de produção. Porém, algumas dificuldades surgiram durante os ensaios com este dispositivo, por exemplo, a falha ocorrida na tentativa de abertura do arco plasma, devido ao mau contato no aterramento entre o tubo de titânio e o dispositivo, ocasionando uma mudança na coloração do tubo de titânio pelo excesso de tempo sob o arco piloto, conforme ilustrado na FIG. 45.

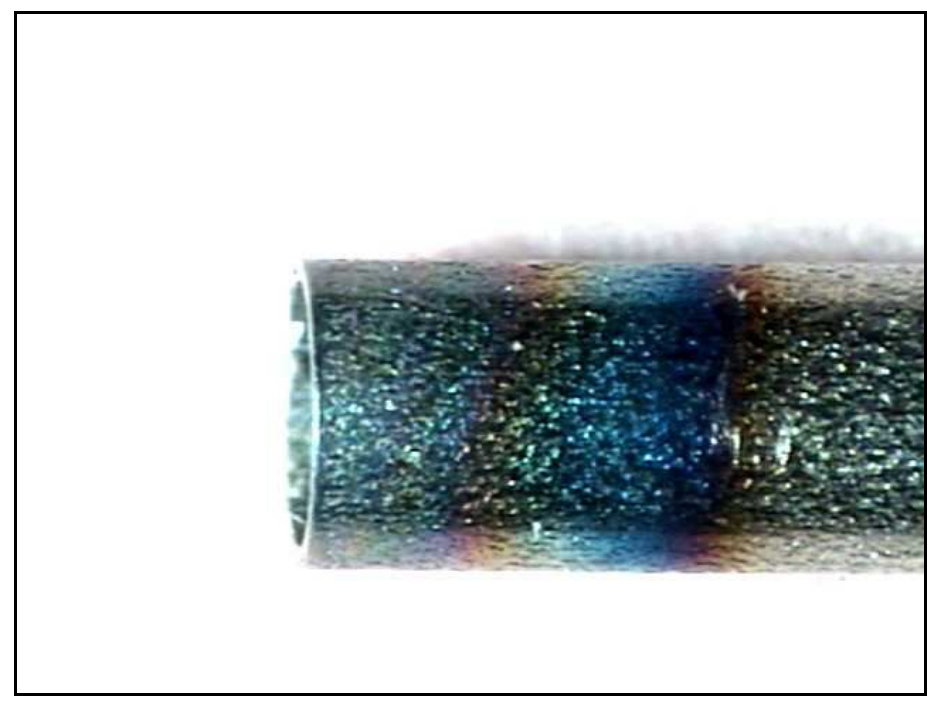

FIGURA 45 - Falha na abertura do arco

$\mathrm{Na}$ FIG. 46 pode ser observada uma falha na selagem do tubo de titânio com fusão parcial devido à variação do comprimento do tubo.

O dispositivo tem duas espessuras distintas. Uma com 5,5 mm, destinada a selagem do primeiro lado do tubo e outra com $4,5 \mathrm{~mm}$ para a selagem do segundo lado do tubo. Uma variação no comprimento do tubo para qualquer uma das duas situações provoca este tipo de falha. 


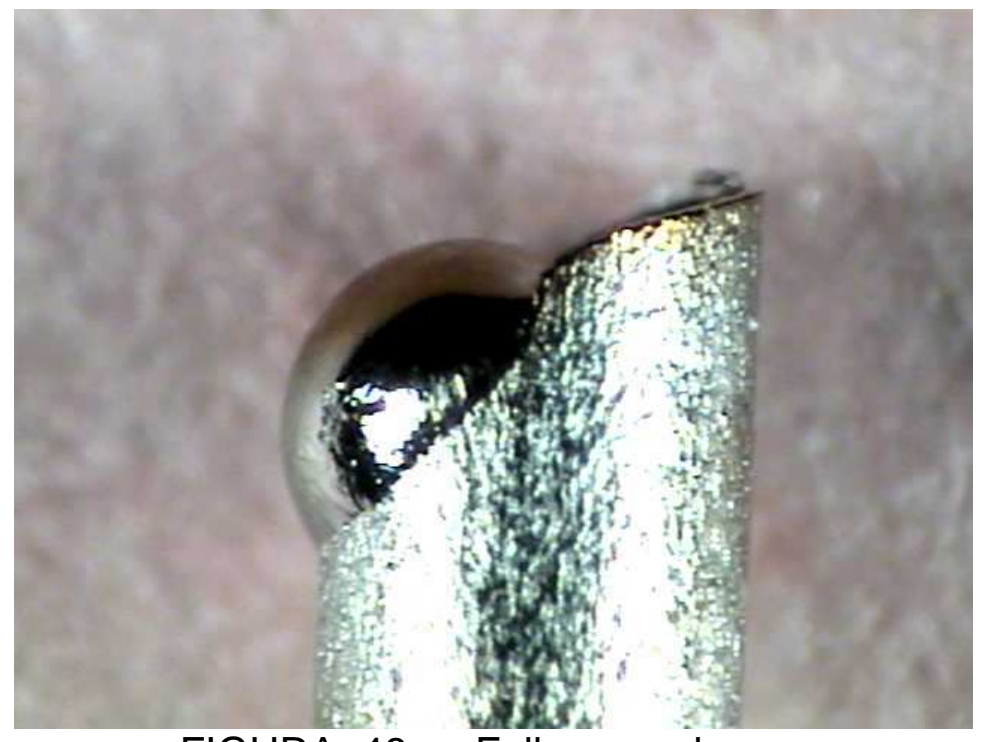

FIGURA 46 - Falha na selagem

Na FIG. 47 observa-se um excesso de material na lateral do tubo, devido a uma corrente elevada (4A) utilizada na tentativa de solucionar os problemas de aterramento do tubo com o dispositivo. Este excesso de material solidificado ocorre na região em que o material fundido entrou em contato com o cobre do dispositivo de soldagem.

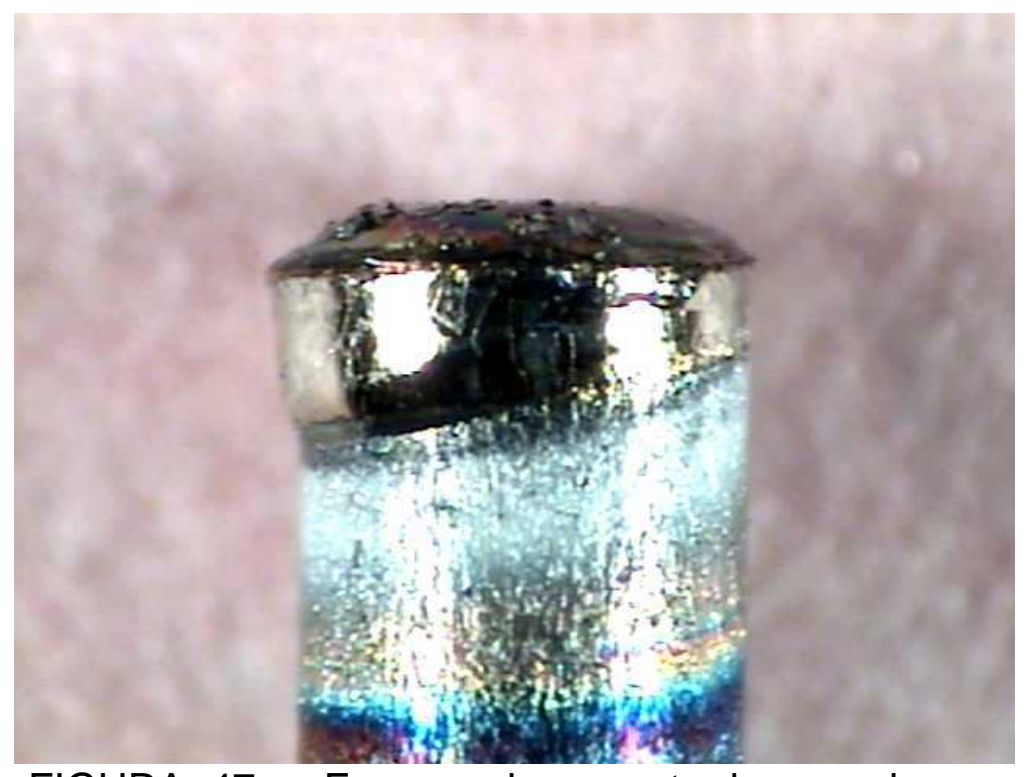

FIGURA 47 - Excesso de corrente de arco plasma

Embora descrito nas literaturas sobre a maior estabilidade de arco ${ }^{59-62}$, pode ser visto na FIG. 48 uma assimetria da solda no tubo de titânio devido à oscilação do arco plasma no momento da selagem. 


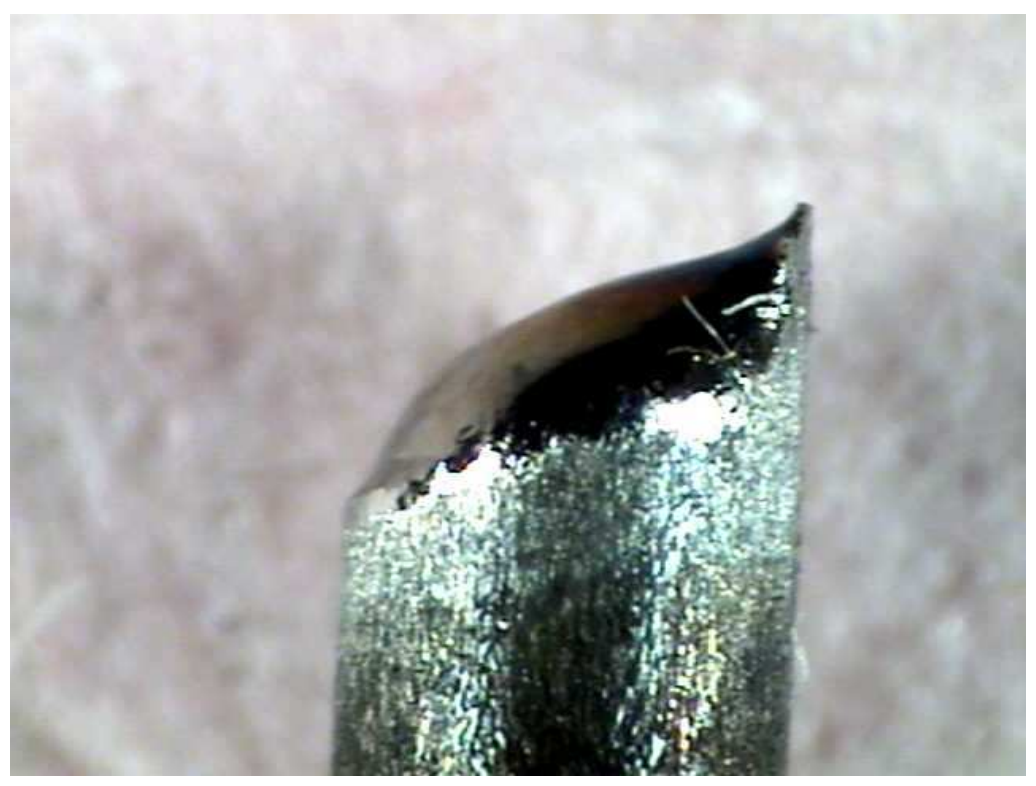

FIGURA 48 - Solda assimétrica

Foram realizados aproximadamente 250 ensaios de selagem com o dispositivo no 1 .

Como este dispositivo apresentou vários problemas para a selagem do tubo, resolveu-se confeccionar um novo dispositivo para tentar eliminar os problemas descritos acima.

\subsubsection{Dispositivo no 2}

Foram realizados aproximadamente 650 ensaios de selagem com o dispositivo $\mathrm{n}^{0} 2$.

O dispositivo ํo 2 foi desenvolvido com propósito de soldar uma semente de cada vez, com fixação por meio de placas bipartidas ou castanhas e apresentando o recurso de ajustar o comprimento de sobrematerial.

Utilizando um sistema de fixação por castanha, eliminou-se a dificuldade de abertura do arco plasma, uma vez que o tubo fica preso entre as duas castanhas, tendo quatro pontos de contatos, diferente do dispositivo oㅜ 1 , em que o tubo ficava solto no orifício da barra de cobre. Outra dificuldade solucionada foi com a adaptação de um micrômetro no dispositivo, que permitiu o ajuste do sobrematerial utilizado para a selagem do tubo. 
O fluxo de gás do arco plasma pode causar turbulência na poça de fusão, a faixa de vazão de gás recomendada na literatura ${ }^{61,62}$ para que isso não ocorra, varia de 0,25 a $5 \mathrm{l} / \mathrm{min}$, porém a faixa de vazão indicada no manual da máquina de solda varia de 0,1 a 0,3 $\mathrm{l} / \mathrm{min}$. A FIG. 49 ilustra um tubo selado utilizando uma vazão de gás de $0,3 / \mathrm{min}$, produzindo uma pressão interna e ocasionando um aumento do diâmetro na região da solda. Para corrigir este problema foi reduzida a vazão para o valor mínimo, ou seja, 0,1 l/min, como indicado no manual da máquina.

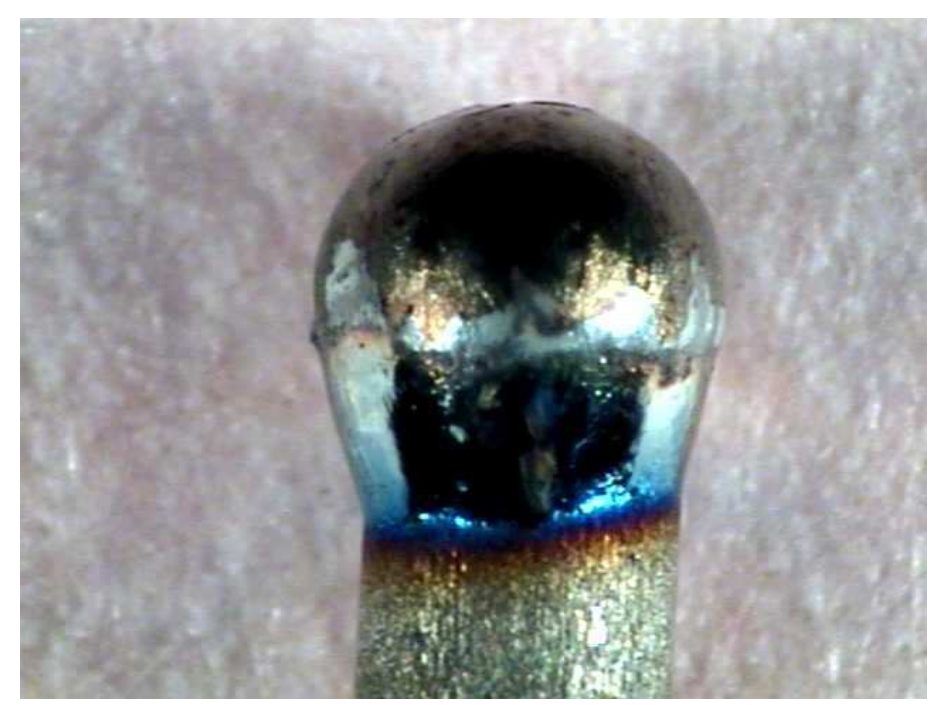

FIGURA 49 - Selagem com vazão de gás incorreta

Com a melhoria no sistema de fixação, proporcionando um bom aterramento entre o tubo de titânio e o arco de plasma e também utilizando uma vazão de gás adequada, foi possível melhorar o acabamento da região da solda. Pode-se observar na FIG. 50 um tubo selado com melhor acabamento e com pouca variação na simetria da solda. 


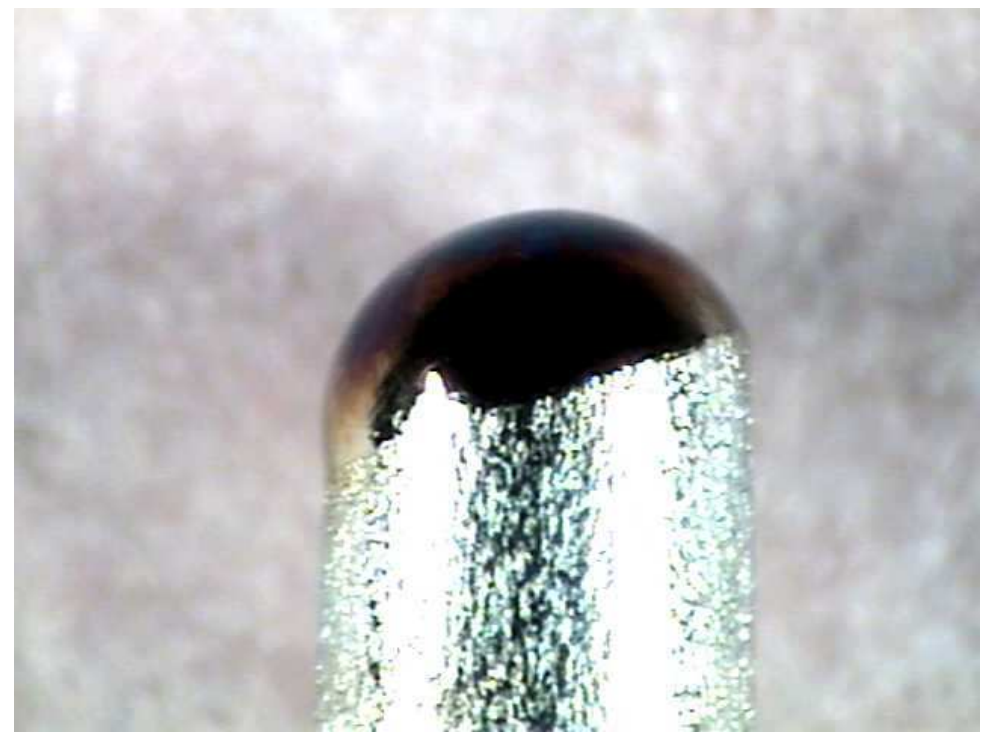

FIGURA 50 - Região da solda assimétrica

Para eliminar a variação na simetria da solda, decorrente da oscilação do arco plasma, foi utilizado um bocal de constrição com diâmetro maior que o diâmetro do tubo.

As FIG 51 e 52 ilustram as selagens dos tubos, utilizando um bocal de constrição com diâmetro de 1,2 mm.

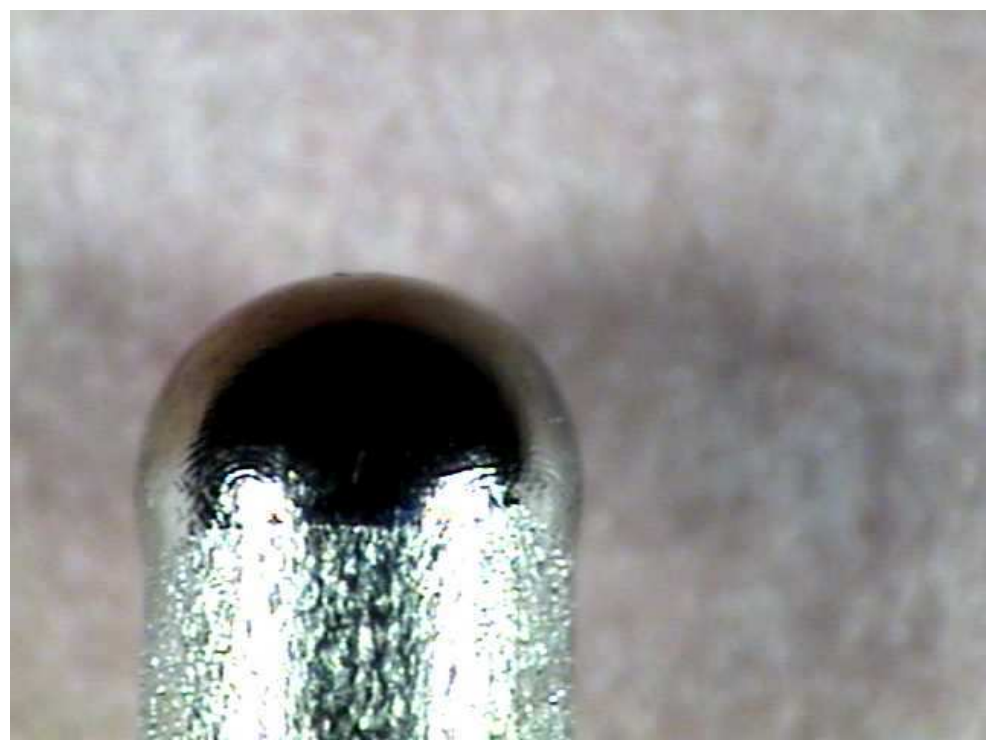

FIGURA 51 - Selagem com parâmetros ajustados 


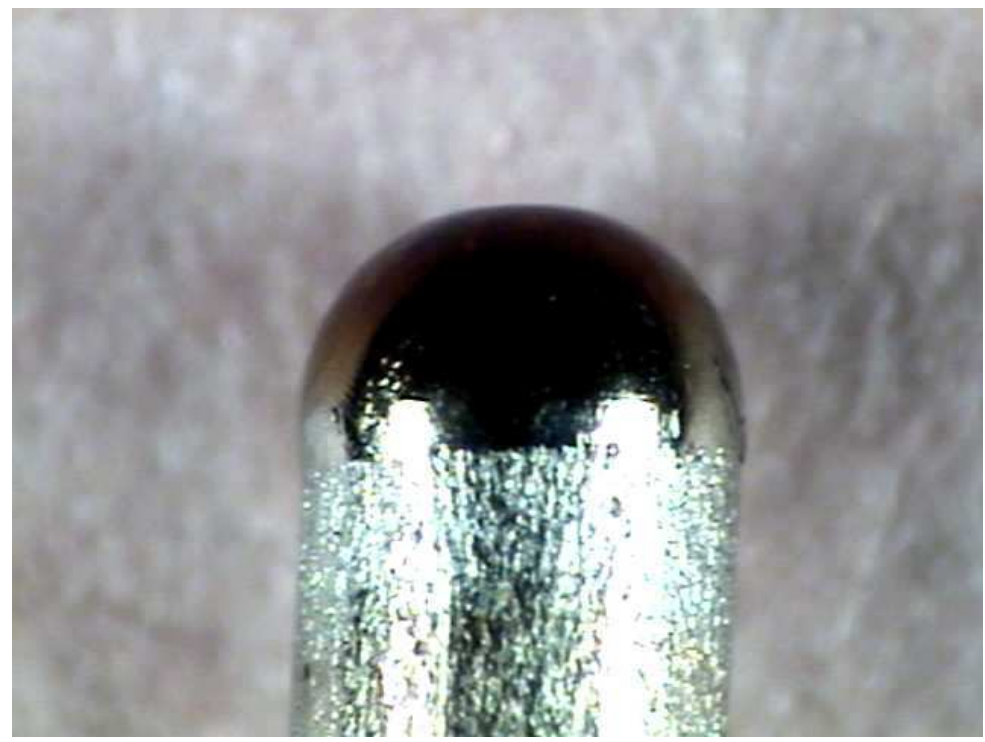

FIGURA 52 - Selagem com parâmetros ajustados

As FIG. 51 e 52 ilustram sementes que foram seladas utilizando os parâmetros finais considerados otimizados nos ensaios de soldagem e apresentados na TAB. 12.

TABELA 12 - Valores dos parâmetros finais de soldagem

\begin{tabular}{|c|c|}
\hline Parâmetros & Valor/Variação \\
\hline Comprimento do tubo & 6,90 à $6,97 \mathrm{~mm}$ \\
\hline Corrente de arco plasma & $0,85 \mathrm{~A}$ \\
\hline Corrente do arco piloto (constante) & $2 \mathrm{~A}$ \\
\hline Tempo de arco aberto & $0,3 \mathrm{~s}$ \\
\hline Diâmetro do bocal de constrição & $1,2 \mathrm{~mm}$ \\
\hline Standoff & $4,6 \mathrm{~mm}$ \\
\hline Vazão do gás do arco plasma & $0,1 \mathrm{l} / \mathrm{min}$ \\
\hline Vazão do gás de proteção & $10 \mathrm{l} / \mathrm{min}$ \\
\hline Sobrematerial da $1^{\text {a }}$ solda & $1,9 \mathrm{~mm}$ \\
\hline Sobrematerial da ${ }^{\mathrm{a}}$ solda & $1,3 \mathrm{~mm}$ \\
\hline
\end{tabular}

Pode ser observado na TAB. 12 uma variação de comprimento nos parâmetros sobrematerial da $1^{\mathrm{a}}$ solda e sobrematerial da $2^{\mathrm{a}}$ solda, ocorrida devido à pressão que se forma no interior do tubo na segunda selagem, havendo a necessidade de diminuir a quantidade de material a ser fundido. 


\subsubsection{Comprimento das sementes}

Na TAB. 13 pode ser visto o comprimento inicial do tubo de titânio e o comprimento final de 10 sementes.

TABELA 13 - Variação do comprimento das sementes após ensaio de reprodutibilidade

\begin{tabular}{|c|c|c|}
\hline Semente & Comprimento inicial $(\mathbf{m m})$ & Comprimento final $\mathbf{m m})$ \\
\hline 1 & 6,92 & 4,64 \\
\hline 2 & 6,91 & 4,58 \\
\hline 3 & 6,91 & 4,62 \\
\hline 4 & 6,92 & 4,64 \\
\hline 5 & 6,91 & 4,84 \\
\hline 6 & 6,90 & 4,60 \\
\hline 7 & 6,93 & 4,55 \\
\hline 8 & 6,91 & 4,56 \\
\hline 9 & 6,90 & 4,51 \\
\hline 10 & 6,91 & 4,52 \\
\hline
\end{tabular}

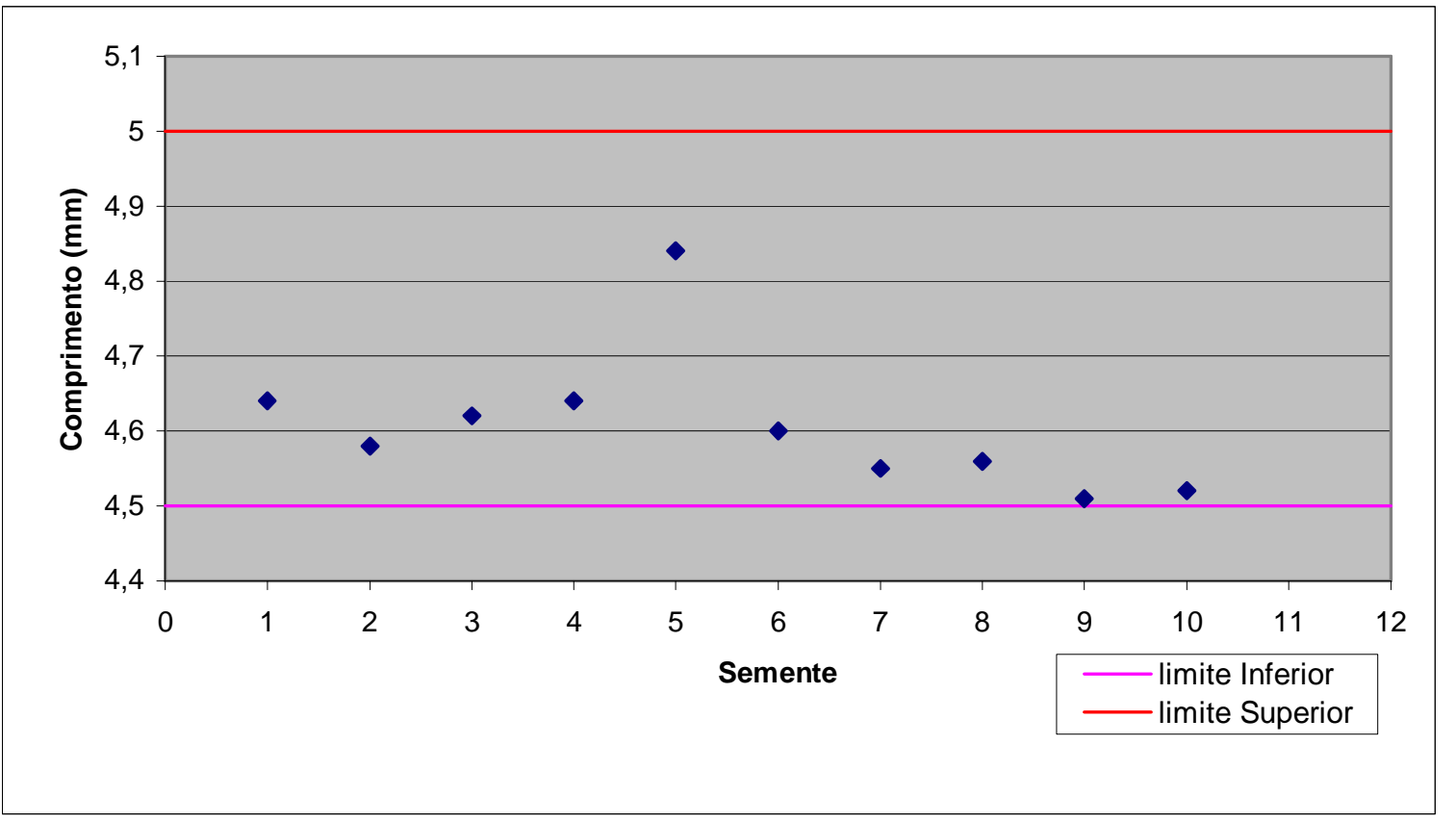

FIGURA 53 - Variação do comprimento das sementes após ensaio de reprodutibilidade 
$\mathrm{Na}$ TAB. 13 e na FIG. 53 verificamos que as variações que ocorreram no comprimento final não são proporcionais às variações do comprimento inicial, porém, os valores finais estão dentro da faixa de aceitação (4,5 à 5mm) conforme indicado nas literaturas $38,40,42,47,48$.

$\mathrm{Na}$ TAB. 14 pode ser visto o comprimento final de um lote de 48 sementes.

TABELA 14 - Comprimento final em um lote de 48 sementes

\begin{tabular}{|c|c|c|c|}
\hline Semente & Comprimento (mm) & Semente & Comprimento (mm) \\
\hline 1 & 5,00 & 25 & 4,78 \\
\hline 2 & 4,91 & 26 & 4,83 \\
\hline 3 & 4,88 & 27 & 4,81 \\
\hline 4 & 4,67 & 28 & 4,86 \\
\hline 5 & 4,79 & 29 & 4,86 \\
\hline 6 & 4,80 & 30 & 4,75 \\
\hline 7 & 4,82 & 31 & 4,94 \\
\hline 8 & 4,83 & 32 & 4,80 \\
\hline 9 & 4,84 & 33 & 5,32 \\
\hline 10 & 4,88 & 34 & 4,76 \\
\hline 11 & 4,83 & 35 & 4,78 \\
\hline 12 & 4,92 & 36 & 4,75 \\
\hline 13 & 4,81 & 37 & 4,83 \\
\hline 14 & 4,81 & 38 & 4,85 \\
\hline 15 & 4,78 & 39 & 4,86 \\
\hline 16 & 4,79 & 40 & 4,88 \\
\hline 17 & 4,79 & 41 & 4,86 \\
\hline 18 & 4,79 & 42 & 4,76 \\
\hline 19 & 4,75 & 43 & 4,93 \\
\hline 20 & 4,74 & 44 & 4,79 \\
\hline 21 & 4,88 & 45 & 4,78 \\
\hline 22 & 4,94 & 46 & 4,77 \\
\hline 23 & 4,77 & 47 & 4,91 \\
\hline 24 & 4,84 & 48 & 4,86 \\
\hline
\end{tabular}




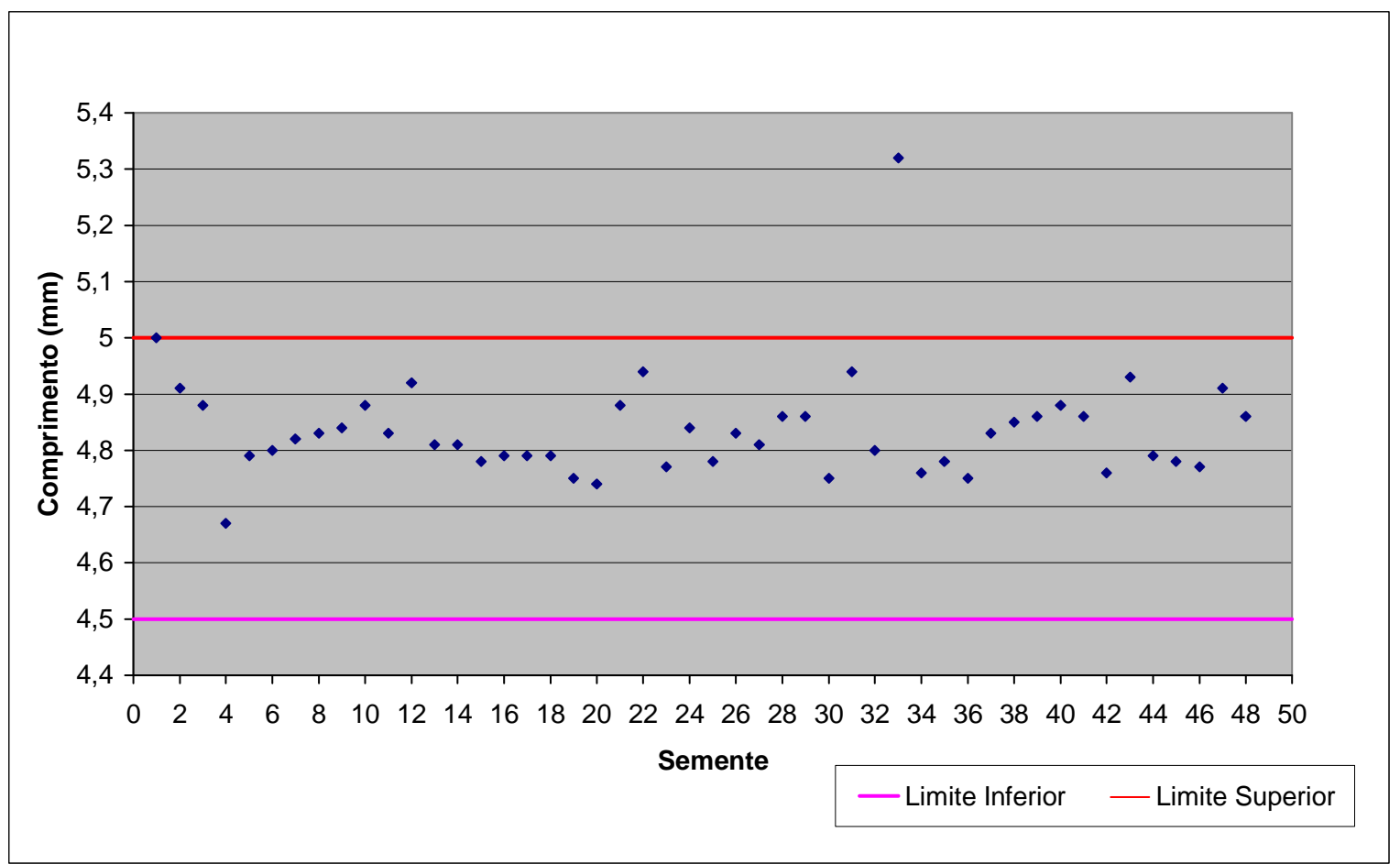

FIGURA 54 - Comprimento final no lote de 48 sementes

A faixa de comprimento inicial dos tubos utilizados para a selagem das 48 sementes tinha uma variação de 6,90 à $6,97 \mathrm{~mm}$. Pode ser observada uma grande variação no comprimento final das sementes, semelhante as que foram seladas para o ensaio de reprodutibilidade, mas que permaneceram dentro da faixa aceitável de 4,5 à 5 mm ${ }^{38,40}$. Apenas a semente de $\mathrm{n}^{\circ} 33$ ficou acima deste valor, a qual representa $2 \%$ do lote.

5.2 Ensaios realizados para qualificar o procedimento de selagem das sementes quanto aos requisitos estabelecidos para a utilização

\subsubsection{Ensaio de estanqueidade}

TABELA 15 - Medidas do padrão P3 no calibrador de dose tipo iodeto de sódio.

\begin{tabular}{|c|c|c|}
\hline Medida & Valor em Bq & Valor em $\mathbf{~ C i}$ \\
\hline 1 & $182,0 \pm 4,8$ & $4,92 \pm 0,13$ \\
\hline 2 & $180,1 \pm 4,7$ & $4,87 \pm 0,13$ \\
\hline 3 & $186,9 \pm 4,8$ & $5,05 \pm 0,13$ \\
\hline 4 & $180,2 \pm 4,7$ & $4,87 \pm 0,13$ \\
\hline 5 & $179,7 \pm 4,7$ & $4,86 \pm 0,13$ \\
\hline
\end{tabular}


Na TAB. 15 calculou-se o valor médio das atividades do padrão P3 e obteve-se o seguinte resultado: $(181,8 \pm 4,7) \mathrm{Bq}(4,9 \pm 0,13) \mathrm{nCi}$.

TABELA 16 - Medidas do padrão e dos BGs no contador de cintilação líquida em recipientes de vidro boro-silicato e polietileno (cpm)

\begin{tabular}{|c|c|c|c|c|c|}
\hline $\begin{array}{c}\text { Padrão P3 } \\
\text { Boro-Silicato }\end{array}$ & $\begin{array}{c}\text { Padrão P3 } \\
\text { Polietileno }\end{array}$ & $\begin{array}{c}\text { BG Água } \\
\text { Milli-Q Boro- } \\
\text { Silicato }\end{array}$ & $\begin{array}{c}\text { BG Água } \\
\text { Milli-Q } \\
\text { Polietileno }\end{array}$ & $\begin{array}{c}\text { BG Titânio } \\
\text { Boro-Silicato }\end{array}$ & $\begin{array}{c}\text { BG Titânio } \\
\text { Polietileno }\end{array}$ \\
\hline 6158,3 & 6294,0 & 51,8 & 51,8 & 49,2 & 50,0 \\
\hline 6227,3 & 6355,3 & 46,2 & 49,6 & 47,6 & 48,2 \\
\hline 6203,6 & 6322,9 & 46,2 & 51,8 & 53,2 & 54,8 \\
\hline 6180,9 & 6118,7 & 54,8 & 50,0 & 50,2 & 50,4 \\
\hline 6148,3 & 6276,1 & 46,4 & 50,6 & 48,2 & 51,4 \\
\hline 6187,1 & 6281,6 & 43,2 & 48,8 & 52,0 & 48,8 \\
\hline
\end{tabular}

Na TAB 16, calculou-se o valor médio das contagens para o padrão P3, BG da água do Milli-Q e do titânio, obtendo-se os seguintes resultados:

- Padrão P3 no vidro boro-silicato - 6184,3 cpm;

- Padrão P3 no polietileno - 6274,8 cpm;

- BG Água Milli-Q vidro boro-silicato - 48,1 cpm;

- BG Água Milli-Q no polietileno - 50,4 cpm;

- BG Titânio no vidro boro-silicato - 50,1 cpm;

- BG Titânio no polietileno - 50,6cpm.

Calculou-se a eficiência do contador de cintilação líquida para o padrão P3 no recipiente de vidro boro-silicato e de polietileno. Os valores foram os seguintes:

$$
\text { Eficiência }=\frac{c p m}{d p m} 100 \% \text {, onde dpm é a atividade de P3 em }
$$
desintegrações por minuto ${ }^{16}$.

- Recipiente de vidro boro-silicato $\Rightarrow$ Eficiência $=56,7 \%$

- Recipiente de polietileno $\Rightarrow$ Eficiência $=57,5 \%$ 
Como o valor obtido em cpm corresponde ao padrão P3, calculou-se proporcionalmente o valor correspondente para $185 \mathrm{~Bq}(\approx 5 \mathrm{nCi})$ e obteve-se 0 seguinte resultado:

- $181,8 \mathrm{~Bq}(\approx 4,9 \mathrm{nCi})-6274,8 \mathrm{cpm}$

- $185,0 \mathrm{~Bq}(\approx 5,0 \mathrm{nCi})-6385,2 \mathrm{cpm}$

Por segurança, adotou-se $6350 \mathrm{cpm}$ como o valor máximo permitido para ${ }^{131}$ I contido no líquido cintilador.

TABELA 17 - Teste de estanqueidade das 48 sementes ( $1^{\mathrm{a}}$ limpeza)

\begin{tabular}{|c|c|c|c|}
\hline Semente & $\begin{array}{c}\text { Líquido } \\
\text { Remanescente (cpm) }\end{array}$ & Semente & $\begin{array}{c}\text { Líquido } \\
\text { Remanescente (cpm) }\end{array}$ \\
\hline 1 & 213,2 & 26 & 785,4 \\
\hline 2 & $1.284,8$ & 27 & $1.136,6$ \\
\hline 3 & 521,8 & 28 & $1.174,0$ \\
\hline 4 & 654,8 & 29 & 815,0 \\
\hline 5 & 709,6 & 30 & $1.435,0$ \\
\hline 6 & 685,4 & 31 & 872,2 \\
\hline 7 & 984,6 & 32 & $4.399,8$ \\
\hline 8 & $1.037,6$ & 33 & $6.530,0$ \\
\hline 9 & 806,4 & 34 & $2.039,8$ \\
\hline 10 & 518,0 & 35 & $2.524,8$ \\
\hline 11 & 455,2 & 36 & 737,4 \\
\hline 12 & 655,8 & 37 & $1.837,6$ \\
\hline 13 & 498,0 & 38 & 726,8 \\
\hline 14 & 699,2 & 39 & $1.315,4$ \\
\hline 15 & $1.221,4$ & 40 & $1.346,6$ \\
\hline 16 & 990,6 & 41 & $2.234,6$ \\
\hline 17 & $1.272,2$ & 42 & $1.776,2$ \\
\hline 18 & $1.527,0$ & 43 & $1.419,2$ \\
\hline 19 & $2.373,8$ & 44 & $10.258,4$ \\
\hline 20 & $5.790,8$ & 45 & $3.145,4$ \\
\hline 21 & $2.359,0$ & 46 & $1.332,2$ \\
\hline 22 & 671,0 & 47 & $2.304,6$ \\
\hline 23 & $1.291,0$ & 48 & $1.722,4$ \\
\hline 24 & $3.026,8$ & BG Água Milli-Q & 47,6 \\
\hline 25 & $2.465,8$ & BG Titânio & 50,2 \\
\hline
\end{tabular}




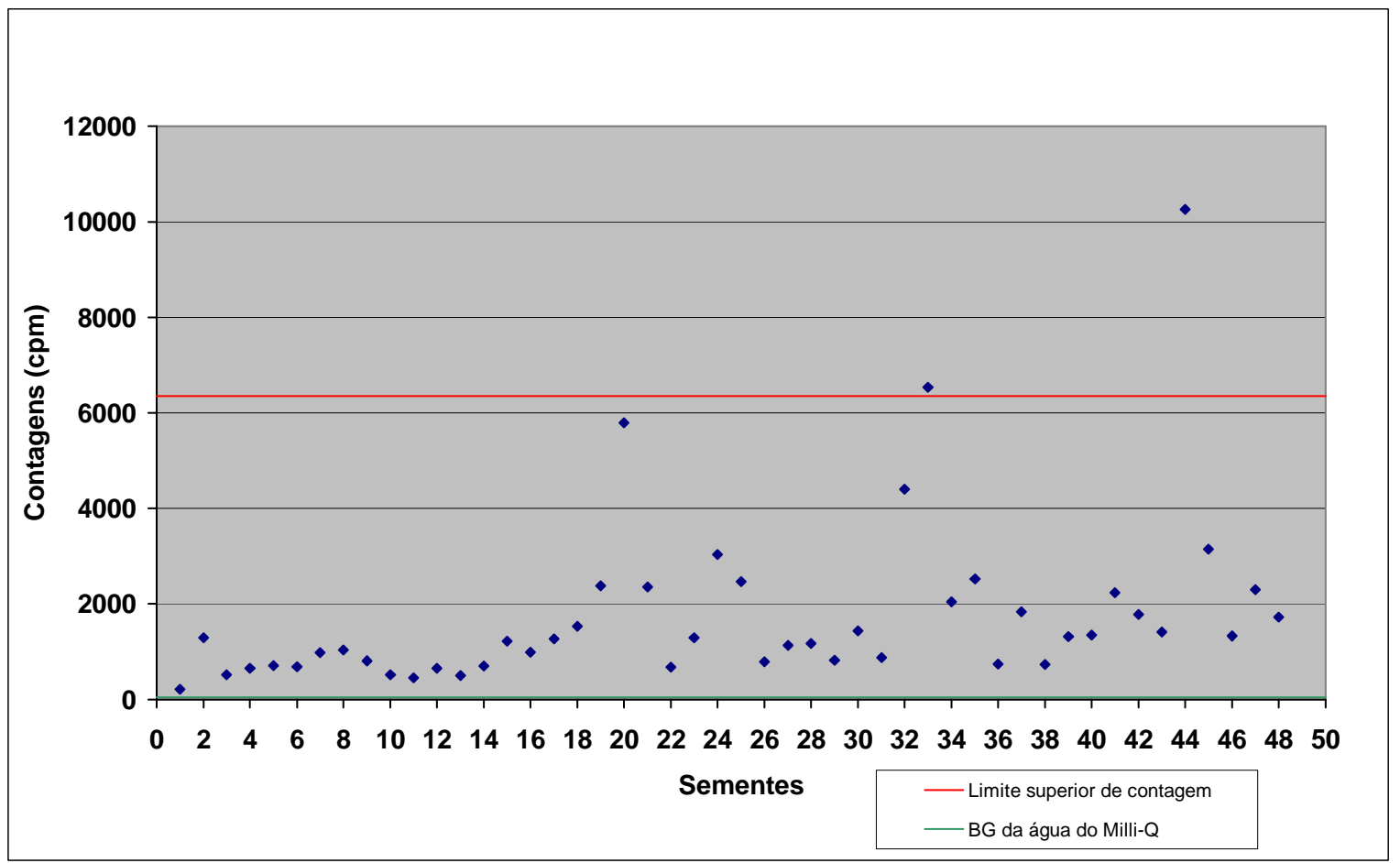

FIGURA 55 - Atividade na água após ensaio de estanqueidade (1aㅡ limpeza)

Após a primeira limpeza observa-se na TAB. 17 e na FIG. 55 uma grande variação nos valores de contagens da radioatividade dos líquidos remanescentes, contudo, ficaram abaixo do limite de $6350 \mathrm{cpm}$, com exceção das sementes de números 33 e 44 . A variação indica a necessidade de maior número de processos de limpeza. 
$\mathrm{Na}$ TAB. 18 podem ser vistos os valores obtidos nos testes de estanqueidade após a $2^{\text {a }}$ limpeza.

TABELA 18 - Teste de estanqueidade das 48 sementes ( $2^{\mathrm{a}}$ limpeza)

\begin{tabular}{|c|c|c|c|}
\hline Semente & $\begin{array}{l}\text { Líquido Remanescente } \\
\text { (cpm) }\end{array}$ & Semente & $\begin{array}{l}\text { Líquido Remanescente } \\
\text { (cpm) }\end{array}$ \\
\hline 1 & 70,0 & 26 & 59,4 \\
\hline 2 & 69,2 & 27 & 66,0 \\
\hline 3 & 65,0 & 28 & 59,6 \\
\hline 4 & 63,4 & 29 & 66,6 \\
\hline 5 & 60,0 & 30 & 73,8 \\
\hline 6 & 68,6 & 31 & 76,0 \\
\hline 7 & 68,2 & 32 & 59,4 \\
\hline 8 & 69,2 & 33 & $4.687,8$ \\
\hline 9 & 58,6 & 34 & 67,4 \\
\hline 10 & 66,6 & 35 & 67,8 \\
\hline 11 & 63,4 & 36 & 68,2 \\
\hline 12 & 66,4 & 37 & 70,6 \\
\hline 13 & 63,6 & 38 & 70,6 \\
\hline 14 & 73,4 & 39 & 66,4 \\
\hline 15 & 69,4 & 40 & 95,4 \\
\hline 16 & 71,0 & 41 & 67,0 \\
\hline 17 & 89,8 & 42 & 64,2 \\
\hline 18 & 67,2 & 43 & 64,0 \\
\hline 19 & 71,0 & 44 & 695,0 \\
\hline 20 & 146,8 & 45 & 138,8 \\
\hline 21 & 69,2 & 46 & 65,6 \\
\hline 22 & 62,6 & 47 & 69,0 \\
\hline 23 & 61,4 & 48 & 106,2 \\
\hline 24 & 58,2 & BG Água Milli-Q & 62,0 \\
\hline 25 & 63,8 & BG Titânio & 47,8 \\
\hline
\end{tabular}




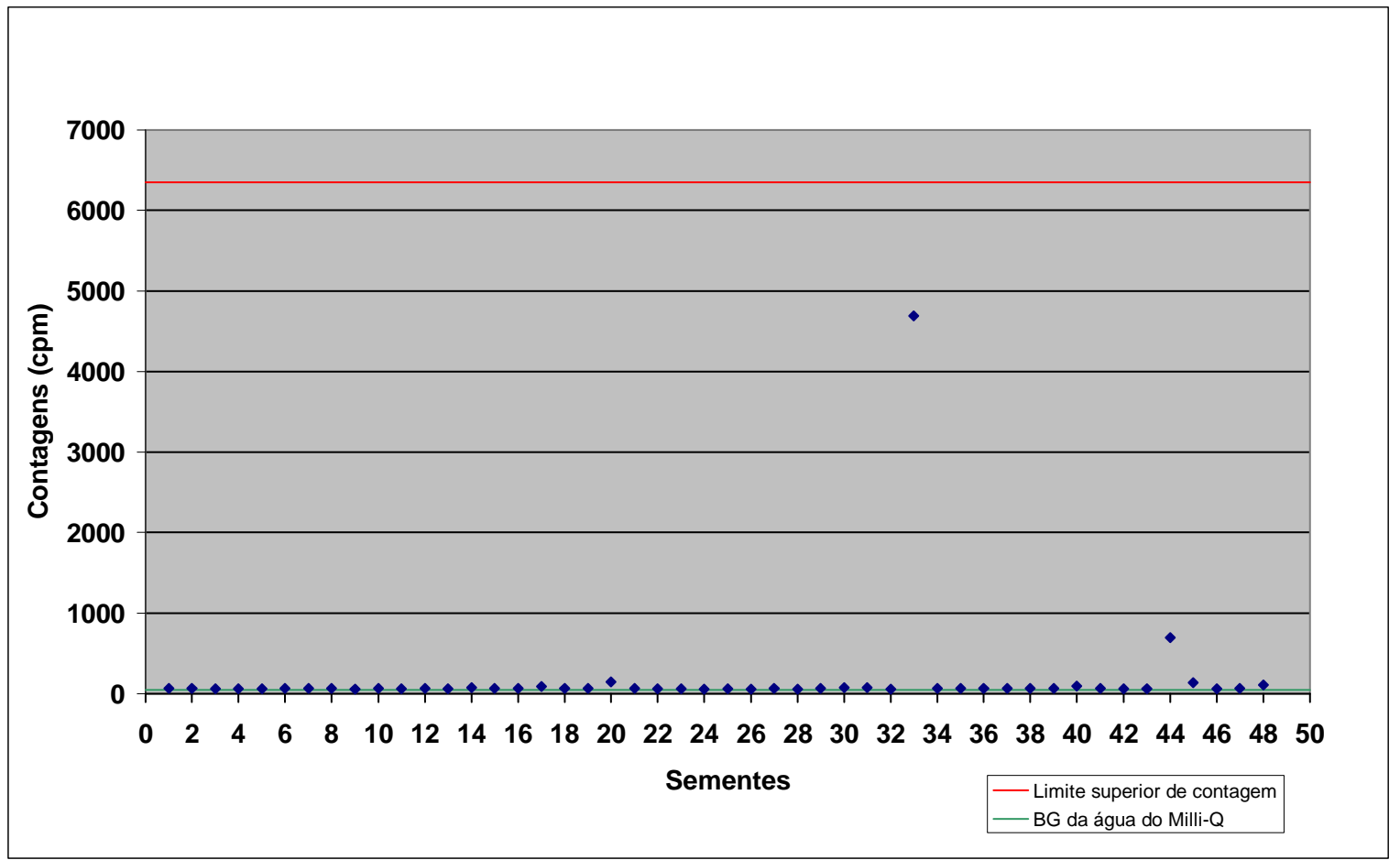

FIGURA 56 - Atividade na água após ensaio de estanqueidade (2ª limpeza)

Após a segunda limpeza, pode-se observar na FIG. 56 que os valores de contagem do líquido remanescente das sementes ficaram bem abaixo dos $6350 \mathrm{cpm}$, inclusive os valores das sementes 33 e 44 . Alguns valores ficaram próximos ao do BG da água Milli-Q.

Por estar com a contagem do líquido remanescente ainda alta, selecionou-se a semente $n^{0} 33$ junto às que ficaram com valor acima de $100 \mathrm{cpm}$ e foram submetidas a novo ensaio de estanqueidade, mostrado na TAB. 19.

TABELA 19 - Teste de estanqueidade das 5 sementes ( $3^{\mathrm{a}}$ limpeza)

\begin{tabular}{|c|c|}
\hline Semente & Líquido Remanescente (cpm) \\
\hline 20 & 116,4 \\
\hline 33 & $309.920,0$ \\
\hline 44 & 107,6 \\
\hline 45 & 72,2 \\
\hline 48 & 67,0 \\
\hline BG Água Milli-Q & 52,2 \\
\hline BG Titânio & 49,7 \\
\hline
\end{tabular}




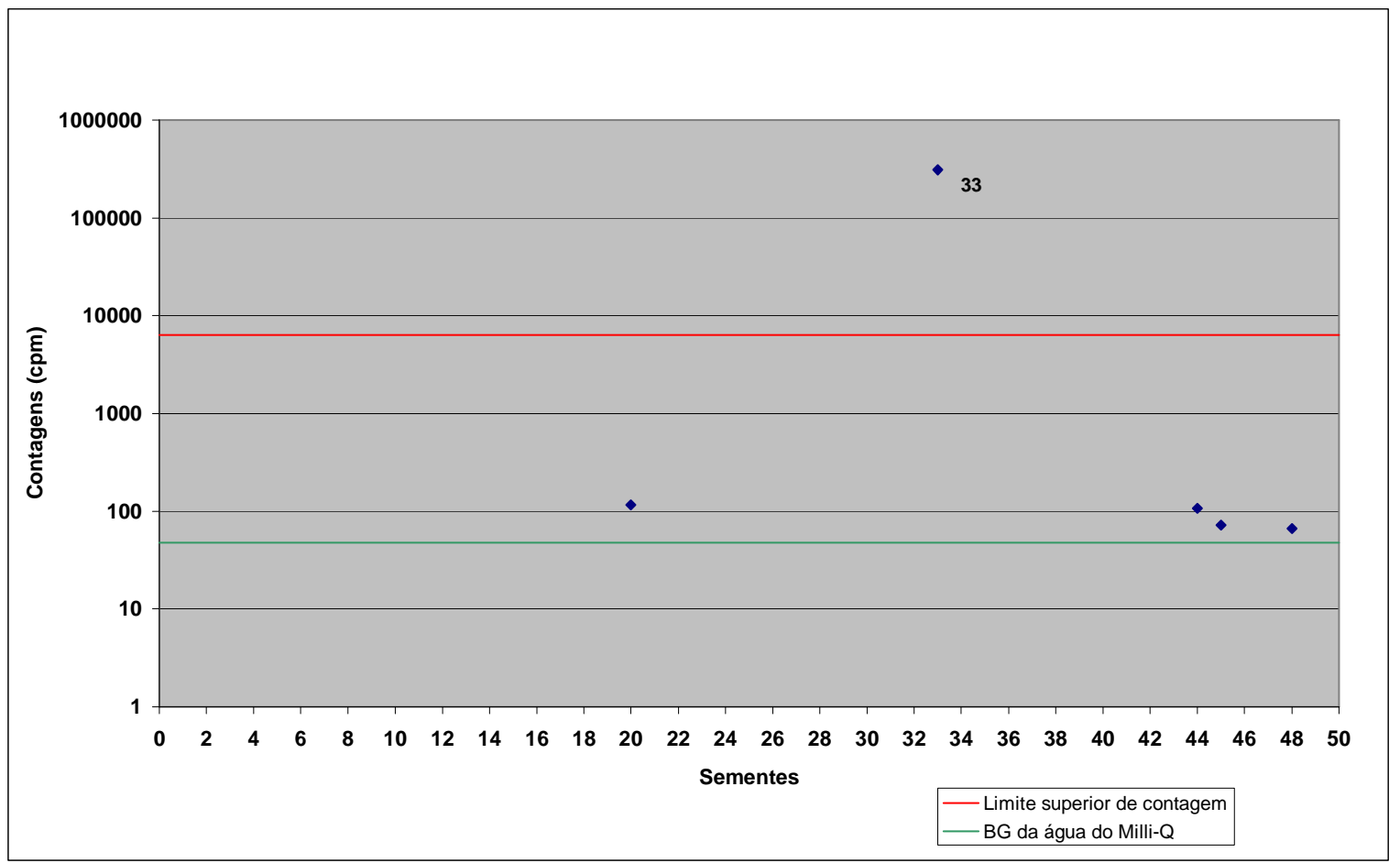

FIGURA 57 - Atividade na água após ensaio de estanqueidade (3ํㅡㄹ limpeza)

Nota-se na FIG. 57 que os valores de contagem do líquido remanescente, após o terceiro ensaio de estanqueidade, ficaram abaixo do limite. Porém, o valor de contagem do líquido da semente no 33 aumentou drasticamente e excedeu o limite determinado pela norma ISO 9978, confirmando um vazamento.

\subsubsection{Ensaios de validação}

Os resultados de estanqueidade das fontes submetidas aos ensaios de Pressão Externa, Impacto e Temperatura são apresentados na TAB. 20. 
TABELA 20 - Teste de estanqueidade das sementes após serem submetidas aos ensaios de validação.

\begin{tabular}{|c|c|c|}
\hline Semente & Ensaio & $\begin{array}{c}\text { Líquido Remanescente } \\
\text { (cpm) }\end{array}$ \\
\hline 28 & Pressão Externa & 75,4 \\
\hline 38 & Pressão Externa & 76,8 \\
\hline 41 & Impacto & 80,6 \\
\hline 42 & Impacto & 70,2 \\
\hline 44 & Temperatura & 71,2 \\
\hline 47 & Temperatura & 78,0 \\
\hline BG Água Milli-Q & - & 53,0 \\
\hline BG Titânio & - & 49,9 \\
\hline
\end{tabular}

Pode ser observado na FIG. 58 uma deformação na parede da semente. Esta deformação foi provocada pelo choque do martelo com o tubo de titânio no ensaio de impacto. Embora apresentando uma deformação no tubo de titânio causada pelo choque do martelo, a semente não apresentou vazamento. Isto pode ser confirmado com os valores de contagem de líquido remanescente apresentados na TAB. 20.

Observando-se a TAB. 20, nota-se que os valores de contagem do líquido remanescente dos testes de estanqueidade após ensaios de validação para fontes seladas usadas em braquiterapia, estabelecidos pela norma ISO 2919, ficaram bem abaixo $6350 \mathrm{cpm}$ ou $185 \mathrm{~Bq}(\approx 5 \mathrm{nCi})$ e atendem ao critério de aprovação especificado pela norma ISO 9978.

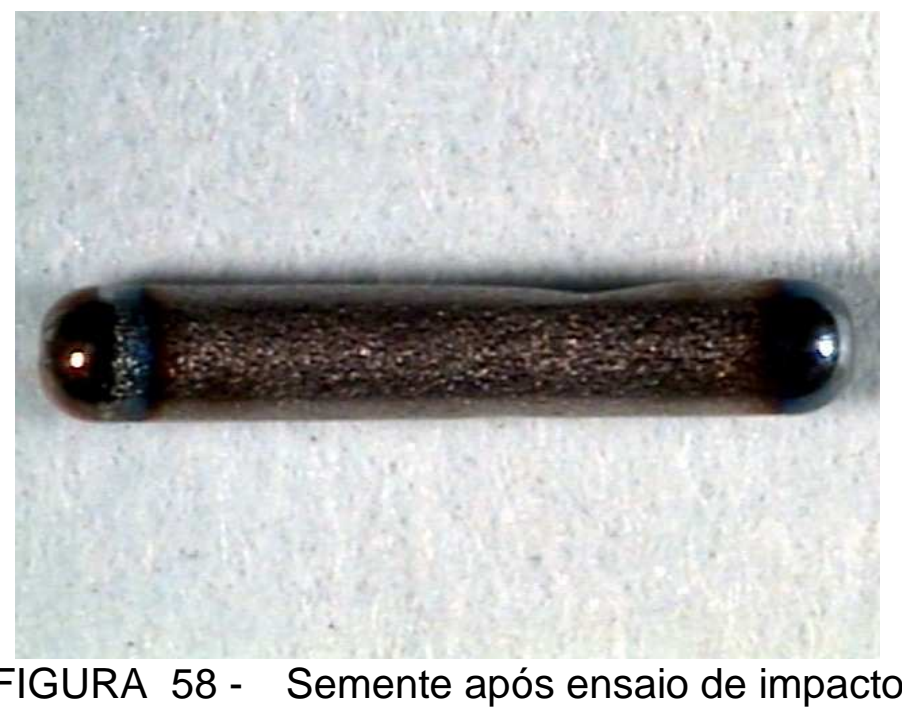




\subsubsection{Ensaio metalográfico}

As FIG. 59 e 60 ilustram a região da solda no tubo. Pode-se observar a ausência de falhas nas selagens. Também se pode observar a qualidade da solda junto à parede do tubo que está isenta de trincas e que a solidificação da gota ocorreu sem porosidade.

A região da gota solidificada ficou esférica, acompanhando a tangência do tubo, o que elimina possíveis interferências mecânicas de travamento durante o carregamento das sementes nas agulhas de braquiterapia.

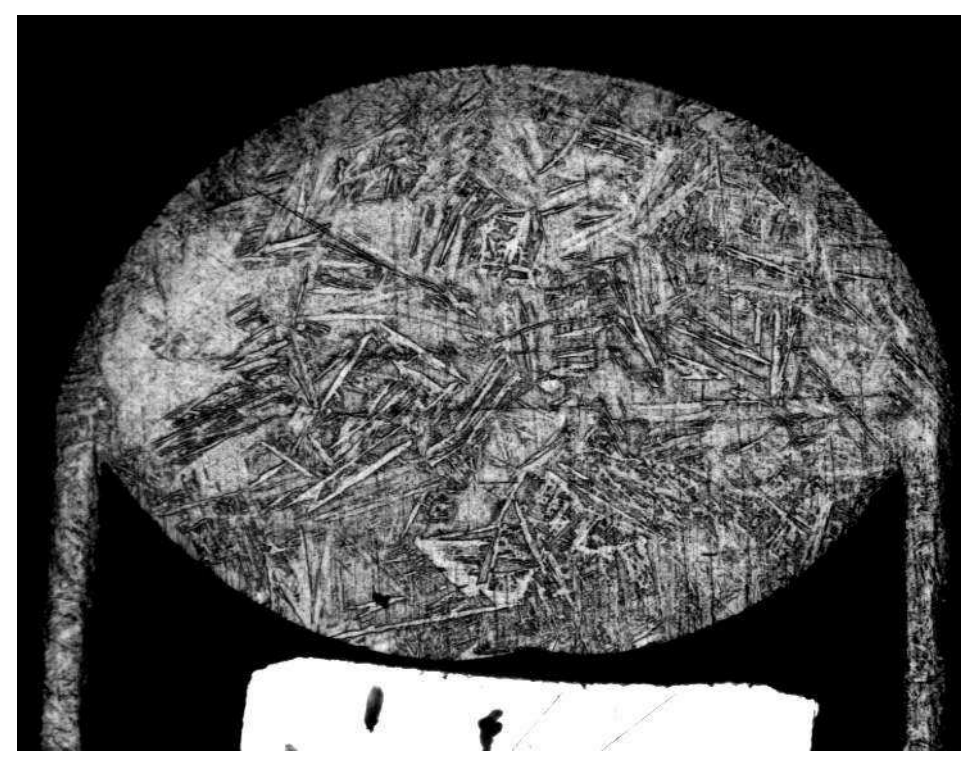

FIGURA 59 - Detalhe da solda, aumento 125X

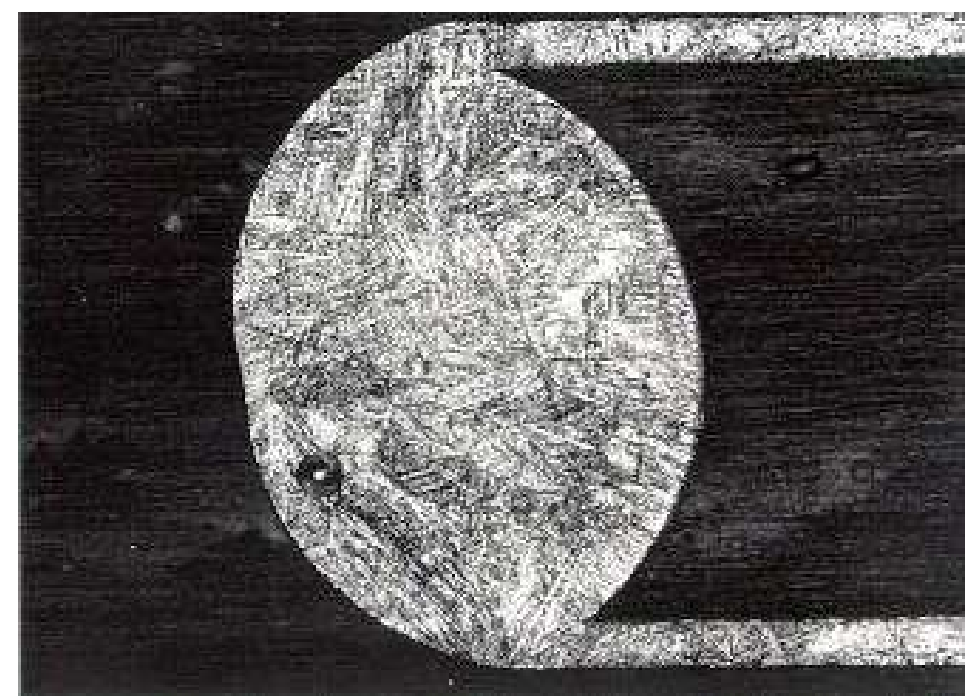

FIGURA 60 - Detalhe da solda, aumento 100X 
5.3 Rotinas de inspeção do corte dos tubos de titânio e de selagem de sementes de ${ }^{125}$ I segundo as Boas Práticas de Fabricação

Uma vez determinado os parâmetros de soldagem das sementes de

${ }^{125}$ I durante os ensaios de selagem e validado o procedimento de soldagem quanto aos requisitos estabelecidos na norma ISO 2919, foram elaboradas as rotinas de fabricação.

As rotinas elaboradas segundo as Boas Práticas de Fabricação são apresentadas no Apêndice A - Inspeção do corte dos tubos de titânio e no Apêndice B - Procedimento de selagem. 


\section{CONCLUSÕES}

O procedimento desenvolvido para a selagem das sementes de ${ }^{125}$ I utilizando o processo de soldagem plasma mostrou-se eficiente, atendendo a todos os requisitos estabelecidos na norma ISO 2919.

Os procedimentos e resultados apresentados neste trabalho possibilitaram a elaboração de métodos e controles a serem utilizados nas selagens das sementes atendendo às Boas Práticas de Fabricação.

Sugestões para trabalhos futuros:

- Automação dos dispositivos para selagem utilizando a técnica com solda plasma;

- Desenvolver a selagem das sementes de ${ }^{125} \mid$ utilizando a técnica de solda laser;

- Desenvolver procedimento utilizando a técnica de soldagem plasma para confecção de fontes seladas de ${ }^{192}$ Ir utilizadas em alta taxa de dose (HDR) para braquiterapia. 


\section{APÊNDICES}

\section{APÊNDICE A - Inspeção do corte dos tubos de titânio \\ Objetivo}

Estabelecer procedimento para inspeção do corte dos tubos de titânio adquiridos externamente.

\section{Campo de Aplicação}

Este procedimento será aplicado no laboratório de produção de fontes para braquiterapia do Centro de Tecnologia das Radiações, quando do recebimento dos tubos de titânio adquiridos externamente.

\section{Procedimento}

- Condições e recursos necessários;

1) Técnico treinado neste procedimento;

2) Equipamento para inspeção visual;

3) Micrômetro com precisão de $0,001 \mathrm{~mm}$;

4) Balança analítica de 0,0001g;

5) Ficha de inspeção.

- Descrição das atividades:

1) Conferir o certificado de análise para verificar se a composição química do titânio e as características dimensionais dos tubos estão conforme especificado no pedido de compra;

2) Com o auxílio de uma balança analítica, verificar se a massa do lote recebido corresponde à quantidade de tubos solicitados no pedido de compra, dividindo a massa total do lote pela massa de uma amostra do tubo de titânio;

3) Retirar do lote recebido amostras de tubos para análise visual do acabamento dos cortes e dimensional;

4) Posicionar um tubo sob a lente do equipamento de inspeção visual e 
comparar a imagem do monitor com a imagem padrão especificada no anexo A deste procedimento;

5) Medir o comprimento e o diâmetro externo de cada tubo da amostragem utilizando um micrômetro com 0,001mm de precisão, comparando com os valores especificados no anexo B deste procedimento. Repetir este procedimento para cada tubo desta amostragem;

6) Anotar os dados obtidos nas análises visual e dimensional na ficha de inspeção - anexo C deste procedimento.

\section{Cuidados especiais}

1) Verificar a calibração da balança analítica, utilizando o procedimento descrito no manual do equipamento.

2) Ligar o equipamento de inspeção visual e ajustar o foco da imagem, utilizando um tubo de titânio cortado.

3) Verificar a calibração do micrômetro, utilizando o procedimento descrito no manual do equipamento.

4) A amostragem dos tubos de titânio de cada lote, destinadas à inspeção visual e dimensional, é realizada segundo as normas ABNT NBR 5426/1985 Planos de amostragem e procedimentos na inspeção por atributos $^{65}$ e ABNT NBR 5427/1985 Guia para utilização da norma NBR 5426 - Planos de amostragem e procedimentos na inspeção por atributos ${ }^{66}$. A quantidade de tubos a ser amostrado por lote e o critério de aprovação/rejeição segue o plano de amostragem simples normal, para um Nível de Qualidade Aceitável - NQA de 2,5 e depende do tamanho do lote. Este plano de amostragem pode ser verificado na TAB. 1 deste procedimento. 
TABELA 1 - Plano de amostragem simples normal

\begin{tabular}{|ccc|c|c|c|}
\hline \multicolumn{2}{|c|}{ Tamanho do lote } & Tamanho da amostra & Aceite & Rejeite \\
\hline 2 & - & 8 & 2 & 0 & 1 \\
\hline 9 & - & 15 & 3 & 0 & 1 \\
\hline 16 & - & 25 & 5 & 0 & 1 \\
\hline 26 & - & 50 & 8 & 0 & 1 \\
\hline 51 & - & 90 & 13 & 0 & 1 \\
\hline 91 & - & 150 & 20 & 1 & 2 \\
\hline 151 & - & 280 & 32 & 2 & 3 \\
\hline 281 & - & 500 & 50 & 3 & 4 \\
\hline 501 & - & 1.200 & 80 & 5 & 6 \\
\hline 1.201 & - & 3.200 & 125 & 7 & 8 \\
\hline 3.201 & - & 10.000 & 200 & 10 & 11 \\
\hline 10.001 & - & 35.000 & 315 & 14 & 15 \\
\hline 35.001 & - & 150.000 & 500 & 21 & 22 \\
\hline 150.001 & - & 500.000 & 800 & 21 & 22 \\
\hline MAIOR QUE 500.001 & 1.250 & 21 & 22 \\
\hline
\end{tabular}

- Se o número de unidades defeituosas encontradas na amostra for igual ou menor do que o número de aceitação, o lote é aprovado e as unidades inspecionadas estarão disponibilizadas para a produção.

- Se o número de unidades defeituosas encontradas na amostra for igual ou superior do que o número de rejeição, procede-se novamente à amostragem para repetição da inspeção. Caso permaneça o dado obtido na primeira amostragem, o lote é rejeitado.

\section{Anexos}

Anexo A - Referência de acabamento

Anexo B - Dimensões do tubo de titânio

Anexo C - Modelo de ficha de inspeção

\begin{tabular}{|l|l|l|l|}
\hline Revisão & Elaborado & Aprovado & Data \\
\hline & & & \\
\hline
\end{tabular}




\section{Anexo A - Referência de acabamento}

Se na inspeção visual for detectada a aparência conforme as FIG. 1 e 2 abaixo, a amostra estará aprovada.

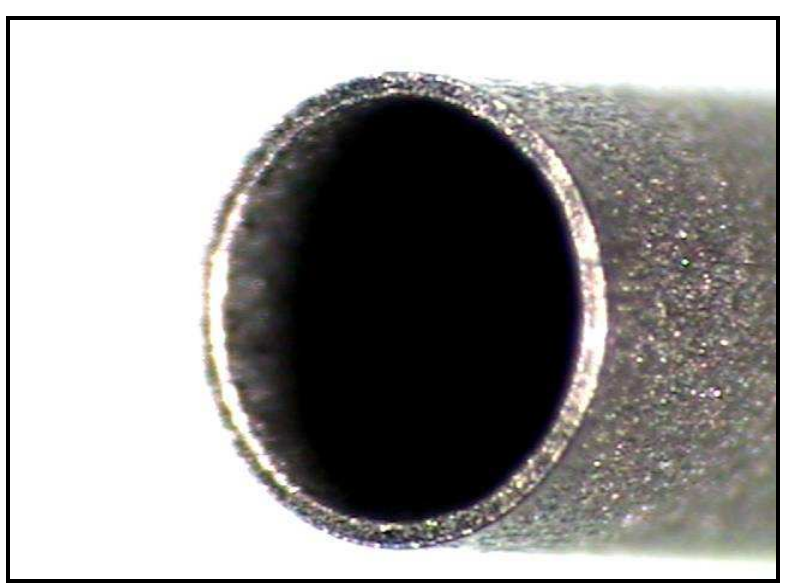

FIGURA 1 - Acabamento desejável Perspectiva

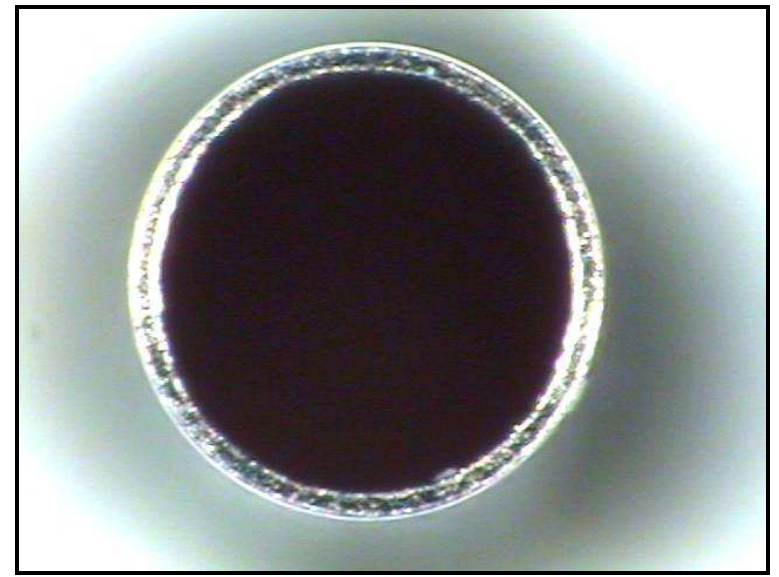

FIGURA 2 - Acabamento desejável Frontal

Se na inspeção visual for detectada a aparência conforme a FIG. 3 abaixo, a amostra estará reprovada.

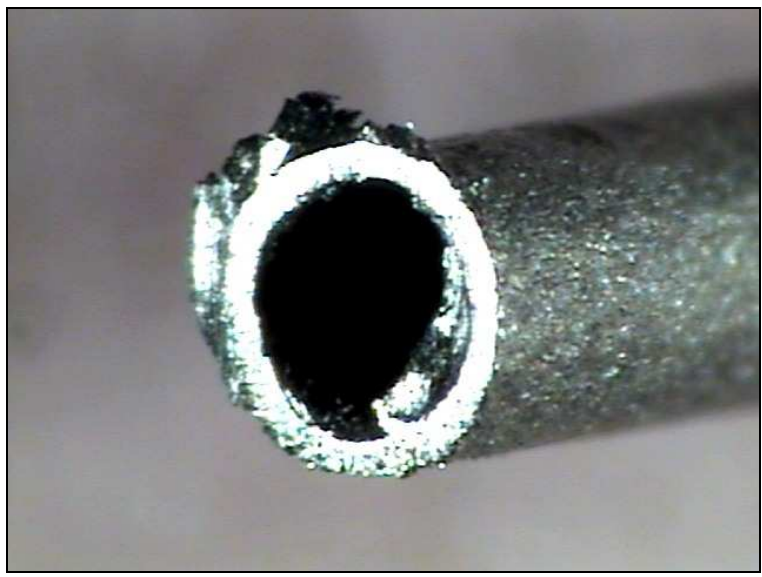

FIGURA 3 - Acabamento não desejável 


\section{Anexo B - Dimensões do tubo de titânio}

Somente se as dimensões de comprimento (A) e diâmetro (B) estiverem dentro dos intervalos indicados na TAB. 1 a amostra estará aprovada.
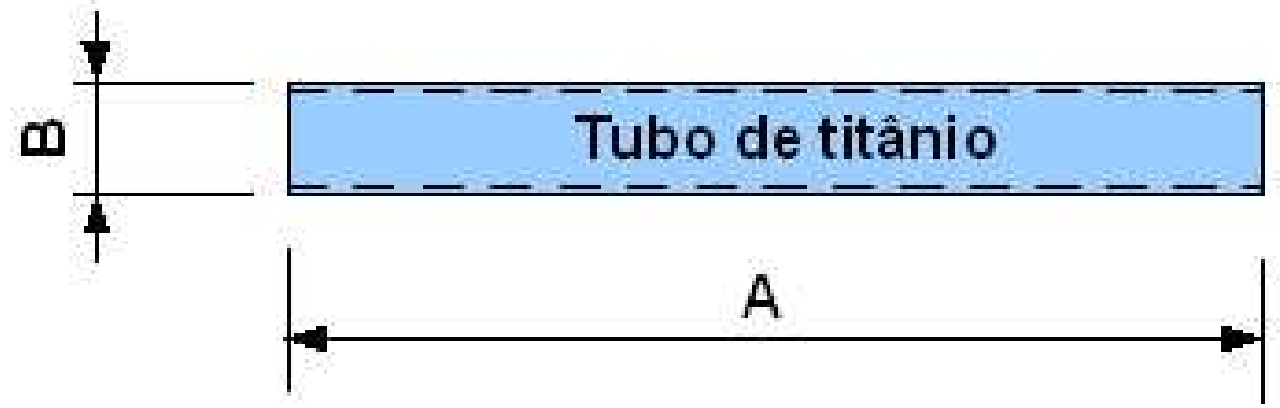

TABELA 1 - Parâmetros dimensionais do tubo de titânio

\begin{tabular}{|c|c|}
\hline Medidas & Variação $(\mathbf{m m})$ \\
\hline A & $6,90-6,97$ \\
\hline B & $0,787-0,813$ \\
\hline
\end{tabular}


Anexo C - Modelo de ficha de inspeção

FICHA DE INSPEÇÃO DE MATÉRIA PRIMA - TUBO DE TITÂNIO

\begin{tabular}{|l|l|l|l|}
\hline Lote IPEN no & $\begin{array}{l}\text { Lote Fornecedor } \\
\mathrm{n}^{\circ}\end{array}$ & \\
\hline $\begin{array}{l}\text { № de unidades } \\
\text { no lote }\end{array}$ & $\begin{array}{l}\text { Amostragem de } \\
\text { Tubo de titânio }\end{array}$ & Quantidade \\
\hline $\begin{array}{l}\text { Data da } \\
\text { Amostragem }\end{array}$ & 1 & Validade do Lote & \\
\hline
\end{tabular}

\begin{tabular}{|c|c|c|}
\hline \multirow[b]{2}{*}{ ENSAIOS } & \multicolumn{2}{|c|}{ RESULTADOS } \\
\hline & $\begin{array}{l}\text { Unidades sem Defeitos } \\
\text { (aceite) }\end{array}$ & $\begin{array}{l}\text { Unidades com } \\
\text { Defeitos (rejeite) }\end{array}$ \\
\hline 1- Rebarbas na face do tubo. & & \\
\hline 2- Medida do comprimento (A). & & \\
\hline 3- Medida do diâmetro externo (B). & & \\
\hline APROVADO & & REPROVADO \\
\hline
\end{tabular}

\begin{tabular}{|l|}
\hline OBSERVAÇÕES: \\
\hline \\
\hline \\
\hline \\
\hline \\
\hline \\
\hline \\
\hline
\end{tabular}

\begin{tabular}{|c|l|l|l|}
\hline \multicolumn{3}{|c|}{ ASSINATURAS } \\
\hline Ensaiado por & Data & Data \\
\hline $\begin{array}{c}\text { Garantia da } \\
\text { Qualidade }\end{array}$ & & \\
\hline
\end{tabular}




\section{APÊNDICE B - Procedimentos para selagem}

\section{Objetivo}

Estabelecer procedimentos para selagem de tubo de titânio utilizados na confecção de sementes de ${ }^{125}$ I.

\section{Campo de Aplicação}

Laboratório de produção de fontes para braquiterapia do Centro de Tecnologia das Radiações.

\section{Procedimento}

- Condições e Recursos Necessários:

1) Técnico treinado neste procedimento;

2) Equipamento de proteção individual;

3) Máquina de solda plasma, marca Secheron Soudure S.A., modelo Plasmafix 50E;

4) Sistema de posicionamento $X Y$ com dispositivo de fixação de tubo;

5) Tubo de titânio;

6) Fios de prata com ${ }^{125}$ I adsorvido;

7) Recipientes para coleta de sementes.

- Descrição das Atividades:

1) Montagem da tocha plasma;

2) Fixar o gabarito de posicionamento do eletrodo no corpo da tocha plasma;

3) Posicionar o centralizador em cerâmica para pinça de fixação de $\varnothing 1,0 \mathrm{~mm}$ no interior da tocha;

4) Posicionar dentro do centralizador cerâmico a pinça de fixação de $\varnothing 1,0 \mathrm{~mm}$; 
5) Introduzir o eletrodo de tungstênio com $\varnothing 1,0 \mathrm{~mm}$ no interior da tocha, passando pela pinça de fixação até encostar-se ao gabarito;

6) Fixar o eletrodo de tungstênio apertando a tampa sobre o corpo da tocha plasma;

7) Retirar o gabarito;

8) Fixar o bocal constritor com $\varnothing$ de 1,2 mm no corpo da tocha plasma;

9) Fixar o bocal cerâmico médio no corpo da tocha plasma.

- Regulagem da máquina de solda:

1) Abrir a válvula do cilindro de gás de arco plasma;

2) Abrir a válvula do cilindro de gás de proteção;

3) Ligar a máquina de solda plasma na chave ON/OFF;

4) Selecionar a corrente de arco piloto em $2 \mathrm{~A}$ desligando a chave $5 \mathrm{~A}$. $\mathrm{O}$ indicador $2 \mathrm{~A}$ irá ascender;

5) Ajustar a vazão gás do arco plasma em $0,1 \mathrm{l} / \mathrm{min}$ no regulador correspondente apertando simultaneamente a chave $G A Z 1$;

6) Ajustar a vazão do gás de proteção em $10 \mathrm{l} / \mathrm{min}$ no regulador correspondente apertando simultaneamente a chave GAZ2;

7) Ajustar o tempo de arco aberto em 0,3s na caixa de regulagem de tempo;

8) Ajustar o Pós-Gás em 50\% no potenciômetro POST;

9) Ajustar o down slope em $100 \%$ no potenciômetro $\square$;

10)Selecionar a faixa de corrente de operação da máquina de solda desligando a chave $50 \mathrm{~A}$. O indicador de $5 \mathrm{~A}$ irá ascender;

11) Ajustar a corrente em $0,85 \mathrm{~A}$ girando o potenciômetro de corrente nominal no sentido horário até a indicação correspondente;

12) Ligar o arco piloto na chave PILOTE. 
- Soldagem do tubo de titânio:

1) Com a máquina de solda ligada e ajustada, inserir um tubo de titânio no centro das placas de latão do dispositivo de soldagem;

2) Com auxílio do micrômetro, ajustar o comprimento de $1,9 \mathrm{~mm}$ de sobrematerial medido a partir das placas de latão;

3) Fixar o tubo nas placas apertando os parafusos de fixação;

4) Ajustar o standoff com comprimento de $4,6 \mathrm{~mm}$;

5) Utilizando o sistema de posicionamento $X Y$, centralizar o tubo de titânio com o eixo do bocal de constrição da tocha plasma;

6) Acionar o dispositivo de soldagem automática da máquina de solda;

7) Deslocar o dispositivo de soldagem, movimentando o sistema de posicionamento $\mathrm{XY}$;

8) Soltar os parafusos de fixação das placas de latão e inverter o tubo de titânio;

9) Colocar um fio de prata com ${ }^{125}$ I adsorvido no interior do tubo de titânio com o primeiro lado soldado;

10)Com auxílio do micrômetro, ajustar o comprimento de $1,3 \mathrm{~mm}$ de sobrematerial medido a partir das placas de latão;

11)Repetir os itens 3, 4, 5, 6 e 7;

12)Soltar os parafusos de fixação das placas de latão e retirar a semente soldada;

13)Colocar a semente soldada no frasco para ensaio de estanqueidade. 


\section{Cuidados especiais}

- A tocha plasma deverá ser limpa antes do início da selagem de cada lote.

- Na afiação do eletrodo de tungstênio o ângulo da ponta deverá ficar entre 15 e $25^{\circ}$ de inclinação.

- Se durante a soldagem do lote das sementes ocorrer oscilação do arco plasma:

1) O processo de selagem deverá ser interrompido;

2) A tocha plasma deverá ser desmontada e os seus componentes deverão ser limpos;

3) A semente que esta sendo soldada deverá ser descartada no frasco de rejeitos;

4) A rotina deverá ser repetida desde o início.

- Deverão ser controlados durante a soldagem os parâmetros indicados abaixo:

\begin{tabular}{|l|c|}
\hline Corrente de arco plasma & $0,85 \mathrm{~A}$ \\
\hline Corrente de arco piloto (constante) & $2 \mathrm{~A}$ \\
\hline Tempo de arco aberto & $0,3 \mathrm{~s}$ \\
\hline Vazão de gás de arco plasma & $0,1 \mathrm{l} / \mathrm{min}$ \\
\hline Vazão de gás de proteção & $10 \mathrm{l} / \mathrm{min}$ \\
\hline Standoff & $4,6 \mathrm{~mm}$ \\
\hline Sobrematerial da $1^{\text {a }}$ solda & $1,9 \mathrm{~mm}$ \\
\hline Sobrematerial da $2^{\mathrm{a}}$ solda & $1,3 \mathrm{~mm}$ \\
\hline
\end{tabular}

\begin{tabular}{|l|l|l|l|}
\hline Revisão & Elaborado & Aprovado & Data \\
\hline & & & \\
& & & \\
\hline
\end{tabular}


ANEXO A - Classificação do radionuclídeo de acordo com sua radiotoxicidade

GRUPO A - ALTA TOXICIDADE

\begin{tabular}{|c|c|c|c|c|}
\hline \multicolumn{2}{|c|}{ Grupo A: Alta Toxicidade } & \multicolumn{3}{|c|}{ (Grupo 1: Toxicidade muito alta) } \\
\hline${ }^{227} \mathrm{Ac}$ & ${ }^{242} \mathrm{Cm}$ & ${ }^{231} \mathrm{~Pa}$ & ${ }^{241} \mathrm{Pu}$ & ${ }^{228} \mathrm{Th}$ \\
\hline${ }^{241} \mathrm{Am}$ & ${ }^{243} \mathrm{Cm}$ & ${ }^{210} \mathrm{~Pb}$ & ${ }^{242} \mathrm{Pu}$ & ${ }^{230} \mathrm{Th}$ \\
\hline${ }^{243} \mathrm{Am}$ & ${ }^{244} \mathrm{Cm}$ & ${ }^{210} \mathrm{Po}$ & ${ }^{223} \mathrm{Ra}$ & ${ }^{230} \mathrm{U}$ \\
\hline${ }^{249} \mathrm{Cf}$ & ${ }^{245} \mathrm{Cm}$ & ${ }^{238} \mathrm{Pu}$ & ${ }^{226} \mathrm{Ra}$ & ${ }^{232} \mathrm{U}$ \\
\hline${ }^{250} \mathrm{Cf}$ & ${ }^{246} \mathrm{Cm}$ & ${ }^{239} \mathrm{Pu}$ & ${ }^{228} \mathrm{Ra}$ & ${ }^{233} \mathrm{U}$ \\
\hline${ }^{252} \mathrm{Cf}$ & ${ }^{237} \mathrm{~Np}$ & ${ }^{240} \mathrm{Pu}$ & ${ }^{227} \mathrm{Th}$ & ${ }^{234} \mathrm{U}$ \\
\hline
\end{tabular}

GRUPO B - MÉDIA TOXICIDADE

\begin{tabular}{|c|c|c|c|c|}
\hline \multicolumn{5}{|c|}{ Grupo B: Média Toxicidade } \\
\hline Subgrupo B1 & \multicolumn{3}{|c|}{ Grupo 2: toxidade alta } \\
\hline${ }^{228} \mathrm{Ac}$ & ${ }^{36} \mathrm{C} 1$ & ${ }^{125} \mathrm{I}$ & ${ }^{212} \mathrm{~Pb}$ & ${ }^{160} \mathrm{~Tb}$ \\
\hline${ }^{110 \mathrm{~m}} \mathrm{Ag}$ & ${ }^{56} \mathrm{Co}$ & ${ }^{126} \mathrm{I}$ & ${ }^{224} \mathrm{Ra}$ & ${ }^{127 \mathrm{~m}} \mathrm{~T}$ \\
\hline${ }^{211} \mathrm{At}$ & ${ }^{60} \mathrm{Co}$ & ${ }^{131} \mathrm{I}$ & ${ }^{106} \mathrm{Ru}$ & ${ }^{129 \mathrm{~m} \mathrm{Te}}$ \\
\hline${ }^{140} \mathrm{Ba}$ & ${ }^{134} \mathrm{Cs}$ & ${ }^{133} \mathrm{I}$ & ${ }^{124} \mathrm{Sb}$ & ${ }^{234} \mathrm{Th}$ \\
\hline${ }^{207} \mathrm{Bi}$ & ${ }^{137} \mathrm{Cs}$ & ${ }^{114 m} \mathrm{In}$ & ${ }^{125} \mathrm{Sb}$ & ${ }^{204} \mathrm{TI}$ \\
\hline${ }^{210} \mathrm{Bi}$ & ${ }^{152(13 \mathrm{y})} \mathrm{Eu}$ & ${ }^{129} \mathrm{It}$ & ${ }^{46} \mathrm{Sc}$ & ${ }^{170} \mathrm{Tm}$ \\
\hline${ }^{249} \mathrm{Bk}$ & ${ }^{154} \mathrm{Eu}$ & ${ }^{54} \mathrm{Mn}$ & ${ }^{89} \mathrm{Sr}$ & ${ }^{236} \mathrm{U}$ \\
\hline${ }^{45} \mathrm{Ca}$ & ${ }^{181} \mathrm{Hf}$ & ${ }^{22} \mathrm{Na}$ & ${ }^{90} \mathrm{Sr}$ & ${ }^{91} \mathrm{Y}$ \\
\hline${ }^{115 m} \mathrm{Cd}$ & ${ }^{124} \mathrm{I}$ & ${ }^{230} \mathrm{~Pa}$ & ${ }^{182} \mathrm{Ta}$ & ${ }^{95} \mathrm{Zr}$ \\
\hline${ }^{144} \mathrm{Ce}$ & & & & \\
\hline
\end{tabular}


GRUPO B - MÉDIA TOXICIDADE

\begin{tabular}{|c|c|c|c|c|}
\hline \multicolumn{5}{|c|}{ Grupo B: Média Toxicidade } \\
\hline \multicolumn{2}{|c|}{ Subgrupo B2 } & \multicolumn{3}{|c|}{ Grupo 3: Toxicidade moderada } \\
\hline${ }^{105} \mathrm{Ag}$ & ${ }^{64} \mathrm{Cu}$ & ${ }^{43} \mathrm{~K}$ & ${ }^{143} \mathrm{Pr}$ & ${ }^{97} \mathrm{Tc}$ \\
\hline${ }^{111} \mathrm{Ag}$ & ${ }^{165} \mathrm{Dy}$ & ${ }^{85} \mathrm{~m} / \mathrm{Kr}$ & ${ }^{191} \mathrm{Pt}$ & ${ }^{97 \mathrm{~m}} \mathrm{~T}$ \\
\hline${ }^{41} \mathrm{Ar}$ & ${ }^{166} \mathrm{Dy}$ & ${ }^{87} \mathrm{Kr}$ & ${ }^{193} \mathrm{Pt}$ & ${ }^{99} \mathrm{Tc}$ \\
\hline${ }^{73} \mathrm{As}$ & ${ }^{169} \mathrm{Er}$ & ${ }^{140} \mathrm{La}$ & ${ }^{197} \mathrm{Pt}$ & ${ }^{125 \mathrm{~m}} \mathrm{Te}$ \\
\hline${ }^{74}$ As & ${ }^{171} \mathrm{Er}$ & ${ }^{177} \mathrm{Lu}$ & ${ }^{86} \mathrm{Rb}$ & ${ }^{127} \mathrm{Te}$ \\
\hline${ }^{76}$ As & ${ }^{152(9,2 h)} \mathrm{Eu}$ & ${ }^{52} \mathrm{Mn}$ & ${ }^{183} \mathrm{Re}$ & ${ }^{129} \mathrm{Te}$ \\
\hline${ }^{77}$ As & ${ }^{155} \mathrm{Eu}$ & ${ }^{56} \mathrm{Mn}$ & ${ }^{186} \mathrm{Re}$ & ${ }^{131 \mathrm{~m}} \mathrm{Te}$ \\
\hline${ }^{196} \mathrm{Au}$ & ${ }^{18} \mathrm{~F}$ & ${ }^{99} \mathrm{Mo}$ & ${ }^{188} \mathrm{Re}$ & ${ }^{132} \mathrm{Te}$ \\
\hline${ }^{198} \mathrm{Au}$ & ${ }^{52} \mathrm{Fe}$ & ${ }^{24} \mathrm{Na}$ & ${ }^{105} \mathrm{Rh}$ & ${ }^{231} \mathrm{Th}$ \\
\hline${ }^{199} \mathrm{Au}$ & ${ }^{55} \mathrm{Fe}$ & ${ }^{93 \mathrm{~m}} \mathrm{Nb}$ & ${ }^{220} \mathrm{Rn}$ & ${ }^{200} \mathrm{TI}$ \\
\hline${ }^{231} \mathrm{Ba}$ & ${ }^{59} \mathrm{Fe}$ & ${ }^{95} \mathrm{Nb}$ & ${ }^{222} \mathrm{Rn}$ & ${ }^{201} \mathrm{TI}$ \\
\hline${ }^{7} \mathrm{Be}$ & ${ }^{67} \mathrm{Ga}$ & ${ }^{147} \mathrm{Nd}$ & ${ }^{97} \mathrm{Ru}$ & ${ }^{202} \mathrm{TI}$ \\
\hline${ }^{206} \mathrm{Bi}$ & ${ }^{72} \mathrm{Ga}$ & ${ }^{149} \mathrm{Nd}$ & ${ }^{103} \mathrm{Ru}$ & ${ }^{171} \mathrm{Tm}$ \\
\hline${ }^{212} \mathrm{Bi}$ & ${ }^{153} \mathrm{Gd}$ & ${ }^{63} \mathrm{Ni}$ & ${ }^{105} \mathrm{Ru}$ & ${ }^{48} \mathrm{~V}$ \\
\hline${ }^{82} \mathrm{Br}$ & ${ }^{159} \mathrm{Gd}$ & ${ }^{65} \mathrm{Ni}$ & ${ }^{35} \mathrm{~S}$ & ${ }^{181} \mathrm{~W}$ \\
\hline${ }^{14} \mathrm{C}$ & ${ }^{197} \mathrm{Hg}$ & ${ }^{239} \mathrm{~Np}$ & ${ }^{122} \mathrm{Sb}$ & ${ }^{185} \mathrm{~W}$ \\
\hline${ }^{47} \mathrm{Ca}$ & $197 \mathrm{~m} H g$ & ${ }^{185}$ Os & ${ }^{47} \mathrm{Sc}$ & ${ }^{187} \mathrm{~W}$ \\
\hline${ }^{109} \mathrm{Cd}$ & ${ }^{203} \mathrm{Hg}$ & ${ }^{191}$ Os & ${ }^{48} \mathrm{Sc}$ & ${ }^{135} \mathrm{Xe}$ \\
\hline${ }^{115} \mathrm{Cd}$ & ${ }^{166} \mathrm{Ho}$ & ${ }^{193}$ Os & ${ }^{75} \mathrm{Se}$ & ${ }^{87} Y$ \\
\hline${ }^{141} \mathrm{Ce}$ & $130 \mathrm{I}$ & ${ }^{32} \mathrm{P}$ & ${ }^{31} \mathrm{Si}$ & ${ }^{90} Y$ \\
\hline${ }^{143} \mathrm{Ce}$ & 132। & ${ }^{233} \mathrm{~Pa}$ & ${ }^{151} \mathrm{Sm}$ & ${ }^{92} Y$ \\
\hline${ }^{38} \mathrm{Cl}$ & ${ }^{134} I$ & ${ }^{203} \mathrm{~Pb}$ & ${ }^{153} \mathrm{Sm}$ & ${ }^{93} Y$ \\
\hline${ }^{57} \mathrm{Co}$ & $135 \mathrm{I}$ & ${ }^{103} \mathrm{Pd}$ & ${ }^{113} \mathrm{Sn}$ & ${ }^{175} \mathrm{Yb}$ \\
\hline${ }^{58} \mathrm{Co}$ & ${ }^{115 m} \mathrm{In}$ & ${ }^{109} \mathrm{Pd}$ & ${ }^{125} \mathrm{Sn}$ & ${ }^{65} \mathrm{Zn}$ \\
\hline${ }^{51} \mathrm{Cr}$ & ${ }^{190} \mathrm{Ir}$ & ${ }^{147} \mathrm{Pm}$ & ${ }^{85} \mathrm{Sr}$ & ${ }^{69 m} \mathrm{Zn}$ \\
\hline${ }^{131} \mathrm{Cs}$ & ${ }^{194} \mathrm{Ir}$ & ${ }^{149} \mathrm{Pm}$ & ${ }^{91} \mathrm{Sr}$ & ${ }^{97} \mathrm{Zn}$ \\
\hline${ }^{136} \mathrm{Cs}$ & ${ }^{42} \mathrm{~K}$ & ${ }^{142} \mathrm{Pr}$ & ${ }^{96} \mathrm{Tc}$ & \\
\hline
\end{tabular}


GRUPO C - BAIXA TOXICIDADE

\begin{tabular}{|c|c|c|c|c|}
\hline \multicolumn{2}{|c|}{ Grupo C: Baixa toxicidade } & \multicolumn{3}{|c|}{ Grupo 4: Baixa toxicidade } \\
\hline${ }^{37} \mathrm{Ar}$ & ${ }^{111 \mathrm{~m}} \mathrm{In}$ & ${ }^{193 \mathrm{~m}} \mathrm{Pt}$ & ${ }^{96 \mathrm{~m}} \mathrm{Tc}$ & natural $\mathrm{U}$ \\
\hline${ }^{58 \mathrm{~m}} \mathrm{Co}$ & ${ }^{113 \mathrm{~m}} \mathrm{In}$ & ${ }^{197 \mathrm{~m}} \mathrm{Pt}$ & ${ }^{99 \mathrm{~m}} \mathrm{Tc}$ & ${ }^{131 \mathrm{~m}} \mathrm{Xe}$ \\
\hline${ }^{134 \mathrm{~m}} \mathrm{Cs}$ & ${ }^{85} \mathrm{Kr}$ & ${ }^{87} \mathrm{Rb}$ & ${ }^{232} \mathrm{Th}$ & ${ }^{133} \mathrm{Xe}$ \\
\hline${ }^{135} \mathrm{Cs}$ & ${ }^{97} \mathrm{Nb}$ & ${ }^{187} \mathrm{Re}$ & natural Th & ${ }^{91 \mathrm{~m}} \mathrm{Y}$ \\
\hline${ }^{71} \mathrm{Ge}$ & ${ }^{59} \mathrm{Ni}$ & ${ }^{103 \mathrm{~m}} \mathrm{Rh}$ & ${ }^{235} \mathrm{U}$ & ${ }^{69} \mathrm{Zn}$ \\
\hline${ }^{3} \mathrm{H}$ & ${ }^{15} \mathrm{O}$ & ${ }^{147} \mathrm{Sm}$ & ${ }^{238} \mathrm{U}$ & ${ }^{93} \mathrm{Zr}$ \\
\hline${ }^{129} \mathrm{I}$ & ${ }^{191 \mathrm{~m}} \mathrm{Os}$ & ${ }^{85 m} \mathrm{Sr}$ & & \\
\hline
\end{tabular}




\section{REFERÊNCIAS BIBLIOGRÁFICAS}

1 - RICE, D.P.; HODGSON, T. A. Incidences socials et economiques du cancer aux États-Unids d' Amerique. World health stat., v. 33, n.1, p. 56-100, 1980.

2 - INSTITUTO NACIONAL DE CÂNCER. Estimativa da incidência de câncer no Brasil 2006. Rio de Janeiro: 2006

3 - INSTITUTO NACIONAL DE CÂNCER. Câncer de próstata. Disponível em <http://www.inca.gov.br/cancer/prostata/>, acesso em: 20/08/2003.

4 - INSTITUTO NACIONAL DE CÂNCER. Estimativa da incidência e mortalidade por câncer no Brasil 1999. Rio de Janeiro: 1999

5 - AMERICAN CANCER SOCIETY, NCCN-ACS. Prostate cancer treatment guidelines for patients. USA: 1999.

6 - KHAN, F. M. The physics of radiation therapy. 2. ed., Baltimore: Williams \& Wilkins, 1994.

7 - AMERICAN UROLOGICAL ASSOCIATION PROSTATE CANCER. Clinical guidelines panel. The management of localized prostate cancer - a patient's guide. USA: 1998.

8 - BLASKO, J. C. ; GRIMM, P. D. ; RAGDE, H. Brachytherapy and organ preservation in the management of carcinoma of the prostate. Semin. Rad. Oncol., v. 3, n. 4, p. 240-249, 1993.

9 - POLLACK, A. ; ZAGARS, G. K. ; ROSEN, I. I. Prostate cancer treatment with radiotherapy: maturing methods that minimize morbidity. Semin. Oncol. M. $\boldsymbol{D}$. Anderson Cancer Center, v. 26, n. 2, p.150-161, 1999.

10 - MEIGOONI, A. S. ; GEARHEART, D. M. ; SOWARDS, K. Experimental determination of dosimetric characteristics of best I-125 brachytherapy source. Med. Phys. , v. 27, n. 9, Sept., 2000.

11 - STRUM, S. B. ; SCHOLZ, M. C. Implantation of prostate cancer with radioactive isotope-brachytherapy. USA: 1996.

12 - BUTLER, W. M. Review of modern prostate brachytherapy In: WORLD CONGRESS ON MED. PHYS. AND BIOMED. ENG. , July 23-28, 2000, Chicago. Proceedings... Chicago, 2000.

13 - MEIGOONI, A. S. Dosimetric characterization of low energy brachytherapy sources: measurements. In: WORLD CONGRESS ON MED. PHYS. AND BIOMED. ENG. , July 23-28, 2000, Chicago. Proceedings... Chicago, 2000. 
14 - ROSTELATO, M. E. C. M.; RELA, P. R.; GASIGLIA, H. T.; LEPKI, V.; FEHER, A.; lodine-125 seeds production for brachytherapy use. In: WORLD CONGRESS ON MEDICAL PHYSICS AND BIOMEDICAL ENGINEERING, 2000, Chicago. Proceedings... Chicago, 2000.

15 - GRAY, J. R. Braquiterapia da próstata. UroNews, Disponível em: <http://www.uronews.org.br/24_uro/24_braqu1.htm>. Acesso em : 13 mar. 2006.

16 - ROSTELATO, M. E. C. M.; Estudo e desenvolvimento de uma nova metodologia para confecção de sementes de lodo-125 para aplicação em braquiterapia. 2005. Tese (Doutorado) - Instituto de Pesquisas Energéticas e Nucleares, São Paulo.

17 - MENTOR CORPORATION - 2005 Annual report. Disponível em: <http://www.mentorcorp.com/about/investor.htm>, acesso em 02/03/2006.

18 - AMERICAN SOCIETY FOR TESTING AND MATERIALS, Unalloyed titanium for surgical implant applications, 1977. (F 67-77).

19 - AMERICAN SOCIETY FOR METALS, Metals handbook. Ohio, 1980. Properties and selection: stainless steels, tool materials and special-purpose metals. 9 ed., vol 3, p.374-375.

20 - ASSOCIAÇÃO BRASILEIRA DE NORMAS TÉCNICAS, Implantes para cirurgia - materiais metálicos parte 2: titânio puro, Maio 2001. (NBR ISO 5832-2).

21 - SHEARER, D. R. Recent advances in brachytherapy physics. USA: AAPM, 1981. N.7: Medical Physics Monograph.

22 - BLASKO, J. ; DATOLLI, M. J. ; WALLNER, K. Prostate brachytherapy. Washington: Smart Medicine, 1997.

23 - INTERNATIONAL STANDARD ORGANIZATION. Radiation protection Sealed radioactive sources - general requirements and classification. Feb. 15, 1999. (ISO 2919).

24 - INTERNATIONAL STANDARD ORGANIZATION - Radiation protection sealed Radioactive Sources - leakage test methods". Feb.15, 1992. (ISO 9978).

25 - INFOMET - Plasma. Disponível em: <http://www.infomet.com.br/s_plasma.php>, acesso em 13/07/2006.

26 - ASSOCIAÇÃO BRASILEIRA DE CÂNCER - Braquiterapia. Disponível em: $<$ http://www.abcancer.org.br/materia.asp?id=168>, acesso em 08/03/2006. 
27 - FERNANDES, M. A. R.; Utilização de moldes radioativos especiais de folha de Ouro-198 para braquiterapia em tumores de pele. 2000. Tese (Doutorado) - Instituto de Pesquisas Energéticas e Nucleares, São Paulo.

28 - HAZLETON-NUCLEAR SCIENCE CORPORATION. Donald C. Lawrence. Therapeutic metal seed containing within a radioactive isotope disposed on a carrier and method of manufacture. US Pat. n. 3,351,049, 7 nov. 1967.

29 - WHITMORE, W. F.; HILLARIS, B.; GRABSTALD, H. Retropubic implantation of iodine-125 in the treatment of prostatic cancer. J. Urol., v. 108, p. 918, 1972.

$30-\mathrm{HOLM}, \mathrm{H}$. H. The history of interstitial brachytherapy of prostatic cancer . Semin. Surg. Oncol., v. 13, n. 6, p. 431-437, 1997.

31 - REVISTA SOCIEDADES BRASILEIRAS DE CANCER - Braquiterapia de câncer de próstata - revisão e experiência inicial. Disponível em: <http://www.rsbcancer.com.br/rsbc/8artigo2.asp?nrev=№ 8>. Acesso em 25 set. 2006.

32 - PROSTATE CANCER CENTRE - Brachytherapy. Disponível em: $<$ http://www.prostatecancercentre.com/treatments/brachy.html>, Acesso em 26/10/2006.

33 - UROMED. Symetra l-125. USA: 2000. (catálogo comercial).

34 - HEINTZ, B. H.; WALLACE, R. E. ; HEVEZI, J. M. Comparison of I-125 sources used for permanent interstitial implants. Med. Phys., v. 28, n. 4, p. 671-682, Apr., 2001.

35 - BEST MEDICAL INTERNATIONAL. Double wall best iodine-125 source. USA: 2000. (catálogo comercial).

36 - BARD UROLOGICAL. BrachySourc iodine-125 seed. USA: 2000. (catálogo comercial).

37 - MENTOR CORPORATION. Prostate brachytherapy - loGold I-125. USA: 1999. (catálogo comercial).

38 - MINNESOTA MINING AND MANUFACTURING COMPANY. David O. Kubiatowicz. Radioactive iodine seed. US Pat. n. 4,323,055, 6 Apr. 1982.

39 - THERAGENICS CORPORATION. John L. Russell Jr. X-ray-emitting interstitial implants. US Pat. n. 4,702,228, 27 Oct. 1987.

40 - THERAGENICS CORPORATION. John L. Russell Jr. ; David N. Coggins. Capsule for interstitial implants. US Pat. n. 4,784,116, 15 Nov. 1988. 
41 - BEST INDUSTRIES, INC. Krishnan Suthanthiran. Device and method for encapsulating radioactive materials. US Pat. n. 4,891,165, 02 Jan. 1990.

42 - NORTH AMERICAN SCIENTIFIC. Michael L. Cutrer. Laser welded brachytherapy source and method of making the same. US Pat. $n$. 5,997,463, 07 Dez. 1999.

43 - ROBERT ROBERTSON. Encapsulated low-energy brachytherapy sources. US Pat. n. 6,099,458, 08 Aug. 2000.

44 - NYCOMED AMERSHAM PLC. David W Bolenbaugh. Brachytherapy seeds. US Pat. n. 6.132.359 Oct. 2000.

45 - SYNTHEON, LLC. Charles R. Slater; Thomas O. Bales; Kevin W. Smith. Radioactive therapeutic seed having selective marker configuration. US Pat. n. 6,200,258, 13 Mar. 2001.

46 - BRISTOL-MYERS SQUIBB PHARMA COMPANY. Prahlad R. Singh; Gerald P. Tercho; Jack N. Wentz; Keith R. Olewine. Radioactive seeds for brachytherapy and a process for making the same. US Pat. n. 6,391,279, 21 May 2002.

47 - EUROTOPE ENTWICKLUNGSGESELLSCHAFT FUR ISTOPENTECHNOLOGIEN MBH. Jurgen Ziegler; Cláudia Muller; Gunnar Mann; Andre Hess. Medical radioactive iodine-125 miniature radiation sources and methods of producing the same. US Pat. n. 6,485,406, 26 Nov. 2002.

48 - NORTH AMERICAN SCIENTIFIC. Michael L. Cutrer. Radioactive seed with multiple markers and method for using same. US Pat. n. 6.503.186 07 Jan.2003.

49 - TIBRASIL TITÂNIO - O que é titânio. Disponível em: <http://www.titanio.com.br/news.htm>, acesso em 24/04/2006.

50 - REALUM - Titânio - histórico. Disponível em: <http://www.realum.com.br/tita-esp.htm>, acesso em 24/04/2006.

51 - TIBRASIL TITÂNIO - Noticiário técnico. Disponível em: <http://titânio.com.br/pr03.htm>, acesso em 25/04/06.

52 - REALUM - Titânio medicinal. Disponível em: <http://realum.com.br/titamedi.htm>, acesso em 25/04/06.

53 - CAMACAM - Titânio. Disponível em: http://www.camacam.com.br/produtos_baixo.htm, acesso em 02/07/04. 
54 - NERIS, MANOEL MESSIAS. Soldagem dos metais. Santos, SP. Universidade Santa Cecília, 2002. (material didático do curso de Soldagem dos Metais).

55 - MECATRÔNICA FÁCIL - Soldagem industrial. Disponível em: $<\mathrm{http}: / /$ www.mecatronicafacil.com.br/artigos/soldagem01/index.htm > acesso em 17/01/2006.

56 - MODENESI, P.; MARQUES, P. Introdução aos processos de soldagem. Belo Horizonte, MG. Universidade Federal de Minas Gerais, 2000. (material didático do curso de Soldagem I).

57 - SOUZA. GILBERTO F. M.; Processos de junção e corte. São Paulo, SP. Universidade de São Paulo, 2004. (material didático do curso de Introdução à manufatura mecânica).

58 - WIKIPEDIA - Processos de soldagem. Disponível em : $<$ http://pt.wikipedia.org/wiki/soldagem>, acesso em 04/10/2006.

59 - BRACARENSE, A. Q. Soldagem a plasma. Belo Horizonte, MG. Universidade Federal de Minas Gerais, 2000. (material didático do curso de processo de soldagem).

60 - RELA, P, R., Processo de soldagem com plasma. In: WAINER, E.; BRANDI, S. D.; MELLO, F. D. H. Soldagem: processo e metalurgia. São Paulo, S.P.: Edgard Blucher (Ed.), 1992. v.1. p. 156-179.

61 - AMERICAN WELDING SOCIETY, Welding handbook. Miami, FL: O’Brien R.L. (Ed.), 1991. 8 ed., Welding Processes. v. 2, cap. 10, p. 329-350.

62 - JR, L. G.; JOAQUIM, R. Soldagem. São Paulo, SP: SENAI, 1997. cap. 3, Processo por arco plasma. p. 227-234.

63 - INFOSOLDA - Soldagem laser. Disponível em: <www.infosolda.com.br/soldagem_laser.htm\#etc>, acesso em 06/03/2006.

64 - AGÊNCIA NACIONAL DE VIGILÂNCIA SANITÁRIA. Boas Práticas de Fabricação de produtos médicos. Brasília. 2000. Resolução RDC nำ59. anexol.

65 - ASSOCIAÇÃO BRASILEIRA DE NORMAS TÉCNICAS. Planos de amostragem e procedimentos na inspeção por atributos. Jan. 1985. (NBR 5426).

66 - ASSOCIAÇÃO BRASILEIRA DE NORMAS TÉCNICAS. Guia para utilização da norma NBR 5426 - Planos de amostragem e procedimentos na inspeção por atributos. Jan. 1985. (NBR 5427). 